\title{
To strip or not to strip the incompetent saphenous vein
}

Citation for published version (APA):

Rutgers, P. H. (1993). To strip or not to strip the incompetent saphenous vein. [Doctoral Thesis, Maastricht University]. Rijksuniversiteit Limburg. https://doi.org/10.26481/dis.19930611pr

Document status and date:

Published: 01/01/1993

DOI:

10.26481/dis.19930611pr

Document Version:

Publisher's PDF, also known as Version of record

\section{Please check the document version of this publication:}

- A submitted manuscript is the version of the article upon submission and before peer-review. There can be important differences between the submitted version and the official published version of record.

People interested in the research are advised to contact the author for the final version of the publication, or visit the DOI to the publisher's website.

- The final author version and the galley proof are versions of the publication after peer review.

- The final published version features the final layout of the paper including the volume, issue and page numbers.

Link to publication

\footnotetext{
General rights rights.

- You may freely distribute the URL identifying the publication in the public portal. please follow below link for the End User Agreement:

www.umlib.nl/taverne-license

Take down policy

If you believe that this document breaches copyright please contact us at:

repository@maastrichtuniversity.nl

providing details and we will investigate your claim.
}

Copyright and moral rights for the publications made accessible in the public portal are retained by the authors and/or other copyright owners and it is a condition of accessing publications that users recognise and abide by the legal requirements associated with these

- Users may download and print one copy of any publication from the public portal for the purpose of private study or research.

- You may not further distribute the material or use it for any profit-making activity or commercial gain

If the publication is distributed under the terms of Article $25 \mathrm{fa}$ of the Dutch Copyright Act, indicated by the "Taverne" license above, 


\section{TO STRIP OR NOT TO STRIP}

THE INCOMPETENT SAPHENOUS VEIN 



\section{TO STRIP OR NOT TO STRIP THE INCOMPETENT SAPHENOUS VEIN}

\section{PROEFSCHRIFT}

ter verkrijging van de graad van doctor

aan de Rijksuniversiteit Limburg te Maastricht, op gezag van de Rector Magnificus, Prof. Mr. M.J. Cohen, volgens het besluit van het College van Dekanen, in het openbaar te verdedigen op vrijdag, 11 juni 1993 om 14.00 uur

door

Peter Hans Rutgers

geboren te Den Helder in 1952 


\section{Promotor}

Prof. Dr. P.J.E.H.M. Kitslaar

\section{Beoordelingscommissie}

Prof. Dr. J.W. van Ree (voorzitter)

Prof. Dr. B.C. Eikelboom

Dr. Ir. A.P.G. Hoeks

Prof. Dr. H.A.M. Neumann

Prof. Dr. H.A. Verbeek

CIP-DATA KONINKLIJKE BIBLIOTHEEK, DEN HAAG

Rutgers, Peter Hans

To strip or not to strip the incompetent saphenous vein / Peter Hans Rutgers - Maastricht

Universiteit Maastricht, faculteit geneeskunde proefschrift Rijksuniversiteit Limburg

Met samenvatting in het Nederlands.

ISBN 90-9005562-2

Trefw.: varicosis; diagnostiek, behandeling

Financial support by the Netherlands Heart Foundation for the publication of this thesis is gratefully acknowledged.

Publication of this thesis was also financially supported by : BV Zyma-Nederland, Sigvaris, WL Gore \& Associates BV and Bauerfeind Benelux BV. 
Voor Anneke, Bob en Claire 



\section{CONTENTS}

Introduction

Chapter 1: Historical aspects

Chapter 2: Anatomical considerations

Chapter 3: Physiology and pathophysiology of the venous system and of varicose veins

Chapter 4: Incidence and etiology of varicose veins

Chapter 5: Diagnostic methods in venous insufficiency

Chapter 6: Treatment modalities of varicose veins.

Chapter 7: Varicose veins: symptoms and signs

Chapter 8: Photoplethysmography in the diagnosis of superficial venous valvular incompetence.

Chapter 9: Stripping or high ligation in the treatment of the incompetent greater saphenous vein?

Chapter 10: Surgical implications of the anatomy of the saphenous nerve.

Chapter 11: Varicose veins and the vascular surgeon; from nuisance to challenge

Chapter 12: General Discussion and Summary

Samenvatting

Acknowledgements

Curriculum Vitae 



\section{Introduction}

"In the past there were two camps. In one, varicosities were treated entirely by surgery. In the other, entirely by sclerotherapy. The relations between the two camps were difficult and rare"1,2. Fortunately there are welcome signs of more rational approaches to methods of treatment. A phase of uncritical application of sclerotherapy for example is being succeeded by one in which patients are selected for appropriate treatment or combinations of treatment. Treatment modalities include stripping, high ligation combined with sclerotherapy and sclerotherapy alone. Only a few trials have compared these forms of treatment, most of which were not prospective. Treatment evaluation was based solely on clinical evaluation in most of them.

The approach to the diagnosis of varicose veins varies. Some believe clinical investigation alone is sufficient and no form of further investigation is warranted. Others consider clinical investigations as highly nonspecific and advise an array of non-invasive tests to define the extent of valvular incompetence ${ }^{3}$.

The present study was started with the following objectives:

- To evaluate some frequently used non-invasive tests in superficial venous valvular incompetence.

- To compare the symptomatic, clinical and haemodynamic results of treatment of isolated valvular incompetence of the greater saphenous vein by classical stripping operation to treatment by high ligation combined with sclerotherapy. Because of the high rate of damage to the saphenous nerve found after stripping, also an in vivo study of the anatomic relationship between the saphenous vein and the saphenous nerve was conducted. This understanding might minimise the risk of damage to the nerve during stripping.

- To investigate the relationship between symptoms, signs and hemodynamic findings in patients with varicose veins. 
The diagnostic and therapeutic studies were conducted in the Surgical Department of the University Hospital Maastricht.

In chapter 1 historical aspects of the treatment of varicose veins are given. In chapter 2 the anatomy of the venous system of the lower extremity is outlined. Chapter 3 describes the physiology of the venous system and the pathophysiology resulting in varicose veins. In chapter 4 the incidence of varicosis is given, and the factors thought etiological are summarised. In chapter 5 the value of the existing diagnostic methods in venous insufficiency are outlined and a description of the symptoms and signs of the various forms of venous valvular incompetence is given. Chapter 6 deals with the various treatment modalities of varicose veins and descibes briefly what complications can arise.

In the chapters $7,8,9$ and 10 results of own clinical investigations are reported.

In chapter 7 the relation between symptoms and signs and hemodynamic findings in the own patient population are described. In chapter 8 a study comparing photoplethysmography to clinical investigation combined with Doppler ultrasound is described. In chapter 9 the results of a prospective randomised trial comparing two treatments of isolated incompetence of the greater saphenous vein are reported. Chapter 10 describes the anatomy of the saphenous nerve to the saphenous vein in an in vivo study. Chapter 11 is a plea for a rational and differential approach to varicose veins by surgeons. In the final Chapter 12 the results of the different studies are discussed. 


\section{References}

1 Eklof B. Modern treatment of varicose veins.

Br J Surg. 1988; 75: 297-298.

2 Ouvry PA, Davy A. Sclerotherapy after stripping. In: Phlebology 85. Negus D, Jantet G, Eds. London, Paris: John Libbey and Co Ltd., 1986: 125-128

3 Haeger K. Venous incompetence and concomitant disease of the leg. J Cardiovasc Surg 1965; 6: 482-489. 


\section{Chapter 1: Historical Aspects of the Treatment of Varicose Veins.}

"Child bearing and standing too much before kings were thought to be the chief cause of varicose veins"

(Marianus Sanctus of Barletta 1555)

The first recollection of varicose veins is thought to be in the papyrus of Ebers (1550 B.C.) in which the author advises against operation for this condition and in which he describes the veins as "tortuous, solid with many knots, as if blown up by air" ${ }^{1}$. Hippocrates (460-377 B.C.) described the use of compressive bandages and is sometimes quoted as advising small punctures in varicose veins, but warning against opening them freely for fear of large ulcers as consequence of the incisions ${ }^{2}$. An early account of an operative treatment of a patient with varicose veins, is that of the roman Caius Marius ( 86 B.C.) who, after undergoing excessive torments due to surgery for deforming varicosities on one leg, declined to have the other done, saying "I see the cure is not worth the pain"3. Aurelius Cornelius Celsus (25 B.C.-50 A.D.) treated varicose veins by exposure and avulsion with a blunt hook or by a touch of cautery as did Claudius Galen (130-200 A.D. $)^{4}$. The byzantine physician Aetius of Amida (502-575 A.D.) performed the first ligations of varicose veins. Paulus Aeginetta (607-690 A.D.) performed this operation by ligating the veins on the inner part of the thigh "where they generally arise, for below this they are divided into many ramifications"s. This mid-thigh ligation preceded Trendelenburg's classical operation by some twelvehundred years. In the tenth century Ali Ibn Al-Abbas, an arabian physician, gave a description of varicose veins in the dermatological section of a treatise on medicine, the arabic name for varicose veins being dawali, a vine. Albucacis of Cordova (1013-1106), a famous arabian surgeon, described the technique of multiple ligations and vein stripping as later advocated by Mayo (1905); he begins and ends his book with the motto "caution". Apart from obscure writings of the monks there is but little medical literature during the next 400 years.

The church was against the shedding of blood which caused the lack of 
medical progress, since medical treatment was mainly in the hands of religious orders. In the middle of the fourteenth century the french surgeon Gui de Chauliac (1300-1368) was a prominent authority who wrote extensively on the subject of varicose veins. He favoured cautery and opening of the veins at different sites and he insisted that clots should be evacuated, while not being averse to avulsion of the varicose veins. The french army surgeon Ambroise Paré (1510-1590), known as the surgeon of princes and the prince of surgeons, did the mid-thigh ligation in a similar way as it was done by Paulus Aeginetta in the seventh century. He advocated the use of escharotics to the skin overlying the varix in order to produce thrombosis ${ }^{4,7}$. Fabritius $A b$ Aquapendente (1533-1619) tied the vein above and below the varix and obliterated the cavity by compression after puncturing the vein. In his books, Johan Scultetus, town surgeon at Ulm, describes instruments for treatment of varicose veins ${ }^{6}$. Jean Louis Petit (1674-1750), first director of the Academie de Chirurgie de Paris, wrote extensively regarding the radical excision of varicose veins which he practised. He noted that pregnancies were important in the causation of this trouble ${ }^{3}$.

Nowadays ligation of the saphenous vein is usually associated with the name of Friedrich Trendelenburg (1844-1924), although Paré already practised the same operation in the sixteenth century and the test which still bears his name was described by Sir Benjamin Brodie some 50 years before Trendelenburg did so. Pierre Dionos (1668-1718) recommended, as one method of treating varicose veins, that the vein should be punctured, the blood removed and compression applied. He also recommended percutaneous thread ligature through the skin under and around the varix ${ }^{3}$. Lorenz Heister (1683-1758) believed that "the worst of the varicose veins should be opened by a longitudinal incision with the scalpel or a lancet and then eight or ten ounces of the grumous and viscid blood being taken away"3. Sir Everard Home (1756-1832) worked on the treatment of leg ulcers. He described the salutary effects of including the greater saphenous vein in a ligature above the knee.

Leg ulcer treatment was considered a branch of military surgery. Home 
comments "no surgical complaint, incident to the soldier has deprived his majesty's service of so many men as that of ulcers of the $\mathrm{leg}^{4}$. Sir Benjamin Brodie (1783-1862) merely divided the varicose vein subcutaneously with a bistoury. The surgical treatment of varicose veins does not seem to have been popular. Apart from the question of suffering during operation, the complication of sepsis made it highly dangerous. Richard Wiseman wrote in 1676 "I have never met with one patient that cared to hear of the cure by ligature, nor indeed have I seen any great reason for it". Sir Astley Cooper (1824) stated that no fewer than eight cases terminating fatally after ligature had come to his knowledge and Chapman (1864) wrote "One of these accidents it is said, happened in the practise of Sir Astley himself, some months after he had roundly declared that the surgeon who performed such an operation deserved "to have a ligature applied round his own neck" ${ }^{\prime 3}$. The dangers of operation were diminished by the advent of anti-septic surgery following the teaching of Lister (1827-1912), and were almost eradicated when the importance of a-sepsis became recognised. Percutaneous ligation was reintroduced and again discarded in the nineteenth century. Davat (1833) used to pass several needles through the skin and under the affected veins, then tied figure of eight ligatures around both ends of each needle. This resulted in an inflammatory reaction in the veins and finally in their obliteration $^{3}$. Otto Wilhelm Magdelung (1846-1926) described the complete extirpation of the long saphenous vein and its main tributaries, through lengthy incision in the thigh and lower leg. The method was discarded due to the high mortality from pulmonary embolism. Moore of Melbourne (1896) was the first to perform a high resection of the greater saphenous vein on a patient who remained ambulatory. A development, reminiscent of Celsus using his blunt hook, is "the stripping operation". Keller (1905) removed the greater saphenous vein by passing through the vein a wire loop or probe with a ligature attached which was tied to the end of the vein and inverted the vein as it was extirpated. Mayo (1904) described an extra-luminal vein stripper that resembles a blunt uterine curet, which he used to strip out segments of saphenous vein from mid 
thigh to the lower leg. Babcock (1907) described an intraluminal stripper which had a slender shaft with an olive-shaped tip; this instrument was introduced inside the lumen of the vein and the vein was telescoped on it upon extraction of the stripper. This stripper is the prototype of all intraluminal strippers currently in use. In Figure 1-1 the site of ligation in relation to the period in time is demonstrated.

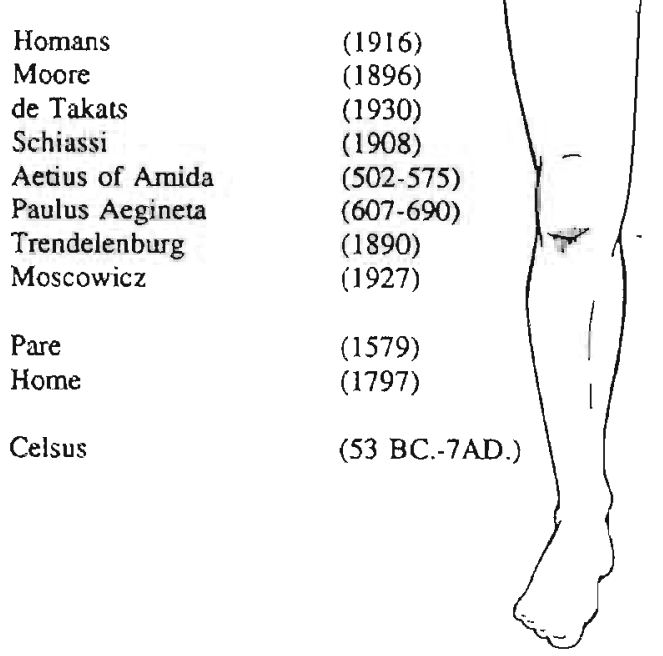

Figure 1-1: Site of ligation (as described by Edwards, 1934) 
Hodgson (1815) noticed that coagulation of blood in veins "terminated in a spontaneous cure of varicose veins". A means of producing this coagulation was sought and resulted in so-called galvanopuncture used by Chapman (1864). The injection of substances directly into a vein to produce thrombosis was, as Boyd (1948) said, "fortunately delayed until the introduction of the hypodermic syringe in 1845 by Francis Rynd" In his book on varicose veins Chapman reported that "a frenchman CharlesGabriel Pavaz has tried to sclerose varicose veins by injecting perchloride of iron into them ${ }^{\prime 3}$. During the 50 years following the introduction of the hypodermic syringe there is but little evidence that more than a few patients received sclerosant treatment. Toxic substances were used and the reported results were most unsatisfactory, since infection and suppuration were all too common.

Chassaignac (1855) was the next to treat varicose veins by injection of ferrochloride. In the eighteenhundred-seventies many continental clinics practised perivenous injection, depending on scar tissue resulting from the inflammatory process occasioned by the irritant injected. In 1894 the surgical congress at Lyons condemned the sclerosant treatment of varices. Only after Ehrlich proved that chemical thrombosis could be safely induced, it was recommenced (1911). In 1904 Tavel of Berne combined the operation of ligation with injection of carbolic acid 5 per cent. In 1911 Sicard of Paris used sodium salicylate in various strengths, a relatively non-toxic substance used for over 20 years. In 1921 Génevrier introduced the solution of quinine and urethane as sclerosants which is still in use today. In 1925 Maingot introduced the "twin injection method", in which both quinine and salicylate solutions are used simultaneously. Invert sugar was introduced in 1917 by Kausche, and even now is still being used by some practitioners. Linser employed hypertonic sodium chloride although, owing to the pain produced by the injection, its main value lies in its use under general anaesthesia. Warwick wrote in 1931 "the fear of fatal embolism is so ingrained in anyone who has observed the tragedy of its occurrence, that the almost universal and unquestioning belief in the danger of a deliberately induced 
thrombosis generally deterred the medical profession as a whole from attempting to cure varicose veins by injection in the period 1880-1920". Individual efforts continued to be made to develop the method into a safe yet sound remedy. Gradually its effectiveness was established and confidence in the method was won, until in the period 1920-1935 the injection of varicose veins was the method of choice for their treatment. Since 1935 its scope has narrowed from its erstwhile use for every case of varicose veins to a more limited application in selected cases. Especially Fegan was responsible for the place sclerotherapy takes in modern surgery. 


\section{References}

1 Ebbel B. The papyrus Ebers: The greatest Egyptian medical document. Copenhagen, 1937

2 Chadwick J, Mann WN. The medical works of Hippocrates. Blackwell, Oxford, 1950

3 Rowden Foote R. Some Historical Landmarks in the treatment of Varicose veins. In: Varicose Veins. Butterworth, London, 1952: 1-21

4 Anning ST. Historical Aspects. In: The Pathology and Surgery of Veins of the lower limb. Dodd H, Cockett FB. Eds. Livingstone, Edinburgh, 1956: 6-28

5 Browse NL, Burnand KG, Thomas ML. Milestones, pebbles and grains of sand. In: Diseases of the Veins Pathology, Diagnosis and Treatment. Edward Arnold, London, 1988: 1-20

6 Bischof J, Grossmann K, Schlolz A. Phlebologie, von der Empire zur Wissenschaft. Gustav Fischer Verlag, Jena, 1988: 1-40

7 Gurlt E. Geschichte der Chirurgie. August Hirschwald, Berlin, 1898: 74648

8 Fegan WG. Continuous compression technique of injecting varicose veins.

Lancet 1963; I: 109-113 


\section{Chapter 2: Anatomical Considerations}

The venous system of the lower extremity is commonly divided into three systems, the superficial veins, the communicating or perforating veins and the deep veins.

The superficial veins lie superficial to the muscle fascia. Their major components are the greater and lesser saphenous veins (saphenous is the Greek word for visible, in Hebrew it means hidden). The greater saphenous vein has its origin from the medial border of the foot. It receives tributaries from the deep veins of the foot, the dorsal venous arch, the digital veins from the toes and a perforating tributary vein from the medial aspect of the foot ${ }^{2}$. It courses upward with a constant location anterior to the medial malleolus. The perforating veins do not join the saphenous vein directly until the proximal third of the thigh is reached. The clinically important perforating veins in the distal third of the leg join the posterior venous arch directly and then eventually join the saphenous vein at knee level ${ }^{3}$. The vein continues up the anteromedial aspect of the thigh, receiving tributary veins from the medial and lateral aspects, the ascending medial and lateral veins. A constantly present perforating vein is located near the adductor channel. As the vein reaches the femoral trigone (fossa ovalis) it receives tributary veins of which the number and the location are variable. Of the lateral and medial cutaneous branches, the external circumflex iliac vein, the superficial epigastric vein and the internal pudendal vein are constantly present ${ }^{4}$. The small external pudendal artery courses transversely from the common femoral artery and may cross over the greater saphenous vein on the ventral side. The confluence of the greater saphenous vein and the common femoral vein lies 2.5 to $3 \mathrm{~cm}$ lateral and 2 to $3 \mathrm{~cm}$ caudal to the tuberculum pubicum. The confluence is often called "crosse", which is french for crosier. The trunk of the greater saphenous vein is doubled in $3 \%$ of the population, in exceptional circumstances it can be tripled ${ }^{6}$. 
In the majority of cases a doubled vein will also be encountered in the opposite leg.

The lesser saphenous vein emerges from the lateral side of the foot, running behind the lateral malleolus and upward over the dorsum of the calf. In contrast to the greater saphenous vein, the confluence of the lesser saphenous vein with the deep veins exhibits a wide variation. A true sapheno-popliteal junction is present in $66 \%$, in which case the lesser saphenous vein joins the popliteal vein 2 to $7 \mathrm{~cm}$ above the level of the knee joint $(30 \% \text { at } 3 \text { to } 5 \mathrm{~cm})^{7}$. Confluences with the deep system distal to the knee joint, terminating in the calf either by joining the gastrocnemius vein via the mid-calf perforating vein or via a communicating vein of the greater saphenous vein are very rare ${ }^{8.9}$. In $30 \%$ the lesser saphenous vein does not join the popliteal vein, but terminates high in the thigh by joining the greater saphenous vein, often directly or by means of the postero-medial vein. Another common vein found in this area is the Giacomini vein (femoro-popliteal vein) that ascends from the proximal part of the lesser saphenous vein, deep in the posterior aspect of the thigh, parallel to the skin, to terminate as the posteromedial tributary of the greater saphenous vein or rarely by joining tributaries of the internal iliac veins ${ }^{10}$.

High confluences, up to $14 \mathrm{~cm}$ above the knee joint are encountered in 10 to $1.5 \%$ of the population. A network of superficial veins interconnect the two major superficial trunks.

The communicating or perforating system consists of numerous vessels passing through the fascia of the leg thus connecting the superficial and the deep system. Their number is extremely large, possibly even $300^{11}$, 155 with a constant localisation have been described. The communicating veins have been divided into direct veins (connecting superficial to deep veins) and indirect veins, when the connection is through sinusoids in the muscles. The direct communicating veins are the haemodynamically important ones, and are always paired, whereas the indirect veins are solitary ${ }^{12}$. The communicating veins do not pierce the 
fascia perpendicular, but slightly angled. When the fascia is stretched this leads to a valve mechanism which works similar to the intraluminar valves and maybe even more effective. In a strict sense the largest communicating veins are the greater and lesser saphenous veins. Of the perforating veins the medial groups are responsible in $90 \%$ of the cases for primary varicose veins, while the lateral groups are only of clinical importance in $10 \%$ of the cases ${ }^{7}$. Four distinct groups of perforating veins have been named. One of them is the Cockett group, by which the posterior arch vein of the greater saphenous vein is connected to the posterior tibial veins. So the venous drainage from superficial to deep in this area is not directly via the greater saphenous vein. The lowest of the three medial communicating veins, or Cockett's 1 , is situated at about 7 $\mathrm{cm}$, the middle, or Cockett's 2 , at about $12 \mathrm{~cm}$ and the highest, or Cockett's 3 , at about $18 \mathrm{~cm}$ above the medial malleolus $(13.5,18.5$ and $24 \mathrm{~cm}$. above the foot sole). Just below the medial malleolus a group of perforating veins is situated named after Kuster ${ }^{7}$. Ten $\mathrm{cm}$ below the knee joint on the medial aspect of the calf Boyd's perforating vein is situated $^{13}$. In the thigh the most important group, called Dodd's perforating veins, consists of one or more veins which pass through Hunter's channel, and connect the greater saphenous vein to the superficial femoral vein ${ }^{14}$. Three more constant perforators are the subsartorial vein, the lower subsartorial vein and a perforating vein from the greater saphenous vein to the femoral vein 6 to $8 \mathrm{~cm}$ below the sapheno-femoral junction $^{14}$. On the lateral aspect of the lower leg the communicating veins do not have constant sites. The most important communicating vein, which connects the lesser saphenous vein with the peroneal veins can be located from just above the lateral malleolus to the junction of the lower and middle third of the calf. Two more constant posterior communicating veins are located at about 5 and $12 \mathrm{~cm}$ above the os calcis and are referred to as the soleal and the gastrocnemius points ${ }^{12}$.

The deep (subfascial) veins of the leg emerge from the foot and are usually paired, running as venae comitantes with the three crural stem 
arteries. At the level of the ankle, the posterior tibial veins are most pronounced as they drain the extensive rete venosum of the sole of the foot (Leonardo's plexus). The posterior tibial veins run behind the posterior tibial artery, easily palpated behind the medial malleolus. More proximally the soleal and gastrocnemius veins drain into the posterior tibial veins ${ }^{15}$. The dorsum of the foot drains by means of the dorsal pedal vein into the anterior tibial veins, which run in the deep part of the anterior compartment close to the interosseous membrane. The peroneal veins lie directly behind and medial to the fibula ${ }^{16}$. In the upper part of the calf the paired stem veins merge to form single trunci and then unite at different levels to form the popliteal vein. The superficial femoral vein is the continuation of the popliteal vein and passes obliquely upwards and medially across the lower femur. It receives the deep femoral vein at approximately $9 \mathrm{~cm}$. below the inguinal ligament and from there it is called the common femoral vein. The medial and lateral circumflex femoral veins are direct side branches of the deep femoral vein. The common femoral vein becomes external iliac vein while passing under the inguinal ligament. After it has joined with the internal iliac vein it is called the common iliac vein and confluences with the vein from the opposite side at the level of the 5th lumbar vertebra. The left common iliac vein is often compressed by the right common iliac artery, causing intimal adhesions ${ }^{17,18}$.

The venous system is characterised by the presence of valves. In the absence of valves the venous muscle pump would fail. The communicating veins in the foot have their valves pointed outward to permit filling of the superficial veins from the deep veins. Cephalid to the malleoles the valves point inward to permit flow from superficial to deep ${ }^{20}$. The cusps of the valves lie with their edges parallel to the skin surface or fascia $^{19}$. With a few exceptions the valves in the main venous trunci of the lower extremity are bicuspid. The sapheno-femoral valve, which in humans is the largest, is sometimes tricuspid. The number of valves increases in a distal direction. The inferior vena cava and common iliac 
veins are valveless or in 7\% contain very small incompetent valves; $75 \%$ of the external iliac veins are valveless, in $75 \%$ there is one valve in the common femoral vein above the sapheno-femoral junction. Otherwise valves are absent in the ileo-femoral region, exposing the highest valve in the greater saphenous vein to thoraco-abdominal pressures ${ }^{21}$. Normally the greater saphenous vein contains 7-9 valves, of which 3 are major valves. The lesser saphenous vein contains an average of 8 valves of which one is major. In the calf veins the valves become numerous and the distances between each valve are smaller. Venules of less than $1 \mathrm{~mm}$. in diameter are again valveless ${ }^{12}$. 


\section{References}

1 Pinkhof-Hilfman, Geneeskundig woordenboek. De Erven Bohn BV, Amsterdam , 1973

2 Gray's Anatomy, Warwick R, Williams PL. Eds. Longman; London, 1973

3 Die Flebografie der unteren Extremität, May R, Niss] R. Eds. Georg Thieme Verlag, Stuttgart, 1973

4 Furderer CR, Marescaux J, Pavis d'Èscurac, Stemmer R. Les crosses saphéniennes. Anatomie et concepts thérapeutiques. Phlebologie 1986; 39; 3-14

5 Neumann HAM. Flebologie in kort bestek. Zyma, Mijdrecht, 1988: 12

6 Hermann H. Zur Frage der sogenannten doppelten Vena Saphena Magna und ihrer operativen Entfernung unter Verwendung eines Lokalisators.

Zbl Phlebol 1965; 4: 2-9

7 Schwilden ED. Neue Aspekte der Varicenchirurgie.

Chirurg 1985; 56:81-89

8 Hobbs JT. A new approach to short saphenous vein varicosities. In: Surgery of the Veins. Bergan JJ, Yao JST Eds. Grune \& Stratton, Orlando, 1985: 301-321

9 Gillot G. Die Intraoperative Phlebographie der Vena Saphena Parva. In: Die Kniekehle. Hrsg.: U.Brunner; Huber, Bern Stuttgart Wien, 1975

10 Vasdekis SN, Clarke GH, Hobbs JT, Nicolaides AN. Evaluation of noninvasive and invasive methods in assessment of short saphenous vein termination.

Br J Surg 1989; 76: 929-932

11 Ryan TN. The Management of Leg Ulcers 2nd Edition, Oxford University Press, Oxford, 1987

12 Browse NL, Burnand KG, Thomas ML. Diseases of the Veins. Edward Arnold, London, 1988: 44-45

13 Boyd AM. Discussion on primary treatment of varicose veins.

Proc R Soc Med 1948; 41: 633

14 Papadakis K, Christodoulou C, Christopoulos D, Hobbs JT, Malouf GM, Grigg $M$, Irvine A, Nicolaides $A N$. Number and anatomical distribution of incompetent thigh perforating veins. 
Br J Surg 1989; 76: 581-584

15 Voorhoeve $\mathrm{R}$. The diagnosis of deep venous thrombosis.

Thesis, Maastricht, the Netherlands, 1986

16 Anson BJ, Mcvay CB. Surgical Anatomy. W.B.Saunders, Philadelphia, 1988: 1191

17 May R, Tumer J. The cause of the predominantly sinistral occurrence of thrombosis of the pelvic veins.

Angiology $1957 ; 8: 419-427$

18 Schneider W, Fischer H. Die chronische Venöse Insuffizienz. Ferdinand Enke Verlag, Stuttgart, 1969; 26-27

19 Edwards EA. Orientation of venous valves in relation to body surfaces. Anat Rec 1936; 64: 369-372

20 van den Broek ThAA. Chronische veneuze insufficientie en veneuze reconstructieve chirurgie. Thesis, Amsterdam, the Netherlands, 1989

21 Basmajian JV. The distribution of valves in the femoral, external iliac and common iliac veins and their relationship to varicose veins.

Surg Gynec Obst 1952; 95: 537-542 
Chapter 3: Physiology and pathophysiology of the venous system and of varicose veins.

\section{Physiology}

Unlike their arterial counterparts, veins are collapsible, thin walled tubes. When fully extended, they have a circular cross-section; but when they are collapsed, they assume a dumbbell configuration. The resistance to blood flow becomes less as the cross-section changes from ellipse to circle. Until the cross-section becomes circular, the vein can accommodate an increasing volume of blood without a significant increase in distending pressure (intraluminal minus extraluminal or tissue pressure). Once the cross-section is circular, further increases in volume are associated with a disproportionate increase in pressure. In distended state, the cross-sectional area of veins is roughly three to four times that of corresponding arteries. The extrapulmonary veins contain about twothirds of the blood in the body ${ }^{1}$, approximately $3300 \mathrm{ml}$.. Normally 350 $\mathrm{ml}$. of blood is confined to the venous system of the lower extremities. The veins have two functions: conduction of blood and blood storage ${ }^{2}$. Veins of the extremities are divided in the deep and superficial systems. The deep veins are delicate structures. The large deep veins that drain blood from the calf muscles are referred to as sinusoids. As major components of the muscle pump mechanism these sinusoids are physiologically important. The superficial veins are thick-walled and more muscular than deep veins. The direction of venous blood flow is controlled by the valves. The valves in the axial veins prevent blood flow away from the heart. In the perforating veins the valves prevent blood flow from deep to superficial, except in the foot where the flow direction is reversed.

With inspiration there is a negative intrathoracic pressure tending to draw blood into both superior and inferior vena cava. With the descent of the diaphragm on inspiration, there is a rise of the intra-abdominal pressure, which empties the splanchnic veins and compresses the vena cava and iliac veins. If the femoral valves are competent blood is drawn into the 
thoracic cavity. This mechanism is termed vis a fronte. During expiration, because of the drop in intra-abdominal pressure, the valves in the lower limbs will open, allowing filling of the iliac veins and inferior vena cava. There is a difference between the upper and lower extremity. In the upper extremity venous flow is increased during inspiration, due to the negative intra-thoracic pressure. Conversely venous flow in the lower extremities is interrupted during inspiration, due to an increase in intra abdominal pressure ${ }^{3}$. Occasionally venous flow can be augmented in the lower extremities during inspiration, this is when predominantly thoracic respiration is performed, such as after laparotomy or in respiratory distress ${ }^{4}$.

Active and variable tone is provided by the smooth muscle in the tunica media. The passive tone is provided by the elastic properties of the vein wall; this cannot be changed. Most veins have little active tone when the body is at rest. Changes in tone are mediated through sympathetic nerves and by circulating smooth muscle stimulants or relaxants. Venoconstriction is caused by emotion, pain, standing up and a deep breath. Venorelaxation is caused by sleep and an increased body core temperature. Overall, the most important reflex role of the subcutaneous veins is thermoregulation 5 . The pressure in a foot vein when a subject is supine is approximately $15 \mathrm{~mm}$. $\mathrm{Hg}$. The right atrial pressure is normally between 0 and $2 \mathrm{~mm} \mathrm{Hg}$, so the venous return is generated by a pressure gradient of 13-15 mm. $\mathrm{Hg}$. The pressure drop between venules and right atrium is termed vis a tergo. Important is that the venous system is a low pressure system; also the resistance is extremely low. Small differences in pressure are sufficient to cause venous flow.

In the normal venous system the standing superficial venous pressure at the ankle is equal to the hydrostatic pressure of the blood extending from the right atrium. The distance from the heart to the foot defines this venous pressure. This pressure is usually about $100 \mathrm{~mm}$. $\mathrm{Hg}$, extremely long individuals can have pressures between 115 and $120 \mathrm{~mm} . \mathrm{Hg}^{6.7}$. Various authors found equal pressures in the deep and superficial venous systems. Arnoldi found higher pressures in the posterior tibial veins 
compared to the greater saphenous vein ${ }^{2}$. With ambulation the superficial venous pressure should drop to about 20 to $30 \mathrm{~mm}$. $\mathrm{Hg}$ to guarantee adequate venous drainage. With every muscle contraction (every step) $30-40 \mathrm{ml}$. of blood is pumped into the outflow tract. After cessation of muscle exercise the pressure in the veins will return to resting pressures in 20 to 40 seconds. The effectivity of the muscle pump can be deranged by defective muscle function (paralysis, atrophia), defective valve function and obstruction of outflow. During the contraction the pressure considerably exceeds the resting pressure values. Some authors mention "systolic" pressures of $100 \mathrm{~mm}$. Hg. above the resting pressure; during the following "diastole" the pressure drops to far below the resting values ${ }^{3}$. Normal average pressure drops of between $50-90 \%$ were reported by various authors ${ }^{3}$. This is caused by flow of blood from superficial to deep veins through perforating veins as result of contraction of calf muscles. The calf pump is proportionally the most important and sometimes termed second heart of the circulation. Also other muscle groups act as venous pumps, in particular the thigh muscles, the muscles surrounding the ankle and the foot musculature. Thigh muscle contraction, calf muscle contraction and standing on the sole of the foot are the propelling powers respectively. The soleal sinuses and gastrocnemius veins lie within the muscles. The posterior, anterior and peroneal veirs lie between the muscles. The intermuscular veins are not emptied as forcefully by muscular contractions as the intramuscular veins. The intermuscular veins act as outflow tract for the foot ${ }^{3}$. In order to obtain adequate venous drainage from the legs in the upright man, the four above mentioned factors (vis a tergo, vis a fronte, venous tone and muscle pumps) are essential.

\section{Pathophysiology}

Varicose veins are classified as primary or secondary. Primary varicose veins refer to isolated varicosities of the superficial system with normal deep and communicating veins. Secondary varicose veins refer to varicosities in patients with underlying deep and communicating venous 
disease, usually the result of prior deep vein thrombosis.

Secondary varicose veins usually develop as a result of collateral circulation around previously thrombosed veins ${ }^{6}$. Varicose veins are usually associated with dilatation and malfunctioning venous valves, which allow reflux to occur.

It is not clear whether valvular incompetence occurs first and produces the dilatation, or vice versa ${ }^{8}$. Two theories exist concerning the development of varicose veins. The accepted view is that varicose veins are primarily due to valvular incompetence. The second theory claims a weakness of the vein wall as the cause of dilatation resulting in secondary incompetence of the valves. The first theory is the oldest and was originally suggested by Harvey ${ }^{9}$. The main function of the valves was seen in assisting the return of blood to the heart. An incompetent valve would result in distention of the vein distal to it, producing a varicose vein. This theory of descending valvular incompetence was supported by various later authors ${ }^{10}$. The absence of valves in the ileo-femoral region was thought causative in the development of varicose veins by exposure of the first competent valve to thoraco- abdominal pressures ${ }^{11,12}$. There are patients who have a congenital absence of all venous valves and who do often develop severe varicose veins ${ }^{13}$. In the absence of valves in the ileo-femoral region a pressure reducing effect of the inguinal ligament has been demonstrated ${ }^{12}$. Some degree of reflux can occur in normal valves $^{7,13}$ It is well known and demonstrated by Doppler ultrasound investigations that varicose veins can develop distal to competent val$v^{8} s^{8,9}$. Response to chronic back pressure should be hypertrophy instead of atrophy and dilatation. This is demonstrated when a normal saphenous vein is used as an arterial bypass. Varicose veins do not behave in this way, they will only dilate further and for this reason are not suitable for arterial bypass procedures ${ }^{15}$.

Examination of the various theories about the development of varicose veins suggests that the "weak wall theory" is the most likely ${ }^{16}$. Varicose veins developing during pregnancy, can disappear after delivery, hence incompetence can be reversible. Estrogens cause dilatation of the vein 
wall which involves the valve ring and consequently the cusps are unable to meet. When hormonal influence of pregnancy has waned the process goes into reverse. ${ }^{8}$. If valvular atrophy were the cause there would be no way this could reverse. Rose suggests that in the development of varicose veins the balance between muscle cell fibres, collagen fibres and elastic fibres becomes disturbed at cellular level resulting in a loss of contractility $^{8}$. A clear difference in elasticity between normal veins and varicose veins has been demonstrated ${ }^{16}$.

In patients with primary varicose veins the standing venous pressure is similar to that of normal individuals. The ambulatory venous pressure is higher than in normal individuals. This is caused by retrograde flow in the saphenous vein; blood flows from the deep veins down the incompetent superficial system and then back into the deep system through communicating veins of the lower leg. This causes an ineffective circular motion of blood and increases the volume of blood that has to be pumped out of the lower leg. Varicose veins only contain $5-10 \%$ of the total blood in the lower limb, but the volume of blood refluxing through them may be considerable.

Eventually this added load can jeopardize calf pump function and cause skin damage 4 . Varicose veins do not occur in quadrupeds. Despite exhaustive inquiries made by Foote he has not been able to find a single instance of any four legged animal suffering from a varicose vein ${ }^{17}$. Even large animals like the elephant and the giraffe are free of varicosis. He suggests that apart from the erect stance as cause of varicose veins in humans, the reason for absence of varicosis in quadrupeds may be that the superficial veins in animals receive a firmer support from the superficial cutaneous fascia than in humans. 


\section{References}

1 Sumner DS. Applied physiology in venous problems. In: Surgery of the veins. Bergan JJ, Yao JST. Eds Grune \& Stratton, Orlando, 1985: 3-23

2 Arnoldi $\mathrm{CC}$. Venous pressure in the leg of healthy human subjects at rest and during muscular exercise in nearly erect position.

Acta Chir Scand 1965: 130: 570-572

3 Boersma W. Het chronisch veneuze insufficientiesyndroom. Thesis, Amsterdam, 1973

4 Browse NL, Burnand KG, Lea Thomas ML. Diseases of the veins. Edward Amold, London, 1988: 53-69

5 Netzer CO. Die Physiologie des Niederdrucksystems. In: Venöse Abflussstörungen. Ehringer H, Fischer H, Netzer CO, Schmutler R, Zeitler E. Eds. Ferdinand Enke, Stuttgart, 1979: 23-62

6 Sumner DS. Diagnosis of venous thrombosis by Doppler ultrasound. In: Venous problems. Bergan JJ, Yao JST. Year Book Medical Publishers Inc., Philadelphia, 1978: 159-185

7 Ludbrook J, Beale G. Femoral venous valves in relation to varicose veins. Lancet 1962: 2: 79-81

8 Rose SS, Ahmed AA. Some thoughts on the etiology of varicose veins. J Cardiovasc Surg 1986; 27: 534-543

9 Timmons MJ. Willam Harvey revisited. Reverse flow through the valves of the forearn veins.

Lancet 1984; 2: 394-395.

10 Ludbrook J. Valvular defect in primary varicose veins. Cause or effect? Lancet 1963; 2: 1289

11 Bames RW. The clinical spectrum of venous disease. In: Noninvasive diagnostic techniques in vasicular disease. Bernstein EF. Ed. The C.V. Mosby Company, St. Louis 1985 712-724

12 Basmajian JV. The distribution of valves in the femoral, extemal iliac and common iliac veins and their relationship to varicose veins.

Surg Gynec Obstet 1952; 95: 537

13 Lindvall N, Lodin A. Congenital absence of venous valves. Acta Chir Scand 1962; 124: 310-314 
14 Ackroyd JS, Pattison M, Browse NI. A study of the mechanical properties of fresh and preserved human femoral vein wall and valve cusps. Br J Surg 1985; 72: 117-119

15 Campbell PA. Vein grafts for arterial repair, their success and reasons for failure.

Ann R Coll Surg Eng 1981; 4: 257-260.

16 Clarke H, Smith SRG, Vasdekis SN, Hobbs JT, Nicolaides AN. Role of venous elasticity in the development of varicose veins.

Br J Surg 1989; 76: 577-580.

17 Rowden Foote R. Varicose veins. Butterworth \& Co. Ltd., London, 1952: $38-43$ 
Chapter 4: Incidence and etiology of varicose veins.

Communities who strain at stool have varicose veins. (Burkitt 1972)

\section{Incidence and prevalence}

In 1918 Santler wrote "Varicosis und C.V.I. machen rund 1\% der Krankmeldungen bei Gebietskrankenkassen aus"1. In 1937 Meisen found that $17 \%$ of a group of conscripts in Denmark were suffering from varices of some degree ${ }^{2}$. Of 48000 American recruits between 18 and 19 years of age 0.7 promille were rejected because of varicose veins ${ }^{3}$. The Ministry of Health Bulletin in 1946 showed that nearly $10 \%$ of the hospital admissions to Emergency Medical Service hospitals of Great Britain during World War II were sufferers from varicose vein disease and its complications ${ }^{4}$. In 1942 Lake found varicose veins in 50\% of the persons working at Macy's department store 5 . In the Wurzener study (1976) Hackel found varicose veins in $18 \%$ of the investigated men $^{6}$, Fischer (1981) found 15\% in a representative group of the west-German population $^{7}$ and Winker (1981) in $14 \%$ of a representative sample of East-Germans ${ }^{8}$. A prevalence of $30 \%$ was found in the Basle study ${ }^{9}$, in workers in the chemical industry in Barcelona ${ }^{10}$, and also in women employed in department stores and clockwork factories in Neuchatel ${ }^{11}$. In the United States varicosis is ranked 7th amongst a list of 28 chronic diseases, in Great Britain 16th amongst 48. Coon estimated that 24 million persons, or approximately $12 \%$ of the adult population in the United States, had significant varicose veins ${ }^{12}$. In the US health survey venous disease was, among 28 chronic diseases, in 7 th position for prevalence, in 21 th position for disability, in 23rd position for invalidity and in 28th position for mortality ${ }^{13}$. All these studies may overestimate the prevalence of this venous problem. In the Cardiff study Weddel could discover varicose veins in only $30 \%$ of the relatives of venous patients who claimed to be sufferers in a questionnaire ${ }^{14}$. On the other hand, in the Basle study only $15 \%$ of the persons who were found to 
have an isolated insufficiency of the long saphenous vein, answered the questionnaire positively. In total in Europe and North-America about $10 \%$ of the adults over 25 years of age will have clinically relevant varicosis; in this way the prevalence of varicose veins is near to that of diabetes mellitus and stomach ulcers. Widmer estimated that in Switzerland the costs of in-patient treatment of peripheral venous disease may be approximately 50 million Swiss francs or $\$ 20$ million a year ${ }^{12}$. In the Netherlands in 1989, 10527 patients were operated upon under the primary diagnosis "varicose veins".

\section{Etiology}

The real cause of varicose veins is, despite the magnitude of the affliction, not completely clear. Commonly an inherited weakness of the vessel wall or the connective tissue is thought to be causative, whereas other factors, mainly mechanical and secondly degenerative, play a role in favouring the condition. Various mechanical factors are given a quite differing importance by various authors. Because age has been found to be the single most important risk factor in numerous studies, all investigations on prevalence which have been analyzed without adjustment for age, have a limited epidemiological value ${ }^{13}$. Age, sex, childbirth, hormonal factors, hereditary factors, racial factors, bowel habit and position at work will be dealt with separately.

\section{- The vein wall}

The part played by the vein wall in the venous return has only received scant attention as has its role in the development of varicose veins. Treatment of varicose veins is directed at valular incompetence. However, why valves become incompetent is not completely clear. It has been stated that valves tend to disappear with advancing age; this has been confirmed by embryological studies ${ }^{15}$. It has further been suggested that the patient who is prone to develop varicose veins is either born with fewer valves or has valves which undergo atrophy more quickly or there is a combination of both ${ }^{15}$. Recently the important role of oestrogen 
on development on varicose veins has been stressed ${ }^{15}$. Estrogens produce relaxation of smooth muscle cells and softening of collagen fibres; veins first become hypotonic then atonic and finally dilate. When the vein wall is dilated the valve ring becomes involved and the valve cusps are then unable to meet.

\section{- Age}

All surveys show that the prevalence of varicose veins increases with age, the peak frequency being between 50 and 60 years and thereafter declining. This latter observation may however be incorrect because elderly patients with varicose veins are rarely referred for surgery. In the Basle study, as in previous studies, age has been found to be the most important risk factor ${ }^{9}$. In the 60 year old group varicose veins are four times more prevalent than in those aged 20 years. The linear correlation found in this study between the incidence and age in the range of 30 to 70 years of age is in accordance with most other investigations ${ }^{9}$. In the Neuchatel study, in which causative factors of varicose veins were studied, age was found the single significant factor ${ }^{17}$. Factors such as childbirth, body weight and obesity, standing occupation and even the wearing of corsetry appeared only significant because of the higher average age in this population group ${ }^{17}$.

\section{- Sex}

Sex appears to be less prominent than expected from observations in surgical practise in which a predominance was found of four females to one male. Different investigators found that the incidence was equal up to the twentieth year, between the ages of 20 and 30 the ratio was three women to one man and between 30 and 40 years of age the ratio was four women to one $\operatorname{man}^{2}$. Women attend in far greater numbers at the average clinic than men do, since they are probably more inclined to attend for cosmetic reasons. This gives rise to the general impression that varices are essentially a disease of the female.

As Madar pointed out, epidemiological studies give female/male ratios 
varying from $0.7: 1$ to $2.1: 1$, whereas surgical studies give female/male ratios of $4: 1^{18}$. The Basle Survey is the only study that shows a male to female preponderance ${ }^{15}$.

\section{- Pregnancy}

An increased incidence of varicose veins was found in women who had been pregnant compared to the nulliparous group ${ }^{4}$. The incidence of varicose veins developing during pregnancy varies from 8 to $20 \%$. Women who have given childbirth are four times more prone to develop varices than men. In the first months of pregnancy, well before the uterus enlarges significantly, humeral factors cause the veins to become more compliant. Together with the increased venous pressure that occurs later in gestation, this causes significant venous distention. Because of these factors the velocity of blood flow in the leg veins gradually decreases as pregnancy progresses. When a woman is in the third trimester of pregnancy the enlarged uterus tends to compress the inferior vena cava and the iliac veins. As a result venous pressure is increased and venous flow patterns become less responsive to respiration. Although pregnancy does not cause varicose veins, the increased pressure and venous distensibility exaggerate predisposing factors. Varicose veins often appear during the first pregnancy and become more severe during following pregnancies ${ }^{13.16}$. However, the Neuchatel study demonstrated clearly that, although the overall prevalence of varicose veins increased with the number of children, this increase was not due to childbirth but only to age ${ }^{16}$. The Basle survey failed to confirm a relation between childbirth and prevalence of varicose veins ${ }^{15}$.

\section{- Hormonal factors}

In 1958 the important role of hormonal factors in the development of varicose veins was proposed by Arnoldi' ${ }^{19}$; a late menarche was present in families with varicose veins, and the manifestation of varicose veins occurred at the time of three major changes in women: the menarche, during pregnancy and at the menopause ${ }^{19}$. Also a relationship was found 
between the subjective symptoms of varicose veins and the menstrual period. Of a group of women between the age of 15 and 45 years of age, $73 \%$ claimed to have aggravating symptoms of their varicose veins during the last premenstrual week. In $83 \%$ of them diuretic therapy, started ten days before the first day of the menstruation, lessened the symptoms ${ }^{20}$. The effect of oestrogen has been discussed under "vein wall".

\section{- Hereditary factors}

Almost all authors consider heredity as one of the predisposing factors for varicose veins ${ }^{21}$. Not varicosis itself is inherited but a certain disposition which weakens the connective tissue. Often there is a combination with flat feet, spread feet, inguinal hernias and haemorrhoids. For the manifestation of the varicose veins other predisposing factors such as agreviating pressure are necessary. Foote reported that the majority of patients who attended for their varicose veins proffer information that one or other of their parents was a sufferer ${ }^{2}$.

Ottley believed the inheritance was of a simple dominant type ${ }^{4}$. Some authors support the theory of polygenetic inheritance of varicose veins which assumes the existence of a number of independent complementary genes, each representing only a minor effect, but when present will lead to manifestation of the disease. Although men in general are more rarely affected with varicose veins than women, the relatives of male patients, especially in case of fathers and brothers, run a higher risk of the affection than relatives of affected women ${ }^{22}$. The only existing series of twins studied seems to assign equal weight to genetic as well as external etiological factors ${ }^{23}$. Reagan and Folse found by Doppler examination that the incidence of femoral vein reflux among children was twice as great if their parents had varicose veins ${ }^{24}$. Munn reported a positive family history in $80 \%$ of the patients admitted for surgery of the greater saphenous vein ${ }^{25}$. 


\section{- Racial factors}

That racial factors influence the development of varicose veins comes from the observation that in certain races varicose veins are unknown or extremely rare, like in Japan and in West-Africa. However black Americans have varicose veins in the same percentage as their white counterparts, which would point to ecological factors. Even the frequently reported low prevalence of varicose veins in coloured races seems to be mainly due to the greatly different life expectancy between Africans and the Western population ${ }^{26}$. Ethnic differences were demonstrated by Beaglehole who found varicose veins in $15 \%$ of the inhabitants of Cooke Island compared to but $0.8 \%$ for the original inhabitants of the rest of the atoll ${ }^{27}$.

\section{- Bowel habit}

Constipation was long time considered etiological in varicose disease especially if located on the left side. Cleave suggested that lack of fibre in the western diet causes faecal arrest which results in compression of the iliac veins by the distended sigmoid colon and caecum ${ }^{28}$. Burkitt claimed that it was the combination of this with squatting on Western style lavatory seats that raises the venous pressure ${ }^{29}$. In one study $11 \%$ of the varicose population used laxatives which was comparable to a control population without varicosis ${ }^{20}$.

\section{- Anatomical factors}

The greater incidence of left-sided varicose veins has been reported by some workers to be caused by the left common iliac vein being compressed by the right common iliac artery and in this way impeding the venous return ${ }^{30,31}$. Other literature reviews could not confirm this ${ }^{32}$. In the majority of cases varicose veins are purely bilateral. Varicose veins are thought to be more prominent in tall men and short women. There is a significant correlation between height and the resting venous pressure in individuals. One study demonstrates that children with reflux over the saphenous vein have longer legs than children without reflux ${ }^{33}$. Men 
presenting with varicosities tend to be taller than the national average ${ }^{34}$. However Widmer found that $4.5 \%$ of the very tall people in his survey developed varicose veins compared to $5 \%$ of the very short ${ }^{15}$.

\section{- Position at work}

Lake was the first to support the role of prolonged standing in the development of varicosis ${ }^{5}$. Foote believed that occupations involving prolonged standing were causative for evolution of varicose veins ${ }^{2}$. Policemen, waiters and nurses were thought suitable candidates. In the Neuchatel study the prevalence of varicose veins was higher in women standing at work than in those performing their work sitting, but this difference was not significant ${ }^{16}$. In one of the analyses of the Basle study a weak correlation was found between standing occupation and varicose veins ${ }^{15}$.

In conclusion it can be said that recent studies have demonstrated that age is the only and single factor which correlates well with the development of varicose veins. 


\section{References}

1 Nobl G. Der variköse Symptomencomplex. Urban \& Schwarzenberg, Wien, 1918

2 Rowden Foote R. Varicose Veins. Butterworths, London, 1954: 38-43

3 Rowntree LG, McGill K, Edwards ThI. Causes of rejection and the incidence of defects.

JAMA 1943; 123: 183-185

4 Ottley C. Heredity and varicose veins.

Br Med J 1934; 1: 528-533

5 Lake M, Pratt GH, Wright IS. Arteriosclerosis and Varicose veins: Occupational activities and other Factors.

JAMA 1942; 119: 696-701

6 Hackel F, Voigt H, Hanisch HC, Grosser L. Ergebnisse der Wurzener Studie 1971: Zur Epidemiologie der Venenerkrankungen bei Mannern.

Z Inn Med 1974; 29: 611-618

7 Fischer H. Venenleiden - Eine repräsentative Untersuchung in der Bundesrepublik Deutschland.

Urban \& Schwarzenberg, Munchen, 1981

8 Winkler M. Epidemiologie und Pathologie der Varicosis. Euromed 1982; 5: $22-29$

9 Widmer LK, Stahelin HB, Nissen C, Da Silva A. Venen- Arterienkrankheiten. Koronare Herzkrankheit bei Berufstätigen. Basler Studie 1-3. 1959-78, Huber; Bern 1981

10 Cossio JAJ, Manresa EV, Mori AR, Yanez SO. Estudio epidemiologico de varices en una poblacion laboral de 512 individuos.

Med Clin 1977; 69: 415-421

11 Rougemont $\mathrm{A}$. Les varices des membres inferieurs.

Etude epidemiologique chez 610 vendeuses et ouvriers. Thesis Lausanne, 1972

12 Coon WW, Willis PW, Keller JB. Venous thromboembolism and other venous disease in the Tecumseh Community Health Study.

Circulation 1973; 48: 839-845

13 Widmer LK, Mall Th, Martin H. Epidemiology and socio-medical importance of peripheral venous disease. In: The treatment of venous disorders. 
Hobbs JT. Ed. MTP Press, Lancaster, 1977: 6-17

14 Weddel JM. Varicose veins pilot survey 1966. Br J Prev Soc Med 1969; 23: $179-182$

15 Rose SS, Ahmed AA. Some new thoughts on the aetiology of varicose veins.

J Cardiovasc Surg 1986; 27: 534-543

16 Widmer LK. Peripheral venous disorders. Prevalence and Socio-medical Importance. Observations in 4529 apparently healthy persons. Basle 3 study. Bern. Hans Huber 1978

17 Guberan E, Widmer LK, Glaus L, Muller R, Rougemont A, Da Silva A, Gendre F. Causative factors of varicose veins: Myths and Facts Vasa 1973; 2: 114-119

18 Madar G, Widmer LK. Varicosis und chrönisch venöse Insuffizienz, Geringfügige Gesundheitsstörung oder Krankheit? Phlebol Proktol 1990; 19: $69-79$

19 Amoldi CC. The Heredity of Venous insufficiency

Danish Med Bull 1958; 5: 169-172

20 Haeger K, Lundskog O, May R. Chirurgie der Bein und Beckenvenen. Georg Thieme Verlag Stuttgart 1974: 85-96

21 Ehringer $\mathrm{H}$, Fischer $\mathrm{H}$, Netzer $\mathrm{CO}$, Schmutzler R, Zeitler E. Venöse Abflussstörungen. Ferdinand Enke Verlag Stuttgart 1979: 125-126

22 Gundersun J. Hereditary factors in varicose veins. In: The treatment of venous disorders. Hobbs JT. Ed. M.T.P.Press, Lancaster, 1977: 12-17

23 Niermann H.Genetische Problematik des Variköse Symptomencomplexes. Erg Ang 1971; 4: 25-32

24 Reagan B, Folse R. Lower limb venous dynamics in normal persons and children of parents with varicose veins.

Surg Gynecol Obstet 1971; 132: 15-22

25 Munn SR, Morton JB, McBeth WAAG, McLeish AR. To strip or not to strip the long saphenous vein? A varicose vein trial.

Br J Surg 1981; 68: 426-428

26 Rougemont A. Varicose Veins in tropical Africa.

Lancet 1974: 870-473

27 Beaglehole R, Prior IAM, Salmond CE, Davidson F. Varicose veins in the south Pacific 
Int J Epidemiol 1975; 4: 295-299

28 Cleave TL. On Causation of Varicose veins and their Prevention and Arrest by Natural Means. In: Diseases of the Veins. Browse NL, Burnand KG, Lea Thomas M. Eds. Edward Amold London 1988: 160

29 Burkitt DP. Varicose veins, deep vein thrombosis and haemorrhoids: epidemiology and suggested etiology.

Br Med J 1972; 2: 556-62

30 May $R$, Thurner $J$. The cause of the predominately sinistral occurrence of thrombosis of the pelvic veins.

Angiology 1957; 8: 419-427

31 Cockett FB, Lea Thomas $M$, Negus D. Iliac vein compression: its relation to ilio-femoral thrombosis and the post thrombotic syndrome.

Br Med J 1967; 2: 14-19

32 Renes GJ. Over de oorzaken, het onderzok en de behandeling van spataderen. Thesis Leiden, the Netherlands 1950

33 Schultz-Ehrenburg U, Weindorf N. Prospective epidemiological study on development of varicosis in German grammar schools (Bochum study 1).

In: Phlebology 85 Negus D, Jantet G. Eds. John Libbey, London, 1986: 22-25

34 Quaile A, Rowland FH. A retrospective study of the epidemiology and treatment of varicose veins. In: Phlebology 85 Negus D, Jantet G Eds. John Libbey, London, 1986: 33-37 




\section{Chapter 5: Diagnostic methods in venous insufficiency}

The veins produce a heavy and depressing pain which seems to be evenly embedded in them. (Galen 130)

The diagnosis of varicose veins depends on presenting symptoms on clinical examination and specific clinical tests or on non-invasive physiological testing and imaging techniques of the venous system. The basic principles of the objective diagnosis by means of specific clinical and non-invasive functional testing are the demonstration of retrograde filling, abnormally high ambulatory pressures and reverse flow in the superficial veins of the limb.

A brief survey of the various methods will be presented in this chapter.

\section{Symptoms}

To many patients, varicose veins give no trouble but are disfiguring. Other patients complain of varying degrees of discomfort, disability, itching, pain, swelling, skin changes, eczema or ulceration, superficial thrombophlebitis and haemornage ${ }^{1}$.

The chief clinical manifestations and the extent to which these occur are related to both the site of anatomic involvement (superficial, deep or communicating systems or combinations) and to the severity of the disease. Clinical manifestations usually occur in combinations but will be presented separately.

Often unsightly appearance of the varicose veins leads to complaints in no proportion to their magnitude. Massive varicosities in men often cause few symptoms, while minor visible varicosities in women may go with intractable pain ${ }^{1}$. Because of the discrepancy between subjective symptoms and clinical findings deep varicose veins were thought responsible in the past. Nowadays however the role of deep invisible varicose veins is doubted ${ }^{2}$. In women the size of the varices may alter with the menstrual cycle. Varicosities of the greater saphenous vein give a feeling 
of tightness and a heavy feeling in the ankle and front of the leg on prolonged standing and towards the end of the day. Varicosities of the short saphenous vein cause pain and aching in the calf, often also felt in the heel and foot. Warm weather may also alter the size. The local discomforts of varicose vein disease are best explained by local pressure or irritation of cutaneous sensory nerves. Most of the symptoms are due to a functional insufficiency of the muscle pump, which gives rise to a diffuse dull ache felt throughout the leg, which gets worse as the day passes and is exacerbated by prolonged standing. In the morning all complaints should be absent. The typical description of "venous" pain is an ache or discomfort, presence of an acute or sharp pain should suggest another origin. Elevation of the legs, bedrest and walking relieve "venous" pain, standing for prolonged periods makes it worse. Pressure from dilated veins on nerve roots can mimic neurologic conditions ${ }^{2}$.

Itching especially at night is often heard as complaint. The itch is localised in the pretibial region. Often skin changes are absent (Pruritis sine materia) ${ }^{2}$. Dilatation of cutaneous capillaries resulting in impaired skin circulation and nutrition is believed to be the cause ${ }^{23}$.

Restless legs may be caused by entrapment of the saphenous nerve after it emerges from it's lumbar roots ${ }^{4}$. Night cramps can be found in $40 \%$ of the patients with venous problems, due to increased irritability of the neuromuscular junction or to ionic imbalance. ${ }^{5}$. They are characteristic of venous stasis and can be relieved by superficial venous stripping or sclerotherapy.

Venous claudication is found in patients with normal arterial pulses, who complain of distention in the leg or intense bursting pain in the calf after exercise and note that symptoms increase during exercise. These patients must stop exercise and elevate the legs which diminishes the pain, but only after some time has elapsed. These patients have increased intracompartmental pressures. Increased pressures can be due to venous obstruction, severe valvular incompetence or are idiopathic. Taheri 
however found that most patients with venous problems have elevated interstitial fluid pressures in their muscle compartments ${ }^{6}$. Since the greater saphenous vein is accompanied by the saphenous nerve and the short saphenous vein by the sural nerve, any inflammatory changes about these vessels may give pain in the distribution area of these nerves.

Severe edema is rare in patients with primary varicose veins. Edema is usually mild and limited to the area just above the shoe line and only becomes noticeable at the end of the day. Edema occurs quite frequently in patients with incompetent communicating veins and in chronic venous insufficiency, usually accompanied by hyperpigmentation. If there is marked oedema and the patient complains of swelling of the lower leg and ankle, other causes of edema such as deep vein obstruction or lymphatic obstruction must be suspected. Edema was found in $43 \%$ of the patients with primary varicose veins whilst it was found in $83 \%$ of the post-thrombotic limbs. Induration was found in $40 \%$ versus $74 \%$ for both groups?

It has been stated that primary varicose veins never give rise to ulcers. Hoare demonstrated the contrary ${ }^{8.9}$. The striking feature about these patients was the length of time (mean 24 years) that gross varicose veins had been present before the onset of ulceration and the fact that there were twice as many men in this group than women ${ }^{8}$. Sigg states that $40 \%$ of all leg ulcers are due to superficial venous incompetence and $60 \%$ are associated with the post-thrombotic syndrome ${ }^{10}$. A purely superficial insufficiency as demonstrated by Doppler ultrasound was found in $34 \%$ of a population of 382 patients with active leg ulcers ${ }^{11}$. Dilatation of small veins underneath the medial malleolus, the so called "ankle flare" is pathognomonic for chronic venous insufficiency ${ }^{12}$.

A common complication of varicose veins is superficial thrombophlebitis presenting as an extremely tender, hot, red thickening in the course of a vein. In superficial thrombophlebitis the swelling is limited to the skin 
and fat about the affected superficial veins; the area of edema does not involve the muscles. Superficial thrombophlebitis due to trauma also may initiate the onset of varicose veins by scarring the vein wall and destroying the valves ${ }^{13}$. It should be remembered that in $30 \%$ of the patients superficial thrombophlebitis is associated with silent deep vein thrombosis.

In a survey published in 197123 deaths were reported as result of haemorrhage from varicose veins ${ }^{14}$. A further three fatal cases and one non-fatal were later described by Evans ${ }^{15}$. Particularly the elderly patients are at risk. When there is ulceration, the application of potent steroids is thought to cause a deeper perforation of the ulcer and initiate the bleeding ${ }^{15}$.

In pertaining literature surprisingly little is mentioned about symptoms of varicose veins. In only a few trials involving the treatment of varicose veins, the presenting symptoms are briefly mentioned. Table $5-1$ shows the presenting symptoms in five trials. Hamilton Jakobsen ${ }^{16}$ in his trial of 516 patients found as presenting complaints: cosmetic $79 \%$, fatigue $70 \%$, restless legs $60 \%$, pain $50 \%$, cramps $42 \%$, oedema $42 \%$, phlebitis $14 \%$ and ulcer $2.5 \%$. Lofgren ${ }^{13}$ in a group of 350 patients who underwent varicose vein surgery at the Mayo clinics: aching $71 \%$, swelling $60 \%$, heaviness $47 \%$, cramps $39 \%$, itching $30 \%$, cosmetic $25 \%$, stasis dermatitis $16 \%$, pigmentation $16 \%$, burning $16 \%$, ulcer $8 \%$, cellulitis $6 \%$, skin erosion $1 \%$, fatigue $0.6 \%$, restless legs $1 \%$ and no symptoms in $2.3 \%$. Munn $^{17}$ in his varicose vein trial gives a very brief description of preoperative features of 57 patients involved in the trial: ulceration $8 \%$, pigmentation $22 \%$, eczema $26 \%$ and superficial phlebitis $12 \%$. Franks ${ }^{18}$ in 114 patients found swelling in $21 \%$, cramps in $51 \%$, itching in $34 \%$, restless legs in $24 \%$, pain in $45 \%$ and heaviness in $30 \%$. Fegan ${ }^{19}$ found night cramps in $50 \%$ of the patients in his study, a large part of these patients were pregnant. Phlebitis was found in 5\% and ulceration in only $1 \%$. 
Table 5-1: Presenting complaints in various trials

\begin{tabular}{llllllll}
\hline \hline & Cosmetic & Fatigue & Restless & Pain & Cramps & Edema & Phlebi \\
\hline Hamilton & $60 \%$ & $70 \%$ & $60 \%$ & $50 \%$ & $42 \%$ & $42 \%$ & $14 \%$ \\
Lofgren & $25 \%$ & $0.6 \%$ & $0.3 \%$ & $71 \%$ & $40 \%$ & $60 \%$ & -- \\
Franks & -- & -- & $24 \%$ & $45 \%$ & $51 \%$ & $21 \%$ & -- \\
Munn & -- & -- & -- & -- & -- & & $12 \%$ \\
Fegan & -- & -- & -- & -- & $50 \%$ & -- & $5 \%$ \\
\hline \hline
\end{tabular}

\section{Clinical examination}

\section{Inspection}

Legs should be examined in a standing position, preferably with the patient placed on a low stool. Both lower limbs should be exposed from the groins to the toes. Inspection from all aspects is necessary to ensure not missing varicosities in the short saphenous vein area. The distribution of varicosities is noted. Of special interest is the presence spider veins, angiomatous malformations, ankle edema or limb swelling, ankle flares, blow outs over known sites of communicating veins and skin changes like eczema, "atrophie blanche", lipodermatosis and ulceration.

\section{Palpation and percussion}

Some varicose veins are more easily palpated than seen, in particular the upper end of a dilatated long saphenous vein and the full length of the lesser saphenous vein.

\section{Clinical tests}

Clinical tests have evolved in order to determine the competence of the valves in the greater saphenous, lesser saphenous and communicating veins, and to test the patency of the deep venous system. The tests are 
numerous and include:

- The cough impulse test; in this test the finger is placed over the enlarged greater saphenous vein below the foramen ovale. Upon coughing, it is usual to feel an expansile impulse in a varicose greater saphenous trunk. It may be accompanied by a palpable thrill indicating turbulent retrograde flow ${ }^{20,21}$. The sensitivity of this test varies with the degree of reflux according to $\mathrm{Hach}^{22}$. Sensitivity in stage 2 is $42 \%$, in stage 3 is $56 \%$ and in stage 4 is $76 \%$. Specificity of the method is $93 \%$. At the foramen ovale an impulse can occur in the normal femoral vein due to absence of valves in the external iliac and femoral veins (30\% of the individuals).

- The percussion test (Schwartz' tapping test); the examiner places two fingers on the foramen ovale whilst gently tapping the varicosities with another finger. If the greater saphenous vein is incompetent, an impulse is discernible by the palpating fingers ${ }^{20,21,23}$.

- Palpation of fascial defects (Fegan, Cockett); the site at which a dilatated communicating vein pierces the fascia can sometimes be felt as a gap or defect in the deep fascia ${ }^{24}$. This is reported to be an inaccurate method of locating incompetent communicating veins ${ }^{24}$.

- Sliding finger control test; incompetent communicating veins should be suspected if the veins which have been emptied by leg elevation, can be prevented from filling by placing one or more fingers over the suspected sites of communicating vein incompetence ${ }^{25}$. The incompetence can be confirmed when points of control are released.

- Single tourniquet test (Brodie-Trendelenburg test); after the affected leg is raised vertically and the veins are emptied, the tourniquet is placed around the upper thigh. The patient gets up. If no veins fill within 30 seconds the short saphenous vein and the communicating veins below the tourniquet are competent. If within 30 seconds veins visibly refill from above there is a defective perforating or lesser saphenous vein below the tourniquet. When the tourniquet is released after thirty seconds and there is no obvious immediate filling of veins the valve at the sapheno-femoral junction is judged 
competent. If on release the veins distend from above downwards the sapheno-femoral junction is incompetent. When the varices fill within 30 seconds, while the tourniquet is in position, and when it is released they visibly become more prominent, the test is double positive. This indicates defective valves in the greater saphenous vein and in the lesser saphenous vein or in communicating veins below the tourniquet. The test is repeated at the lower third of the thigh, controlling the communicating vein passing into Hunter's Channel, immediately below the knee and the lower leg. Variations are known using double (Foote) or even triple (Mahorner-Ochsner) tourniquets.

- The bandage test (Pratt); in the lying patient the varicose veins are emptied. The leg is firmly bandaged from distal to proximal. The subject stands up, the bandage is unrolled one stroke at a time. A second bandage is meanwhile applied from proximal. Communicating veins will fill the varicose veins if the non bandaged area is proximal to them ${ }^{26}$.

- The Perthes test ; a tourniquet is placed around the thigh and afterwards below the knee. The subject walks on the spot. The veins will collapse if the communicating and the deep veins are competent and unobstructed. Failure of the superficial veins to empty is caused by incompetence of valves in the communicating and the deep veins or caused by deep venous obstruction.

- Rivlin described a test which he considers pathognomonic of varices of the short saphenous system. Application of a tourniquet to the upper thigh has the paradoxal effect of increasing the amount of reflux, as shown by a faster instead of slower refill time, the supposed mechanism being, that the thigh tourniquet blocks off thenormal greater saphenous system, thus throwing into greater prominence the leak from the sapheno-popliteall junction ${ }^{27}$.

Many physicians believe that the majority of patients with straightforward varicose veins require nothing more than a full history and a 
careful physical examination. All too often edema, skin pigmentation, dermatitis or ulceration due to other causes are improperly credited to incompetent venous valves. Such errors were noted by Haeger, who warned against acceptance of clinical criteria alone as rationale for operation $^{28}$. The vascular laboratory can help to identify the etiology of varicose veins and may provide information pertinent to their management ${ }^{29}$. The source of reflux can be identified by Doppler examination for instance. Usually the source of reflux is expected to be found at the sapheno-femoral or at the sapheno-popliteall junction. If these junctional escapes are found to be absent, ligation of these junctions will lead to unsatisfactory results. Recently, junctional escapes from the groin were only found in $71.3 \%$ of the patients thought to have "typical" saphenous varicosities $^{30}$. Venous ulceration may occur due to varicose veins, in the absence of deep venous disease ${ }^{31}$. These ulcers respond favourably to stripping or high ligation. Short saphenous varicosities are underestimated. Series involving clinical assessment alone report rates between 10 and $16 \%$ while in series using Doppler ultrasound assessment considerably higher involvement (27\%-33\%) is found ${ }^{32}$. Failure to treat incompetence of the short saphenous system resulted in failure to control varices in $50 \%$ of the cases. Even when recognised as source of varicosis the sapheno-popliteall junction shows such anatomical variation that preoperative localisation seems mandatory ${ }^{33}$.

When one decides to use further examinations in diagnosing varicose veins the question arises which technique to use. This is determined by availability of equipment and is dependent on experience with the equipment. Various invasive and non-invasive examinations are available for routine clinical application:

\section{Foot vein pressure measurements}

This technique is generally accepted as gold standard for calf muscle function. A vein on the dorsum of the foot is cannulated. The cannula is connected to a strain gauge transducer which in its turn is connected to a 
pen recorder. After calibration of the system, to achieve a stable baseline, the patient exercises by dorsiflexing and plantarflexing the foot vigorously five to ten times and then relaxes his limb completely. The test can be repeated with superficial vein occluding cuffs at different levels of the leg. The fall in pressure during exercise, indicates the efficiency of calf pump function. The rise in pressure after exercise, produced by the combination of arterial influx and venous reflux can be expressed as the time taken to refill completely. Venous pressure measurements using tourniquets can demonstrate the role of superficial and communicating vein insufficiency. The method is very accurate and reproducible. Pressure measurement has the advantage of being quantitive, but it is invasive. It can not be repeated often and cannot be used as a screening test and is more cumbersome than various other methods ${ }^{34}$.

\section{Contrast Phlebography}

Phlebography can be performed in two ways. Ascending phlebography provides visualization of deep veins of the calf, the popliteal vein, the femoral vein and the external and common iliac veins. It is used to judge the passage in the deep veins as well as incompetence of the communicating veins. Descending phlebography is used to demonstrate venous valvular incompetence. Hach defined radiological criteria for the interpretation of findings on the descending phlebogram ${ }^{22}$ :

Stage 1: mild reflux reaching one hand below the groin

Stage 2: reflux reaching the lower third of the upper leg

Stage 3: reflux reaching one hand below the knee

Stage 4: reflux reaching the ankle

There are several side effects of phlebography. First of all it is an invasive procedure and the performance is, for technical reasons, impossible in approximately $10 \%$ of the patients. The injection of contrast agent is experienced as painful. Extravasation may result in ulceration at the injection site. Adverse reactions to contrast media occur in 5\% of the patients (urticaria, bronchospasm, hypotension, circulatory collapse) and 
are fatal in $0.006 \%^{35,36}$. Contrast material is nephrotoxic. Finally phlebography is capable of inducing deep venous thrombosis. Although frequently used for the detection and in particular the localisation of incompetent communicating veins (sensitivity $70 \%$ ), the role of phlebography is thought to be replaced by duplex ultrasound investigations in the future ${ }^{33}$.

\section{Doppler-Ultrasound}

The Doppler ultrasound velocity detector permits qualitative assessment of valvular incompetence in the deep, communicating and superficial system. A piezo-electric crystal within the probe transmits an ultrasonic beam which is reflected from moving particles, like red blood cells. The frequency shift of the reflected sound signal is proportional to the flow velocity. This shift can be heard as a change in an audible signal, or recorded as a written account. The instrument is capable of detecting changes in both flow velocity and direction of blood flow. Normally a Valsalva manoeuvre or manual compression proximal to the site of the Doppler probe causes closure of competent valves. Occasionally a very short refluxing signal $(<1$ seconde) may be heard. This is considered normal. If the valves proximal to the probe are incompetent, retrograde flow will be detected. Further differentiation as to the nature of the incompetence can be made using tourniquets prohibiting superficial reflux. The accuracy of the method varies with the investigator. In literature sensitivity figures of $94 \%$ and specificity figures of $91 \%$ are mentioned, comparing Doppler tests to phlebography ${ }^{22}$. When comparing Doppler ultrasound to the Turner-Warwick refluxtest at operation, Doppler seems to overestimate sapheno-femoral reflux in $24 \%$ of the cases $^{37}$.

\section{B-mode ultrasound echography}

The B-mode imaging techniques are based on the concept that ultrasound traversing biologic tissue is reflected from interfaces between structures with different acoustic impedances ${ }^{38}$. It presents anatomic information. It 
has found little use in the investigation of the superficial venous system, the main use has been in the detection of deep venous thrombosis ${ }^{35}$.

\section{Duplex Scanning}

Duplex scanning, a combination of B-mode echography and pulsed Doppler examination, was introduced in the study of venous disease with promising results. It has been shown to be very accurate in the detection of venous thrombosis and deep vein insufficiency. Duplex scanning has been used in the quantification of spontaneous thrombolysis and the development of valvular incompetence after deep vein thrombosis ${ }^{39,40}$. Recently it has been used to assess venous valvular function. Valves are visualised in a high percentage of cases, valve opening and closure on valsalva can be visualised. The determination of the direction of blood flow in response to compression is a way to evaluate valve function. With proximal compression the valve will normally close and flow will cease abruptly. Flow will resume with release of compression. Quantitative segmental evaluation of venous valvular reflux has been possible with duplex ultrasound scanning ${ }^{41.42}$. Duplex scanning is a non-invasive technique which is almost as accurate as venography and provides additional haemodynamic information about the incompetent veins by demonstrating the presence and extent of reflux ${ }^{33}$. The accuracy of the technique compared with phlebography is $96 \%$. The disadvantage is that the technique is not available in every clinic and experience is required for its use.

\section{Plethysmography}

Qualitative or quantitative evaluation of venous valvular incompetence is possible with a number of plethysmographic techniques. Venous outflow quantification may be carried out by strain-gauge, impedance, pneumatic cuff or water plethysmography. These are mainly used for investigation of deep venous obstruction or insufficiency. Photoplethysmography, which is still widely used in venous diagnosis, is discussed more extensively in chapter 8 . In that chapter it is shown that photo- 
plethysmography is not the method of choice in the evaluation of superficial venous insufficiency ${ }^{43,44}$

In conclusion, functional testing as performed in the vascular laboratory is very helpful in the diagnosis of varicose veins. Depending on the equipment and manpower available a selection has to be made of tests to use in the routine evaluation of varicose veins.

In all types of varices other than primary varicosities of the greater saphenous vein, the relevant pathophysiolocical disturbances cannot reliably be pinpointed or excluded through functional testing alone.

Contrast phlebography or varicography give anatomical information about site, extent and connections of varices. Ascending phlebography gives anatomical information about the state of the deep veins and allows localisation of incompetent communicating veins; descending phlebography gives information about the function of the deep vein valves and can demonstrate presence or absence of long saphenous reflux.

Foot vein pressures give no anatomical information, but are the expression of the calfpump function.

Plethysmography gives no anatomical information. It allows an overall assessment of calfpump function and - in combination with tourniquet testing - to some extent a determination of the separate contribution of the superficial and the deep veins to the reflux.

Doppler ultrasound is usefull to determine reflux in various veins, but has the disadvantage that it is not always possible to detect with it in which specific vein the reflux occurs.

B-mode ultrasound imaging permits real-time visualization of the vessel walls, the venous flow and valve motions and the compressibility of the venous lumen.

Modern Duplex ultrasound examinations combine the advantages of Doppler and B-mode examinations. Their ability to identify specific veins permit a precise interrogation of venous flow.

The usefulness of the presently available tests is summarized in table 52. Doppler examination (or if available a duplex investigation) is 
believed necessary to determine whether varicose veins are primary or secondary and to judge patency of the deep venous system ${ }^{29}$. Especially investigation of the escape points of venous reflux, whether junctional or non junctional, is of great importance since they determine the further mode of treatment.

Table 5-2: Usefulness of various investigative methods in the diagnosis of A: superficial venous valvular incompetence, B: Deep venous valvular incompetence, C: Deep vein thrombosis.

\begin{tabular}{lccc}
\hline \hline & A & B & C \\
\hline Clinical investigation & + & - & - \\
Contrast phlebography & + & ++ & ++ \\
Pressure measurements & + & + & - \\
Photoplethysmography & - & + & ++ \\
Doppler ultrasound & + & + & ++ \\
B-mode imaging & ++ & - & ++ \\
Duplex scanning & ++ & ++ & ++ \\
\hline \hline
\end{tabular}

- = Not useful (sensitivity/specificity $<50 \%$ )

$+=$ Limited use (sensitivity/specificity 50-75\%)

$++=$ Useful test(sensitivity/specificity $>75 \%$ ) 


\section{References}

1 Browse NL, Burnand KG, Lea Thomas M. Diseases of the veins, pathology, diagnosis and treatment. Edward Arnold, London, 1988: 169-197.

2 Schneider W, Fischer H. Die Chronisch-Venose Insuffizienz. Ferdinand Enke, Stuttgart, $1969: 113-114$

3 Villavicencio JL, Collins GJ, Youkey JR, Salander JM, Donohue HT, Elliot BM, Rich NM. Nonsurgical management of lower extremity venous problems. In: Surgery of the veins. Bergan JJ, Yao JST Eds. Grune \& Stratton, Orlando, 1985: 323-345

4 Lewis $F$. The role of the saphenous nerve in insomnia: the proposed etiology of restless legs.

Med Hypotheses 1991; 34: 331-333

5 De Takats G. Venous insufficiency (varicose veins) of the lower extremities. In: Vascular surgery. WB Saunders, Philadelphia, 1959: 324

6 Taheri SA, Yacobucci GN, Williams J, Elias S. Deep posterior compartment pressure in the evaluation of venous insufficiency of the lower extremity: A preliminary report.

Angiology 1984; 35: 173-176

7 Van der Heyde MN. Phlebography and venous pressure determination. Stenfert Kroese, Thesis, Leiden, 1961: 4-5.

8 Hoare MC, Nicolaides AN, Miles CR, Shull K, Jury RP, Needham T, Dudley HAF. The role of primary varicose veins in venous ulceration. Surgery 1982; 92: 450-453

9 Colgan NP, Sumner DS. How does the vascular laboratory influence management of venous disease? In: Vascular surgery issues in current practise. Greenhalgh CW, Jamieson CW, Nicolaides AN. Eds. Grune \& Stratton, London, 1986: 119-135

10 Sigg $\mathrm{H}$. Treatment of varicose veins by injection-sclerotherapy: A method practised in Switzerland. In: The treatment of venous disorders. Hobbs JT. Ed. MTP Press Limited, Lancaster, 1977: 113-138.

11 Nelzen O, Bergqvist D, Linhagen A. Leg Ulcer Etiology: A cross-sectional population study.

J Vasc Surg 1991; 14: 557-564.

12 O'Donnell Jr. TF. Clinical diagnosis and classification of chronic venous 
insufficiency. In: Vascular Surgery, Rutherford RB. Ed. WB Saunders, Philadelphia, 1989: 1504-1507.

13 Lofgren EP. Treatment of long saphenous varicosities and their recurrence: A long-term follow-up. In: Surgery of the veins. Bergaan JJ, Yao JST Eds. Grune \& Stratton, Orlando, 1985: 285-299

14 Harman RRM. Haemorrhage from varicose veins. Lancet 1974; II: 363-365

15 Evans GA, Evans DMD, Seal RME, Cravan JL. Haemorrhage from varicose veins.

Lancet 1973; II: 1359

16 Hamilton Jakobsen B. The value of different forms of treatment for varicose veins.

Br J Surg 1979; 66: 182-184

17 Munn SR, Morton JB, Macbeth WAAG, Mcleish R. To strip or not to strip the long saphenous vein? A varicose veins trial.

Br J Surg 1981; 68: 426-428

18 Franks PJ, Wright DDI, Fletcher AE, Moffatt CJ, Stirling J, Bulpitt CJ, McCollum EA. A questionnaire to assess risk factors, quality of life, and use of health resources in patients with venous disease.

Eur J Surg 1992; 158: 149-155.

19 Fegan WG. Continuous compression technique of injecting varicose veins. Lancet 1963; II: 109-112.

20 Browse NL, Burnand KG, Lea Thomas M. Diseases of the veins. Pathology, diagnosis and treatment. Edward Arnold, London, 1988: 169

21 Dodd H, Cockett FB. The pathology and surgery of the veins of the lower limb. Livingstone, Edinbugh, 1956

22 Hach W, Girth E, Lechner W. Einteilung der Stammvarikose der Vena Saphena Magna in 4 Stadien.

Phlebol Proct 1977; 6: 116-123

23 Foote RR. Varicose veins. Butterworths, London 1954

24 Lofgren KA. Management of varicose veins. In Bergan JJ, Yao JST. Eds. Venous problems. Chicago, Year Book Medical Publishers, 1971

25 Hobbs J. Surgery and sclerotherapy in the treatment of varicose veins. A random trial.

Arch Surg 1974; 109: 793 
26 Van den Broek THAA. Chronische veneuze insufficientie en veneuze reconstructieve chirurgie. Thesis, Amsterdam, 1989

27 Rivlin S. The surgical cure of primary varicose veins. Br J Surg 1975; 62: 913-917

28 Haeger K. Venous incompetence and concomitant disease of the leg. J Cardiovasc Surg 1965; 6: 482-487

29 Colgan MP, Sumner DS. How does the vascular laboratory influence management of venous disease? In: Vascular surgery: issues in current practise. Greenhalgh RM, Jamieson CW, Nicolaides AN eds. Grune \& Stratton, London, 1986: 119-135

30 Goren G, Yellin AE. Primary varicose veins: topographic and hemodynamic correlations.

J Cardiovasc Surg. 1990; 31: 672-682

31 Hoare MC, Nicolaides AN, Miles CR, Shull K, Jury RP, Needham T, Dudley HAF. The role of primary varicose veins in venous ulceration. Surgery 1982; 92: 450-451

32 Mitchel DC, Darke SG. The assessment of primary varicose veins by Doppler ultrasound; the role of sapheno-popliteall incompetence and the short saphenous systems in calf varicosities.

Eur J Vasc Surg 1987; 1: 113-115

33 Vasdekis SN, Clarke GH, Hobbs JT, Nicolaides AN. Evaluation of noninvasive and invasive methods in the assessment of short saphenous vein termination.

Br J Surg 1989; 76: 929-932

34 Nicolaides AN, Zukowski AJ. The value of dynamic venous pressure measurements.

World J Surg 1986; 10: 919-924.

35 Voorhoeve $\mathrm{R}$. The diagnosis of deep venous thrombosis. Thesis, Maastricht, 1986

36 Shehadi WH, Tonolio G. Adverse reactions to contrast media. Radiology 1980; 137: 299-302.

37 Schraibman IG. The diagnosis of sapheno-femoral incompetence. In: Phlebology 85 Negus D, Jantet G Eds. John Libbey, London, 1986: 92-93

38 Flanagan LD, Sullivan ED, Cranley JJ. Venous imaging of the extremities using real-time B-mode ultrasound. In: Surgery of the veins. Bergan JJ, 
Yao JST. Eds. Orlando, Gune \& Stratton, 1985: 91-95

39 van Ramshorst $B, S$ van Bemmelen $P$, Hoeneveld $H$, Faber JAJ, Eikelboom BC. Thrombus regression in deep vein thrombosis; quantification of spontaneous thrombolysis with duplex scanning.

Circulation, accepted for publication 1992.

40 van Ramshorst B. Duplex scanning in the diagnosis and follow-up of deep vein thrombosis. Thesis, Utrecht, 1992: 95-105.

41 van Bemmelen P, Bedford G, Beach K, Strandness DE. Quantitative segmental evaluation of venous valvular reflux with duplex ultrasound scanning.

J Vasc Surg 1989; 10: 425-431.

42 Nicolaides AN. Quantification of venous reflux by means of duplex scanning.

J Vasc Surg 1990; 10: 670-677

43 Rutgers PH, Kitslaar PJEHM, Ermers EGM. Photoplethysmography in the diagnosis of superficial venous valvular incompetence.

Br J Surg,in press 1993

44 van Bemmelen P, van Ramshorst B, Eikelboom B. Photoplethysmography reexamined: lack of correlation with duplex scanning.

Surgery $1992 ; 112,544-549$ 
Chapter 6: Treatment modalities of varicose veins.

In the treatment of varicose veins the surgeon has to decide between operation and compression-sclerotherapy or a combination of both. There is no uniform agreement regarding the exact role of surgery versus compression-sclerotherapy. Some generalisation however may be applied. Surgery is effective in the removal of large varicosities, tributaries and when there is involvement of the main trunks. Compression-sclerotherapy is most effective in the treatment of small venules and venectasies. At least one third of the patients with "varicose" complaints require no treatment at all ${ }^{1}$.

\section{A: Surgical treatment of varicose veins}

The surgical therapy can consist of the following operations:

1. High ligation of the greater saphenous vein.

2. Stripping of the greater saphenous vein.

3. Ligation of sapheno-popliteal junction.

4. Stripping of the lesser saphenous vein.

5. Ligation of incompetent communicating veins.

6. Phlebectomy

Ligation of the sapheno-femoral junction can safely be performed using local infiltration anaesthesia. When ligation is combined with stripping procedures general anaesthesia is preferred. Stripping on outpatient basis under local anaesthesia by means of femoral nerve block combined with intravenous sedation has been advocated ${ }^{23}$.

Stripping of the greater saphenous vein: Since the sapheno-femoral ligation as an isolated procedure and as part of the stripping procedur are identical these will be discussed as one.

The incision is made where the sapheno-femoral junction is expected. The localisation of the junction is constant at $2.5 \mathrm{~cm}$ lateral to and 2.5 
$\mathrm{cm}$ below the pubic tubercle. The incision is usually made oblique just under the crease of the groin. Vertical incisions are advised by some but the cosmetic result is inferior ${ }^{4}$. Dodd advises a curved or "hockey-stick like" incision, especially designed to give access to the postero-medial tributary'. Incisions in the groin crease tend to invert. Both Brunner and May advocate a high groin incision parallel to the inguinal ligament followed by dissection in distal direction in order to avoid damage to the groin lymphatics ${ }^{6}$. For cosmetic reasons the length of the incision should be kept to a minimum, yet adequate exposure is essential and must not be compromised. Dodd advises incisions of $7-10 \mathrm{~cm}$, Browse incisions of 4-6 cm. Incisions of $2-3 \mathrm{~cm}$ are thought inadequate ${ }^{5.7}$. Obese patients deserve incisions of $10 \mathrm{~cm}$. or more. The trunk of the saphenous vein is found and traced upward using both sharp and blunt dissection. The correct plane of cleavage is between the subcutaneous fat and the adventitia of the vein. Occasionally, if the incision is not placed correctly, the fascia covering the pectineus muscle is taken for the long saphenous vein. By inserting two swabs into the depth of the wound and pressing its fatty sides gently apart the saphenous vein will be seen through the fat as it is retracted. If the saphenous vein is not easily located, following any tributary will lead to the saphenous vein. The main trunk of the saphenous vein should not be divided until the sapheno-femoral junction has been clearly seen. The possibility of mistaking the femoral vein or artery for the main trunk of the saphenous vein is very real and leads to disasters. A method used freely and often described in American textbooks to directly divide the saphenous vein after incision of the perivenous tissues is to be condemned ${ }^{8,4}$. Some surgeons start the operation by introducing the stripper at the ankle and use the palpable end of the vein stripper as a guide for the groin cutdow $n^{9}$. This is a dangerous technique as the stripper may pass through lower communicating veins into the femoral vein. Positive identification of the saphenous vein can be made because the saphenous vein lies medial to the femoral vein and is not accompanied by an artery ${ }^{10}$. Another point of identification is the superficial external pudendic artery 
which transverses the saphenous vein. The tributary veins are divided as they are encountered during the approach to the sapheno-femoral junction. The lateral tributaries should be dissected out for a considerable distance. The tributaries joining the termination of the greater saphenous vein are the superficial external pudendal vein, the superficial inferior epigastric vein, the superficial circumflex iliac vein, the antero-lateral vein and the postero-medial vein. Usually these veins each join the greater saphenous vein separately. If the circumflex iliac and anterolateral veins form a single tributary on the lateral aspect of the greater saphenous vein, blood which normally goes down the circumflex iliac vein will then fill the antero-lateral vein and cause it to become varicose. To avoid this, when only a single lateral tributary is found, it must be followed until the formation of the two veins is identified ${ }^{11}$. The saphenous vein is divided flush with the common femoral vein and ligated without leaving a cul-de-sac or a stricture. Halsted (1893) advised a transfixion besides a sole ligation, claiming an encircling ligature can be "shot of" like a pea from a pea-shooter ${ }^{5}$. As pressures exerted on the stump are considerable, the need for security is obvious. Various authors, operating for recurrent varicose veins, report recurrence rates between $72 \%$ and $77 \% \%^{5,12,13}$ as a result of failure to carry out a true juxta-femoral ligation.

The optimal direction for the stripping has been investigated in cadaver studies and in clinical trials. Stripping from groin to ankle diminishes the chance of damage to the saphenous nerve. The incidence of damage to the nerve resulting in distressing saphenous nerve neuralgia ranges from $23-58 \%{ }^{14,15}$. It is doubtful whether stripping from groin to ankle is really necessary. Usually the greater saphenous vein is only incompetent to the upper third of the calf, at which point it is joined by the largest calf tributaries. Passing the stripper retrograde from the groin, in nearly every case it will stop just below the knee. Here the first competent valve is situated. It is unnecessary to strip any part of the vein that is not incompetent ${ }^{16}$. In several trials limited stripping operation gave comparable result to 'long' stripping from ankle to groin ${ }^{16,17}$. 
Ligation of the sapheno-popliteal junction: Ligation of the saphenopopliteal junction is different from ligation of the sapheno-femoral junction due to great variation in anatomy and surrounding structures. For this reason this operation is rather not to be be carried out under local anaesthesia. Whereas juxta-femoral ligation is a relatively straightforward procedure, juxta-popliteal ligation is often difficult. In $60 \%$ of the cases there is a true sapheno-popliteall junction, in $30 \%$ there is a high termination in the deep vein or even in the greater saphenous vein and in $10 \%$ of the cases the lesser saphenous vein terminates in the calf veins $^{18}$. For this reason Hobbs advised a peroperative venography ${ }^{19}$. A further problem arises from the medial and lateral popliteal nerves which have to be moved aside to obtain a good view of the popliteal vein and its environs ${ }^{13}$. If a long saphenous vein operation is to be carried out in the same session, the short saphenous vein operation should be carried out first. Most authors place patients in a prone position, the knee slightly flexed. Hobbs prefers the lateral position ${ }^{20}$. The popliteal fossa is best opened by a transverse incision, some 5 to $8 \mathrm{~cm}$. long, parallel to and $3 \mathrm{~cm}$. proximal to the popliteal crease. A longitudinal incision behind the knee must be avoided because it heals with a wide unsightly scar. The popliteal fascia is exposed which often makes the underlying vein already visible. The fascia is divided transversely in the line of the skin incision to expose the fat and contents of the popliteal fossa. The vein is isolated by blunt dissection. The sural nerve is usually closely applied to the vein and must be carefully and completely separated. All venous tributaries must be identified and divided to ensure flush sapheno-popliteall ligation. One of these is a large superior tributary (Giacomini vein) which is fairly constant. The short saphenous vein is divided by a flush ligation on the popliteal vein. Rivlin believes the short saphenous vein should never be stripped, claiming there are no other incompetent communicating veins in the short saphenous system. Secondly stripping the short saphenous vein which lies in a closed compartment can initiate longstanding edema and cause permanent damage to the sural nerve ${ }^{13}$. Hobbs on the contrary believes that the high 
recurrence rate of short saphenous varicosities can be attributed to simple ligation alone. The proximal short saphenous vein may be small and the distal part grossly dilated because of midcalf perforating veins joining the gastrocnemius vein. Hobbs believes that if the short saphenous vein is dilated and has large varicose tributaries it should be stripped ${ }^{20}$. The stripper is inserted down the short saphenous vein and a small incision is made behind the lateral malleolus to retrieve the stripper. The distal vein is to be carefully separated from the sural nerve. Stripping in a downward direction makes damage to the sural nerve less likely. If the stripper is first introduced behind the malleolus and then the saphenopopliteall junction is in this way located, care must be taken that the stripper does not pass into the popliteal vein.

Ligation of incompetent communicating veins: Because the perforating veins of the medial calf and ankle are the only veins that communicate directly with the deep veins and in thus are a frequent cause of venous ulceration, interruption of these veins, if incompetent, is useful. The approach to the perforating veins is defined by the condition of the overlying skin. If there is no induration the medial approach can be used, if much induration exists the postero-medial approach is preferable. The incision for the medial approach is placed one finger's breadth behind the posterior margin of the tibia and extends from halfway the lower leg to one finger above the internal malleolus. It is carried straight down to the fascia. Cockett described the extrafascial ligation, the original subfascial ligation was described by Linton ${ }^{4,21}$. All perforating veins are identified and ligated, even those that are not incompetent ${ }^{21}$. The TurnerWarwick bleed-back test is a way of ensuring the incompetent communicating vein has been ligated. All excessive undercutting of the skin should be avoided as this leads to destruction of the small perforating arteries and increases the possibility of skin necrosis. The skin and fascia are closed separately. The postero-medial approach was described by Dodd $^{22}$. It avoids the poorly healing indurated skin. The incision is placed slightly medial to the midline in order to avoid scar adherence to 
the Achilles tendon. The advantage of this approach is that all communicating veins are readily identified. A third approach for reaching the incompetent communicating veins is endoscopically. The advantages of this technique are the small incision far from the indurated skin and the minimal dissection, making early mobilisation possible. An incision of 2 $\mathrm{cm}$. is made in Linton's line straight down to and piercing the fascia. A mediastinoscope is passed under the fascia and the incompetent communicating veins are identified, clipped or coagulated ${ }^{23}$. Whether the endoscopic approach should be combined with a paratibial fasciotomy is subject to debate. Hach has postulated that the indurated crural fascia forms a microcirculatory barrier between the extrafascial tissue and the deep compartment. Good results with paratibial fasciotomy without perforating vein dissection seem to confirm this idea ${ }^{24}$.

Phlebectomy: A cosmetically good result can be achieved by complete removal of all varicose segments through multiple small stab incisions. Especially the so-called Müller phlebectomies, performed on an outpatient basis, are notable for their good appearance after healing and little post-operative discomfort.

\section{B: Sclerotherapy}

The aim of this treatment is to convert a toneless, dilated and incompetent vein into a fibrous cord. This is achieved by injecting a sclerosant into the vein, allowing it to irritate the intima, and so initiate an inflammatory reaction in the vein wall ${ }^{24}$ leading to local thrombosis. Unless adequate compression is applied and maintained for a prolonged period of time the pressure in the unthrombosed segment of vein will act as a waterhammer on the thrombosed part. This will cause formation of slitlike channels at the time the thrombus is being invaded by capillaries and fibroblasts at its point of attachment to the vein wall. This causes shrinkage of the clot and reopening of the vein ${ }^{25}$. If compression is maintained for six weeks, a small, hard, non-tender segment of vein will be found. Fegan has given the term "endosclerosis" to this reaction to 
distinguish it from a "thrombophlebitic" reaction, in which there an inflammaion around a lumen swollen with blood clot. The highest percentages of good results were obtained in patients who were found to have this endosclerotic reaction ${ }^{26}$.

The main sclerosants can be divided in the following groups:

- Hypertonic solutions - Sodium chloride

- Glucose

- Sodium salicylate

- Anionic detergents - Sodium tetra decyl sulphate (STD)

- Non-ionic detergents - Oxypolyethoxydodecan

- Restgroup - Ionized iodine

Sodium tetradecyl sulphate (Trombovar) is the most popular sclerosing agent in use; it is essentially a detergent which produces a local chemical phlebitis $^{27}$. Two other sclerosants frequently used are Oxypolyethoxy dodecan (Aethoxysclerol 1\%-3\%) and Ionized iodine (Variglobin 0.5\%). The first has its action mostly on the intima while the latter acts within the adventitia of the vein ${ }^{36}$. All sclerosants are toxic and given in large doses cause haemolysis and renal damage.

Sclerotherapy is contra-indicated:

- During pregnancy (first 3 months and last 6 weeks)

- In women on contraceptive medication

- In patients with a strong history of allergy

In general there are three techniques in use for sclerotherapy.

In Fegan's method the varices are punctured with needles attached to syringes with the patient in a sitting position ${ }^{25}$. Blood is drawn into the syringe and the syringe is taped to the leg. The leg is then elevated while occluding the vein proximal and distal to the injection site with the ring and index fingers and the sclerosant is injected. On withdrawing the syringe the sclerosant is kept in place by the two fingers and covered with a rubber pad. A bandage is then applied over the pad.

In Hobbs' method the needles are inserted while the patient is lying and 
the veins are partially collapsed. When the needle is located in the vein, the vein is emptied by two fingers on both sides of the needle and downward pressure. The injection site is covered by cotton wool balls. When all injections have been completed the leg is bandaged.

In Sigg's method needles are inserted into the veins with the patient standing. Then the patient lies down, the leg is elevated, the syringes are attached and the injections are done ${ }^{28}$.

Fegan stressed that sclerotherapy should be followed by a 6 week period of bandaging. At first he used crepe but in later years recommended Coban, a self-adherent elastic wrap. Recent study has suggested that 3 days is an adequate period when using Coban ${ }^{29}$.

\section{C: Complications of treatment of varicose veins.}

Collection of information about accidents to arteries during treatment of varicose veins is difficult because nobody has published any personal series about such accidents. Some case reports however have appeared $^{30,31,32}$.

Fortunately major arterial accidents with serious sequelae are $\operatorname{rare}^{33,34}$ whereas injury to the common femoral vein is relatively common (up to 3 or $4 \%$ ). In 1948 Luke and Miller reported the arterial and venous complications of high ligation of the greater saphenous vein and of retrograde injection of sclerosing agent into the superficial femoral artery. They reported two instances of limb loss following such complications $^{33}$. Cockett reported on nine cases in a timespan of ten years derived from medico-legal protection societies ${ }^{34}$. In seven out of the nine cases the femoral artery was ligated, in two cases the popliteal artery was ligated while attempting short saphenous ligation. In three cases the superficial femoral artery was actually stripped. Three cases led to high amputations, in five cases a successful graft was inserted in time. Natali recorded twelve cases, five of which came to amputation. In these cases the legal consequences for the physician were often quite severe, because of the disproportion between the sequelae and the easy type of 
surgery $^{30}$. As Cockett remarks "The astonishing fact was that in none of the cases was the error recognised at the time of original operation". All these operations were carried out by either general practitioner assistants or trainee surgeons ${ }^{34}$. Cases carried out by experienced surgeons were reported by Leitz and Liddicott ${ }^{32,34}$.

Arterial injury may arise by inadvertent injection of sclerosing agent into or around an artery. Natali reports on 32 amongst 125 cases of iatrogenic vascular injuries, Cockett on 18 cases $^{30,34}$. The results of these injuries are disastrous. After ligation or inadvertent resection of arteries the damage is less severe than following arterial injection of sclerosing agents. In particular in the case of injection of the external pudendal artery this becomes clear. This artery is often sacrificed while ligating the greater saphenous vein and without any side effects. A few drops of sclerosing agent in this vessel will result in extensive necrosis of the inner thigh and external genitals. Instead of resulting in local occlusion of the vessel the sclerosing agent causes damage to the vessel wall from which detritus emboli arise shutting off the total outflow tract ${ }^{36}$. This may be the reason that there is no effective treatment for this damage. Danger of this complication arises at places of close connection between artery and vein. In the groin these are the external pudendal and femoral arteries, in the knee region the popliteal and sural arteries, on the medial aspect of the ankle the posterior tibial artery and the dorsal pedal artery on the foot. Because the arteries come more close to the surface the more distal they get, the danger of inadvertent injection is greatest at the ankle and the foot. In fact most of the cases described resulted from trying to inject a vein at the site of the internal ankle perforating vein 8$10 \mathrm{~cm}$. above the internal malleolus ${ }^{34}$. The sequence of events after intraarterial injection follows a standard pattern. First there is immediate severe pain at the injection site, the pain propagates into the foot and outer four toes, sparing the great toe as its main arterial supply is from the anterior tibial artery. The foot becomes rapidly white and after some time turns to a bluish colour. The most striking symptom is the excruciating pain which persists for days and even weeks, growing stronger 
when the foot is elevated. The condition deteriorates to gangrene of several toes and often part of the foot sole. The healing takes months and finally a highly disturbing sensibility to cold may remain ${ }^{37}$. When recognised early, immediate treatment with 15000 units of heparin and low-molecular weight dextran intra-venously or intra-arterially, is advised. Lumbar sympathectomy does not seem to alter the events ${ }^{35,35,36}$. Further approaches proposed have been steroids, non-steroidal antiinflammatory drugs and hemodilution ${ }^{37}$. Cockett advised not to try to sclerose ankle perforators because of the danger involved. If one proceeds to inject in the ankle region, Sigg's method of injection seems the safe way. Sigg reported 5 deaths in 106700 patients treated by sclerotherapy ${ }^{28}$.

Cost of treatment: The cost of operative treatment differs considerably from sclero-compression therapy. Sclero-compressiontherapy was found four times less expensive than surgery for varicose veins ${ }^{38}$. In this same study the value of loss of time for the patient had not been calculated. If this is taken into account the cost for compression sclerotherapy are $15 \%$ of those for surgery ${ }^{39}$. In terms of days taken off from work the surgical patients lost an average of 31 days, compared to 6 days in the compression sclerotherapy group. Average loss in earnings in the two groups was 118 pounds in the operative group compared to 29 pounds in the sclerotherapy group. 


\section{References:}

I Bishop CCR, Jarrett PEM. Outpatient varicose vein surgery under local anaesthesia.

Br J Surg 1986; 73: 821-822

2 Brunner U. Zur Vereidung von secundaren Lymphödemen nach Varizenoperation.

Phlebol Proktol 1975; 4: 266

3 Dodd H, Cockett FB. The pathology and surgery of the veins of the lower limb. E \& S Livingstone, Edinburgh, 1956

4 Browse NL, Burnand KG, Lea Thomas M. Diseases of the veins. Edward Arnold, London, 1988

5 Nabatoff RA. Surgical technique for stripping the long saphenous vein. Surg Gynecol Obstet 1977; 145: 81-87

6 Dale WA. Ligation, stripping, and excision of varicose veins. Surgery 1970; 67: 389-393

7 Lofgren EP. Treatment of long saphenous varicosities and their recurrence: A long term follow-up. In: Surgery of the veins. Bergan JJ, Yao JST. Eds. Grune \& Stratton Orlando 1985

8 Hamilton Jakobsen B. Out-patient radical operation for varices performed under local analgesia In: Phlebology 85 Negus D, Jantet G Eds John Libbey, London, 1986: 193-195

9 Hobbs JT. New instruments for vein surgery. In: Phlebology 85. Negus D, Jantet G Eds. John Libbey, London, 1986: 163-167.

10 Haeger $\mathrm{K}$. Technique of high ligation of the long saphenous vein. An analysis of 54 reoperation cases.

Acta Chir Scand 1961; 122: 85-92

11 Rivlin $S$. The surgical cure of primary varicose veins.

Br J Surg 1975; 62: 913-917

12 Munn SR, Morton JB, Macbeth WAAG, McLeish AR. To strip or not to strip the long saphenous vein? A varicose vein trial.

Br J Surg 1981; 68: 426-428

13 Cox SJ, Wellwood JM, Martin A. Saphenous nerve injury caused by stripping of the long saphenous vein.

Br Med J, 1974; 1: 415-417 
14 Negus D, Nichols RWT. Is it necessary to strip the incompetent saphenous vein to the ankle? In: Phlebology 85 Negus D, Jantet G Eds. John Libbey, London, 1986: 148-149

15 Koyano K, Sakaguchi S. Selective stripping operation based on Doppler ultrasonic findings for primary varicose veins of the lower extremities. Surgery 1988; 103: 615-619

16 Eklof B. Modern treatment of varicose veins. Br J Surg 1988; 75: 297-298

17 Hobbs JT. Per-operative venography to ensure accurate sapheno-popliteall ligation.

Br Med J 1980; 1: 1578

18 Hobbs JT. A new approach to short saphenous varicosities. In: Surgery of the veins, Bergan JJ, Yao JST. Eds Grune Stratton, Orlando, 1985: 301321.

19 Cockett FB. The pathology and treatment of venous ulcers of the leg. Br J Surg 1955; 43:260-278

20 Linton RR. Posttrombotic ulceration of the lower extremity: It's etiology and treatment.

Ann Surg 1938; 107: 582-593

21 Negus D. Perforating vein interruption in the postphlebitic syndrome. In: Surgery of the veins. Bergan JJ, Yao JST Eds Grune Stratton, Orlando, 1985: 191-203

22 Dodd H, Cockett FB. The pathology and surgery of the veins of the lower limb. Churchill Livingstone, Edinburgh, 1956: 437-440

23 Hauer G. Operationstechnik der Endoskopischen subfaszialen Diszision der Perforansvenen.

Chirurg 1987; 58: 172-175

24 Reid RG, Rothnie NG. Treatment of varicose veins by compression sclerotherapy.

Br J Surg 1968; 55: 889-895

25 Fegan WG. Continuous compression technique of injecting varicose veins. Lancet 1963; 2: 109-113

26 DeJode LR. Injection-compression treatment of varicose veins. Br J Surg 1970; 57: 285-286

27 Browse NL, Burnand KG, Lea Thomas M. Diseases of the veins. Edward 
Arnold, London, 1988; 239

28 Sigg K. Treatment of varicosities and accompanying complications (ambulatory treatment of phlebitis with compression bandage).

Angiology 1952; 3: 355

29 Fraser IA, Perry EP. Hatton M, Watkin DFL. Prolonged bandaging is not required following sclerotherapy of varicose veins.

Br J Surg 1985; 72: 488-490

30 Natali J, Benhausen AC. Iatrogenic vascular injuries. A review of 125 cases.

J Cardiovasc Surg 1979; 20: 169

31 Eger M, Groleman L, Toroc G, Hirsch M. Inadvertent stripping in the lower limb. Problem of management.

Surgery 1973; $73: 23$

32 Liddicot JE, Bekassy SM, Daniell MB, De Bakey ME. Inadvertent femoral artery stripping. Management.

Surgery 1975; 77: 318

33 Luke JC, Miller GG. Disasters following the operation of ligation and retrograde injection of varicose veins.

Annals of Surg 1948; 127: 426-431

34 Cockett FB. Arterial complications during surgery and sclerotherapy of varicose veins.

Phlebology 1986; 1: 3-6

35 Leitz KH, Schmidt FC. latrogenen Arterienverletzung bei Babcockscher Venenexchairese.

Vasa 1974; $45: 3-6$

36 Hohlbaum GG. Uber iatrogene Schaden bei der Varizensklerosienung.

Phlebol Proktol 1990; 19: 51-54

37 Oesch A, Mahler F, Stirnemann P. Acute ischaemia of the foot following sclerotherapy. In: Phlebology 85 Negus D, Jantet G. Eds., John Libbey \& Co, London, 1986 ;122-124

38 Piachaud D, Weddell JM. Cost of treating varicose veins.

Lancet 1972; ii: 1191

39 Neglen P, Einarsson E, Jonsson B, Eklof B. Socio-economic benefits of ambulatory surgery or compression sclerotherapy of varicose veins. In: Phlebology 85, Negus D, Jantet J Eds. John Libbey \& Co, London, 1986; 
159-162

40 Hach W. Paratibiale Fasziotomie- eine neue Methode der Perforansdissektion oder neues therapeutisches Prinzip beim chrönisch-venösen Stauungssyndrom? In: Therapie der Venen-Erkrankungen- Traum und Wirklichkeit- Denck H, van Dongen RJAM. TM- Verlag, Stuttgart, 1989; 273-279

41 Bergan JJ. Surgery versus sclerotherapy in the treatment of varicose veins. In: Current critical problems in vascular surgery. Veith FJ. Ed. Quality Med Publishing, St Louis, 1989: 139-144. 


\section{Chapter 7: Varicose veins; Symptoms and signs.}

The objective of this part of the study was to investigate the relation between symptoms, signs at clinical examination and hemodynamic findings in patients presenting with varicose veins. Underlying was the question whether it is possible to reach conclusions regarding the type of varicosis from the presence of certain symptoms accompanying the varicose veins and the clinical examination of the extremity. Also the relationship between varicose veins and age, sex and height and certain "predisposing" factors was assessed.

\section{Material and methods}

268 consecutive patients visiting the surgical outpatient department of the University Hospital Maastricht for varicosis of the lower extremities in the period from 1986 to 1988 were asked to participate. All patients were questioned in a standard way. Previous treatments for varicose veins were noted. The reason for seeking treatment was asked and categorised as disfigurement alone and/or presence of the symptoms pain, swelling and cramps. Patients were also asked whether they considered one or more of the following signs a problem in their case: fine venules, pigmentation, eczematous skin condition, phlebitis and ulceration. Presenting complaints for each of the limbs were registered separately. For the three major presenting complaints (pain, cramps and swelling) a "complaint severity score" was made. This severity score ranged from zero to three, zero meaning none of the three complaints being present, and three meaning the presence of pain and cramps as well as swelling. Examination consisted of clinical examination and Doppler ultrasound testing. All clinical investigations in this study were performed by two experienced vascular surgeons and consisted of inspection and palpation of varicosities and tourniquet tests. Patient height was measured. The Doppler ultrasound testing was done by two experienced vascular laboratory technicians using a bidirectional CW Doppler device 
(Vasculab Doppler Medasonics). During the examination the patient was in lying position for the femoral and the posterior tibial vein examination. The popliteal veins were tested in a prone position. The standing position was used for examination of the greater saphenous vein at the sapheno-femoral junction, for the greater saphenous vein at below knee level and for the lesser saphenous vein. Reflux at the sapheno-femoral junction was tested by the Valsalva manoeuvre. Based on all these examinations the legs were classified as having:

- absence of main trunk insufficiency

- greater saphenous vein insufficiency

- lesser saphenous vein insufficiency

- insufficiency of communicating vein

- complex abnormalities, being combinations of the above categories

A total of 532 patient legs with complete data were taken into the study. Based on clinical and Doppler ultrasound examination 298 legs were found to have some form of main trunk insufficiency. In 234 legs no main trunk insufficiency could be demonstrated, these legs were considered to have superficial varicosis only. 67 male patients (25\%) and 201 female patients (75\%) participated. The mean age was 44 years (range 17 to 76 years). Twenty-four percent of the patients performed their work mainly standing, whilst $76 \%$ had a sitting occupation. The left and right legs were equally affected.

The statistical analysis of the data was done in several ways. In the first place a Chi-square analysis was done for the clinical categories of insufficiency versus presenting symptoms and signs, for the Doppler analysis of insufficiency versus presenting symptoms and signs and for the final classification, based on clinical investigation combined with Doppler, versus presenting symptoms and signs. Secondly the correlation between the various categories of insufficiency and the complaint severity score was investigated. To test this correlation the non-parametric $(\mathrm{N}$ par) Mann-Whitney test and Pearson's correlation coefficient were used. 


\section{Results}

The average heights of the investigated patients for different age categories are shown in Table 7-1. For comparison the average height of the Dutch population of the same age groups is also given.

Table 7-1: Average height of patients in comparison to the general Dutch population.

\begin{tabular}{|c|c|c|c|c|c|c|c|}
\hline & Age & $18-29$ & $30-39$ & $40-49$ & $50-59$ & $60-69$ & $>70$ \\
\hline Male patients & & 181.5 & 173.1 & 178.0 & 179.3 & 175,6 & -- \\
\hline Dutch male population & & 181.5 & 179.5 & 177.4 & 176.0 & 175,3 & 173,0 \\
\hline Female patients & & 161.7 & 164.8 & 164.5 & 159.3 & 158,8 & -- \\
\hline Dutch female population & & 168.5 & 167.1 & 166.3 & 165.7 & 165,4 & 163,3 \\
\hline
\end{tabular}

A family history for varicosis was present in $76 \%$ of the patient population. When positive this was further specified as to whether father, mother, brothers or sisters or combinations of these also had varicosis. The results are shown in Table 7-2.

Of the female patients $11 \%$ had never been pregnant, $15 \%$ had been pregnant once, $32 \%$ twice, $21 \%$ three times, $11 \%$ four times, $3 \%$ five times. When having been pregnant the number of pregnancies was related to the age group and compared to the average number of pregnancies of the Dutch population of the same age group. See Table 7-3.

Of the female patients $63 \%$ had used contraceptives in the past, $7 \%$ were still using contraceptives at the time of investigation. 
Table 7-2: Specification of a positive family history of varicosis in the patients according to the family members also having varicosis.

\begin{tabular}{lc}
\hline \hline Father & $10 \%$ \\
Mother & $28 \%$ \\
Both father and mother & $6 \%$ \\
Brothers or sisters & $10 \%$ \\
Father and brothers or sisters & $8 \%$ \\
Mother and brothers or sisters & $29 \%$ \\
Father and mother and brothers or sisters & $9 \%$ \\
\hline \hline
\end{tabular}

Table 7-3: Average number of pregnancies of the patients compared to the general Dutch female population.

\begin{tabular}{lcc}
\hline \hline & Dutch female population & Female patient population \\
\hline $18-19$ years & 0.02 & - \\
$20-24$ years & 0.19 & 0.60 \\
$25-29$ years & 0.87 & 0.64 \\
$30-35$ years & 1.62 & 1.77 \\
$35-37$ years & 1.87 & 2.07 \\
\hline \hline
\end{tabular}

The main presenting symptoms and signs as mentioned in the jnterview are given in Table 7-4. Often one symptom was not more prominent than another, so both were then counted. In the majority of the cases the presenting symptoms came in combinations. It can be seen in table 7-4 that disfigurement and pain were the most frequent reasons for patients to seek treatment. 
Table 7-4: Occurrence of presenting symptoms and signs.

\begin{tabular}{ll}
\hline \hline Pain & $53 \%$ \\
Cramps at night & $32 \%$ \\
Swelling & $26 \%$ \\
Disfigurement & $73 \%$ \\
Venules & $10 \%$ \\
Phlebitis & $10 \%$ \\
Pigmentation & $8 \%$ \\
Eczema & $2 \%$ \\
Ulcer & $1 \%$ \\
\hline \hline
\end{tabular}

Some of the patients had been treated for varicose veins before entering this study. In the majority of the patients this treatment had consisted of wearing compressive stockings. (see Table 7-5)

Table 7-5: Previous treatment per leg

\begin{tabular}{ll}
\hline \hline Compressive stockings & $22 \%$ \\
Sclerotherapy & $12 \%$ \\
Operative therapy & $10 \%$ \\
\hline \hline
\end{tabular}

The classification of the 532 legs in this study according to the final classification used in this study can be seen in Table 7-6.

Using the three major presenting complaints (pain, cramps and swelling) a complaint severity score was made and correlated with the classification of insufficiency. This correlation is shown in Table 7-7. 
Table 7-6: Classification of venous insufficiencies in all patient legs.

\begin{tabular}{lcc}
\hline \hline & $\mathrm{N}$ & $\%$ \\
\hline No main trunk insufficiency & 234 & 44.0 \\
Greater saphenous vein insufficiency & 198 & 37.1 \\
Lesser saphenous vein insufficiency & 28 & 5.3 \\
Communicating vein insufficiency & 29 & 5.5 \\
Complex (combinations of the above) & 43 & 8.1 \\
Total & 532 & 100.0 \\
\hline \hline
\end{tabular}

Table 7-7: Complaint severity score versus nature of insufficiency according to final classification (GSV= greater saphenous vein, LSV= lesser saphenous vein).

\begin{tabular}{|c|c|c|c|c|c|c|c|}
\hline & & $\begin{array}{l}\text { Complaint } \\
\text { severity } \\
\text { score }\end{array}$ & 0 & 1 & 2 & 3 & $\begin{array}{l}\text { Complaint } \\
\text { score } \\
\text { Mean } \pm \text { SD }\end{array}$ \\
\hline \multicolumn{2}{|c|}{ No main tunk insuff. } & & 125 & 48 & 39 & 22 & \multirow[t]{2}{*}{$0.8 \pm 1.0$} \\
\hline$N=234$ & $44 \%$ & & $53 \%$ & $21 \%$ & $17 \%$ & $9 \%$ & \\
\hline \multicolumn{2}{|c|}{ GSV insufficiency } & & 51 & 67 & 59 & 21 & \multirow[t]{2}{*}{$1.2 \pm 0.9$} \\
\hline$N=198$ & $37 \%$ & & $26 \%$ & $34 \%$ & $30 \%$ & $10 \%$ & \\
\hline \multicolumn{2}{|c|}{ LSV insufficiency } & & 4 & 11 & 7 & 6 & \multirow[t]{2}{*}{$1.5 \pm 1.0$} \\
\hline $\mathrm{N}=28$ & $5,3 \%$ & & $15 \%$ & $39 \%$ & $25 \%$ & $21 \%$ & \\
\hline \multicolumn{2}{|c|}{ Commun. vein insuff. } & & 7 & 7 & 10 & 5 & \multirow[t]{2}{*}{$1.4 \pm 1.0$} \\
\hline $\mathrm{N}=29$ & $5,5 \%$ & & $24 \%$ & $24 \%$ & $34 \%$ & $17 \%$ & \\
\hline \multicolumn{2}{|c|}{ Complex } & & 4 & 21 & 14 & 4 & \multirow[t]{3}{*}{$1.4 \pm 0.8$} \\
\hline \multirow[t]{2}{*}{$N=43$} & $8 \%$ & & $9 \%$ & $50 \%$ & $32 \%$ & $9 \%$ & \\
\hline & & & $36 \%$ & $29 \%$ & $24 \%$ & $11 \%$ & \\
\hline
\end{tabular}


The mean complaint severity score for the limbs without main trunk insufficiency was significantly lower $(\mathrm{p}<0.005)$ than the mean complaint severity score for all other categories of venous insufficiency according to the final classification.

Table 7-8: Levels of significance (p-values) for the correlations between presenting complaints and clinical evidence of incompetence of the greater saphenous vein (GSV), of the lesser saphenous vein (LSV) and communicating vein incompetence respectively (Chi-square analysis).

\begin{tabular}{llll}
\hline \hline & $\begin{array}{l}\text { GSV } \\
\text { Incompetence }\end{array}$ & $\begin{array}{l}\text { LSV } \\
\text { Incompetence }\end{array}$ & $\begin{array}{l}\text { Communicating Vein } \\
\text { Incompetence }\end{array}$ \\
\hline Pain & 0.8506 & 0.6547 & 0.7626 \\
Cosmetic & 0.0702 & 0.0070 & 0.0763 \\
Venules & 0.8038 & 0.5471 & 0.4459 \\
Pigment & 0.3968 & 0.3069 & 0.0681 \\
Eczema & 0.4852 & 0.9140 & 0.9765 \\
Ulcer & 0.9882 & 0.4021 & 0.5881 \\
Swelling & 0.1685 & 0.5269 & 0.2728 \\
Cramps & 0.5205 & 0.3344 & 0.3016 \\
Thrombosis & 0.0730 & 0.0288 & $\mathbf{0 . 0 0 5 0}$ \\
Phlebitis & 0.7136 & 0.9821 & 0.9763 \\
\hline \hline
\end{tabular}

The correlations between presenting complaints and the various classifications of the venous insufficiencies were determined by Chi-square analysis. Separate analysis was performed for clinical classification of insufficiency (Table 7-8), Doppler analysis of incompetence (Table 7-9) and the final classification of incompetence based on the combination of 
clinical investigation and Doppler ultrasound tests (Table 7-10).

A significant correlation was found between a patient's history of thrombosis and communicating vein and deep vein incompetence and between skin pigmentation and deep and communicating vein incompetence.

Table 7-9: Levels of significance (p-values) for the correlation between presenting complaints and Doppler ultrasound evidence of incompetence (reflux) of the greater saphenous vein, incompetence of the lesser saphenous vein and deep venous incompetence respectively (Chi-Square analysis). Abbreviations as in Table 7-8

\begin{tabular}{lllll}
\hline \hline & $\begin{array}{l}\text { Reflux } \\
\text { GSV }\end{array}$ & $\begin{array}{l}\text { Reflux saphe- } \\
\text { no-femoral } \\
\text { junction }\end{array}$ & $\begin{array}{l}\text { Reflux } \\
\text { LSV }\end{array}$ & $\begin{array}{l}\text { Deep venous } \\
\text { incompetence }\end{array}$ \\
\hline Pain & 0.6079 & 1.000 & 0.1733 & 0.5454 \\
Cosmetic & 0.3346 & 0.6893 & 0.8339 & 0.1255 \\
Venules & 0.1324 & 0.8729 & 0.1989 & 0.8865 \\
Pigment & 0.7463 & 0.1801 & 0.0500 & 0.3810 \\
Eczema & 0.2088 & 0.2982 & 0.8539 & 0.5083 \\
Ulcer & 0.5151 & 1.000 & 0.4441 & 0.0941 \\
Swelling & 0.1950 & 0.1299 & 0.9085 & 0.2667 \\
Cramps & 0.2112 & 0.9262 & 0.8985 & 0.1770 \\
Thrombosis & 0.9167 & 0.8212 & 0.2996 & 0.0048 \\
Phlebitis & 0.7374 & 0.5859 & 0.5713 & 0.8279 \\
\hline \hline
\end{tabular}


Table 7-10: Levels of significance (p-values) for the correlation between presenting complaints and classification of incompetence based on a combination of clinical investigation and Doppler ultrasound (Chi-square analysis). Abbreviations as in Table 7-8.

\begin{tabular}{lllll}
\hline \hline & $\begin{array}{c}\text { GSV } \\
\text { Incompe- } \\
\text { tence }\end{array}$ & $\begin{array}{l}\text { LSV } \\
\text { Incompetence }\end{array}$ & $\begin{array}{c}\text { Deep Venous } \\
\text { Incompetence }\end{array}$ & $\begin{array}{c}\text { Communicating veins } \\
\text { Incompetence }\end{array}$ \\
\hline Pain & 0.8638 & 0.5978 & 0.7288 & 0.8482 \\
Cosmetic & 0.0678 & 0.0765 & 0.0451 & 0.0359 \\
Venules & 0.8933 & 0.3158 & 0.7604 & 0.4170 \\
Pigment & 0.3814 & 0.3436 & $\mathbf{0 . 0 0 0 0}$ & $\mathbf{0 . 0 0 3 4}$ \\
Eczema & 0.3969 & 0.9241 & 0.9272 & 0.9768 \\
Ulcer & 0.5997 & 0.4207 & $\mathbf{0 . 0 0 0 0}$ & 0.0431 \\
Swelling & 0.1893 & 0.5858 & 0.6804 & 0.7854 \\
Cramps & 0.5178 & 0.2688 & 0.0917 & 0.5198 \\
Thrombosis & 0.0069 & $\mathbf{0 . 0 0 0 6}$ & $\mathbf{0 . 0 0 0 0}$ & $\mathbf{0 . 0 0 2 8}$ \\
Phlebitis & 0.7042 & 0.9855 & 0.7781 & 0.9891 \\
\hline \hline
\end{tabular}




\section{Discussion:}

As noted in Chapter 5, surprisingly little has been published about symptoms and signs of varicose vein disease. The age distribution shows a peak frequency between 50 and 60 years and thereafter the incidence is declining. This is apparently because older patients seek treatment for ailments other than varicosis ${ }^{1}$. The male/female ratio in our investigated population is in accordance with findings in most other clinical trials. The ratio does reflect the sex distribution of that part of the population seeking treatment which is not necessarily identical to the ratio in the total population. Varicose veins are supposed to be more prominent in tall men and short women ${ }^{2}$. Comparing the heights of the investigated group to that of the normal Dutch population of the same age groups can not be done with these figures because the percentage of varicose vein sufferers in the population sample is not known. The number of patients with a sitting occupation is rather high in the studied patients, possibly confirming the minimal influence erect stance has in the pathogenesis of varicosis. Only in the Basle study a weak correlation was found between standing occupation and varicose veins ${ }^{3}$. A positive family history was present in $76 \%$ of the investigated population, $28 \%$ of the population having a mother suffering from varicose veins, whilst in only $9 \%$ the father was affected. The $76 \%$ is in accordance with the $80 \%$ reported by Munn in his group of patients admitted for surgery. ${ }^{4}$. However questionnaire studies might overestimate the familial relationship.

Of the female patients $15 \%$ had been pregnant once, $32 \%$ twice and $21 \%$ three times. Only $11 \%$ had never been pregnant. Recent studies demonstrate that, although the overall prevalence of varicose veins increases with the number of children, this increase is not due to childbirth but to increase in age 6 .

The main reason for seeking treatment for varicose veins is disfigurement (Table 7-4) with an almost even frequency distribution over women and men. It is well to keep in mind when treating varicose veins that the treatment is to a large extent a cosmetic one

The main presenting symptoms are pain, cramps and swelling (53\%, 
$32 \%$ and $26 \%$ respectively). Of the presenting signs especially venules, phlebitis and pigmentation are prominent. In the analysis of the presenting symptoms versus the clinical nature of insufficiency a significant correlation was found between a previous patient's history of thrombosis (given by the patient) and incompetent communicating veins. Also a significant correlation was found between Doppler evidence of deep venous incompetence and previous patient's history of thrombosis. Analysis of the classification of the nature of incompetence based on a combination of clinical investigation and Doppler ultrasound versus presenting symptoms and signs revealed certain significant correlations. Deep vein incompetence gives cosmetic complaints and deep vein incompetence or communicating vein incompetence cause pigmentation. Deep vein incompetence is correlated to a history of ulceration. Incompetence of the greater saphenous vein, deep venous incompetence and communicating vein incompetence all are correlated to a history of thrombosis (Table 7-8). The majority of the limbs of patients presenting with varicose veins in this study had superficial varicosis without main branch involvement. $37 \%$ had incompetence of the greater saphenous vein, while in only $5 \%$ of the legs the lesser saphenous vein was incompetent. This suggests that insufficiency of the lesser saphenous vein might be underestimated in our study. Normally incompetence of the greater saphenous vein should be accompanied by incompetence of the lesser saphenous vein in about $15 \%$ of the cases ${ }^{7}$. Communicating vein and complex insufficiencies form only a minor part of the venous pathology in the limbs in this study.

A complaint severity score was introduced to see if any form of varicosis is characterised by a combination of complaints which would enable it to be singled out on basis of history taking. This appears to be possible in only part of the cases. Statistically significant differences in mean complaint scores were found between legs without incompetence of a main branch and legs in which one of the main trunks was incompetent. These last incompetences give complaint scores which on the average are higher than one. This means that if the complaint score is below one 
involvement of an incompetent main branch is less likely. However because of the large standard deviation, absolute separation between legs with or without main branch insufficiency is not possible. 


\section{References}

1 Browse NL, Burnand KG, Lea Thomas M. Diseases of the Veins, pathology, diagnosis and treatment. Edward Amold, London, 1988: 151-165

2 Quaile A, Rowland FH. A retrospective study of the epidemiology and treatment of varicose veins. In: Phlebology 85, Negus D, Jantet G Eds. John Libbey, London, 1986: 33-37.

3 Widmer LK. Peripheral venous disorders, prevalence and socio-medical importance. Observations in 4529 apparently healthy persons. Basle 3 study, Hans Huber, Bern, 1978.

4 Munn SR, Morton JB, McBeth WAAG, McLeish AR. To strip or not to strip the long saphenous vein? A varicose vein trial.

Br J Surg 1981: 68: 426-428

5 Weddel JM. Varicose veins pilot study. Br J Prev Soc Med 1969; 23: 179

6 Madar G, Widmer LK. Varicosis und chronische venöse Insuffizienz, Geringfügige Gesundheitsstörung oder Krankheit?

Phlebol Proktol 1990; 19: 69-79

7 Rivlin $S$. The surgical cure of primary varicose veins.

Br J Surg 1975; 62: 913-917 


\section{Chapter 8: Photoplethysmography in the diagnosis of superficial}

venous valvular incompetence.

Summary

The diagnostic value of photoplethysmography (PPG) was compared to clinical investigation combined with Doppler ultrasound testing in the diagnosis of superficial venous valvular incompetence of the lower limbs. Two hundred and sixty-eight consecutive patients (533 limbs) were investigated. Twenty-two percent of the performed PPG investigations were uninterpretable because they did not allow reliable determination of the refill time. The agreement between the clinical investigation combined with Doppler ultrasound testing and PPG was found to have a low Kappa value of 0.30 . Based on these results it is our opinion that PPG is not the non-invasive method of choice in the routine evaluation of superficial venous valvular incompetence of the lower extremity.

This chapter has been accepted for publication in the Br J Surg 1993 


\section{Introduction}

Since the now almost classical report by Abramowitz in 1979, in which photoplethysmography (PPG) was compared to venous pressure measurements in the diagnosis of deep venous valvular incompetence, photoplethysmography has been described in various publications as a quantitative, reliable, rapid, reproducible and non-invasive method to test the venous system ${ }^{1.5}$. Consequently, this technique has found widespread use in the diagnosis of venous disorders of the leg. However, various authors have questioned the criteria for interpretation of the PPG as well as its reproducibility ${ }^{6-11}$. In contrast to the alleged quantitative PPG, Doppler ultrasound examination is a qualitative method. It provides information on the presence of venous valvular incompetence with a high degree of sensitivity and specificity ${ }^{12-15}$. Recently also quantitative aspects of venous (duplex) Doppler studies have been published ${ }^{16}$ In modern clinical practice Doppler tests are among the most used diagnostic modalities to complement clinical examination in the diagnosis of superficial venous valvular incompetence ${ }^{13}$.

A study was undertaken to compare the diagnostic value of photoplethysmography to the combination of clinical examination with Doppler ultrasound testing in the diagnosis of superficial venous valvular incompetence of the lower limbs.

\section{Material and methods}

Two hundred and sixty-eight consecutive patients (201 women and 67 men) consulting the surgical department for the first time for varicosities of the lower limbs were included in the study. The mean age was 44 years (range 17 76 years). A total of 533 limbs were examined with the following tests: Photoplethysmography, clinical investigation and Doppler ultrasound investigation. A control group of 5 male and 6 female healthy persons with no clinical manifestation of venous insufficiency (22 limbs) underwent the same examinations. Mean age of the controls was 32 years (range 25-50 years). PPG examination was performed twice in the controls in order to study the reproducibility of the measurement. 
measurement.

Photoplethysmography (PPG)

A photoplethysmograph consists of a transducer, an amplifier and a recorder. The transducer emits infrared light into the underlying tissues. The backscattered light is received by a photodetector and the resulting signal is displayed on a strip-chart recorder. The shift from the baseline reflects the degree of filling of the cutaneous capillaro-venous plexus. The latter is the resultant of arterial inflow, venous outflow and the presence of venous reflux in the limb. The PPG ransducer (EC4 Plethysmograph, Hewlet Packard) was fixed to the skin near the medial malleolus, taking care not to place it directly over the greater saphenous vein. Recordings were obtained with patients sitting, their feet in a nonweight-bearing position. When a stable baseline was obtained at rest, the patient was instructed to perform dorsiflection of the foot at the rate of one movement per second. During dorsiflection the subcutaneous plexus is emptied, which gives a deflection of the PPG signal from the baseline. Ideally this deflection will return to the original baseline after cessation of exercise. The time needed for this return is known as the venous refilling time or RT. A RT longer than twenty seconds is generally termed normal, a RT of twenty seconds or less is abnormal and indicative of venous reflux'. By repeating the test while a tourniquet or cuff with a pressure above the local venous pressure is applied above the knee, below the knee and at calf level, a further differentiation as to the nature of the valvular incompetence is possible $^{12}$. In this study sphygmomanometer cuffs were used. Limbs with deep venous insufficiency have RT's (with cuffs) of less than fifteen seconds, whereas limbs with superficial venous valvular incompetence have RT's (with cuffs) of more than fifteen seconds and less than 20 seconds'.

Four different outcomes of PPG testing could be obtained:

1. Normal PPG result while testing without cuff, indicative of a hemodynamically normal venous system without valvular incompetence.

2. Abnormal PPG result which normalised after placement of a high 
thigh cuff occluding the greater saphenous vein. This is indicative of isolated valvular incompetence of the greater saphenous vein.

3. Abnormal PPG result which does not normalise after placement of a high thigh cuff occluding the greater saphenous vein. This is considered an indication of a more complex venous valvular incompetence like valvular incompetence of the lesser saphenous vein, deep venous valvular incompetence, valvular incompetence of perforator veins or combinations of these with or without greater saphenous vein valvular incompetence. A fourth possible outcome of the PPG testing could be a noninterpretable PPG recording obtained with or without cuff making categorisation in one of the three above groups not possible.

Non-interpretable PPG curves consisted of two types: either the deflection from the baseline did not return to baseline position after cessation of muscle activity or the curves showed continued drifting away from the baseline after exercise. In an attempt to reduce the problem of noninterpretability two other interpretations of the recordings were used (Figure 8-1). First the half venous refill time (HRT), defined as the time in seconds necessary for the baseline shift to return to $50 \%$ of its maximal deflection from baseline, was calculated. Normal values for the HRT are reported as being above 9 seconds ${ }^{1}$. Secondly the tangent of the first part of the recovery slope was drawn and the calculated venous refill time (CRT) was taken as the time from the point of maximum deflection to the intercept of this tangent with the original baseline. The reported normal value for this CRT is $>20$ seconds ${ }^{4}$.

\section{Clinical investigation}

All clinical investigations were performed by two vascular surgeons and consisted of inspection, palpation of varicosities and tourniquet tests. Tourniquet testing was aimed at finding greater saphenous vein valvular incompetence by observing the varicose veins being prevented from filling by a high thigh tourniquet and seen to be filling retrogradely on release of the tourniquet. In a similar way popliteo-saphenous and perforator vein valvular incompetence was looked for with below knee 
tourniquets. Based on these examinations all legs were classified according to presence or absence of greater saphenous vein valvular incompetence.

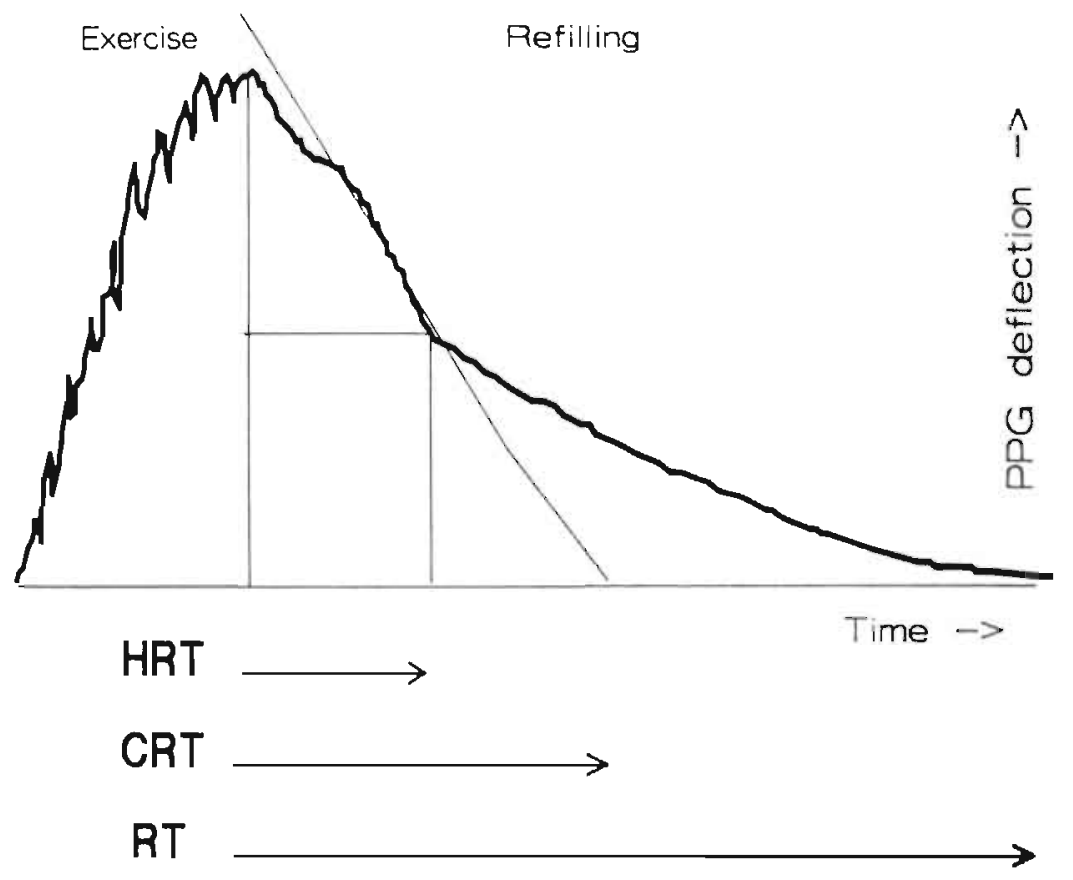

Figure 8-1: Schematic representation of a PPG registration with Venous Refill Time (RT), Half Venous Refill Time (HRT) and Calculated Venous Refill Time (CRT). 
Doppler ultrasound investigation

The doppler ultrasound velocity detector permits qualitative assessment of valvular incompetence in the deep, communicating and superficial veins of the lower limb. By placing the doppler transducer directly on the vein and by giving distal compression, physiological flow can be observed. During proximal compression, reflux can be heard if there is valvular incompetence. Occasionally a short refluxing signal (less than 1 second) may be heard, which is not regarded as pathological. The Doppler investigations for this study were done with a bidirectional $\mathrm{CW}$ Doppler device ( Vasculab Doppler Medasonics). The resulting signals were judged acoustically by two experienced vascular laboratory technicians. During the examination the patient was in a supine position for the femoral vein and the posterior tibial vein examination. The popliteal veins were tested with patients in a prone position. The erect position was used for examination of the greater saphenous vein at the saphenofemoral junction, for the saphenous vein at below knee level and for the lesser saphenous vein. Reflux at the sapheno-femoral junction was tested by the Valsalva manoeuvre.

\section{Final classification}

The results of the clinical investigation by the vascular surgeon were combined with the ultrasound results of the vascular laboratory to come to a final classification of the limbs for comparison with the PPG classification. Limbs were classified either as normal, or as having isolated valvular incompetence of the greater saphenous vein or as having a complex valvular incompetence (lesser saphenous vein valvular incompetence, perforating vein valvular incompetence, deep vein valvular incompetence or combinations of these).

\section{Statistical methods}

The mean values for RT, HRT and CRT were compared by Student's Ttest, the agreement between final classification and PPG classification was expressed as a Kappa value ${ }^{17,18}$. Kappa is a measurement of agree- 
ment, its values can range from 0.0 to 1.0 ( 0.0 meaning no agreement at all and 1.0 meaning complete agreement). A clinically relevant test should have a Kappa of $\geq 0.6$.

\section{Results}

In Table 8-1 the comparison between the final classification and the PPG classification of limbs is given. The total number of non interpretable PPG tests was 118 or $22,1 \%$ of the total. The final classification divided them into: 53 no venous valvular incompetence, 54 isolated greater saphenous vein valvular incompetence and 11 complex venous valvular incompetences. The non interpretable PPG tests were equally distributed over the three classifications of limbs. The agreement between final classification and PPG tests was very poor. Excluding the non-interpretable PPG results, the Kappa value as measure of agreement was 0.30. Including the non-interpretable results, the Kappa value was as low as 0.21 .

In Table 8-2 the mean values and their standard deviations are given of the RT, HRT and CRT for the limbs with and without venous valvular incompetence and for the healthy controls. For controls the average of two measurements was taken. The mean values of RT, HRT and CRT for the legs with and without any form of venous valvular incompetence were significantly different $(\mathrm{P}<0.001)$ but the standard deviation was found to be so large that this difference has no clinical relevance for the individual patient.

The number of non-interpretable PPG curves was high, 95 for the RT, 269 for the HRT and 124 for the CRT determination. 
Table 8-1: Comparison between the final classification and the PPG classifications of the limbs. (GSV = isolated greater saphenous vein valvular incompetence, Complex $=$ Lesser Saphenous vein valvular incompetence, perforating vein valvular incompetence, deep vein valvular incompetence or combinations of these).

\begin{tabular}{lccccc}
\hline \hline & \multicolumn{5}{c}{ PPG Classification } \\
\hline Final classification & normal & GSV & Complex & Non-interpretable & total \\
normal & 118 & 22 & 39 & 53 & 232 \\
GSV & 57 & 52 & 38 & 54 & 201 \\
Complex & 20 & 14 & 55 & 11 & 100 \\
Total & 195 & 88 & 132 & 118 & 533 \\
\hline \hline
\end{tabular}

Table 8-2: Mean values and standard deviations of RT, HRT and CRT for limbs without and with venous valvular incompetence and normal controls.

\begin{tabular}{llll}
\hline \hline & RT & HRT & CRT \\
Incompetence & $22 \pm 13$ & $17 \pm 13$ & $31 \pm 20$ \\
No incompetence & $17 \pm 11$ & $11 \pm 11$ & $25 \pm 21$ \\
Controls & $31 \pm 21$ & & \\
\hline
\end{tabular}

In Figure 8-2 the correlation between the first and second measurements in the healthy controls is shown. In the group of controls the mean refill time was 29 seconds with a standard deviation of 19 seconds for the first measurement, 34 seconds with a standard deviation of 23 seconds for the second measurement. The number of non-interpretable registrations in the controls was 5 and 2 respectively. 


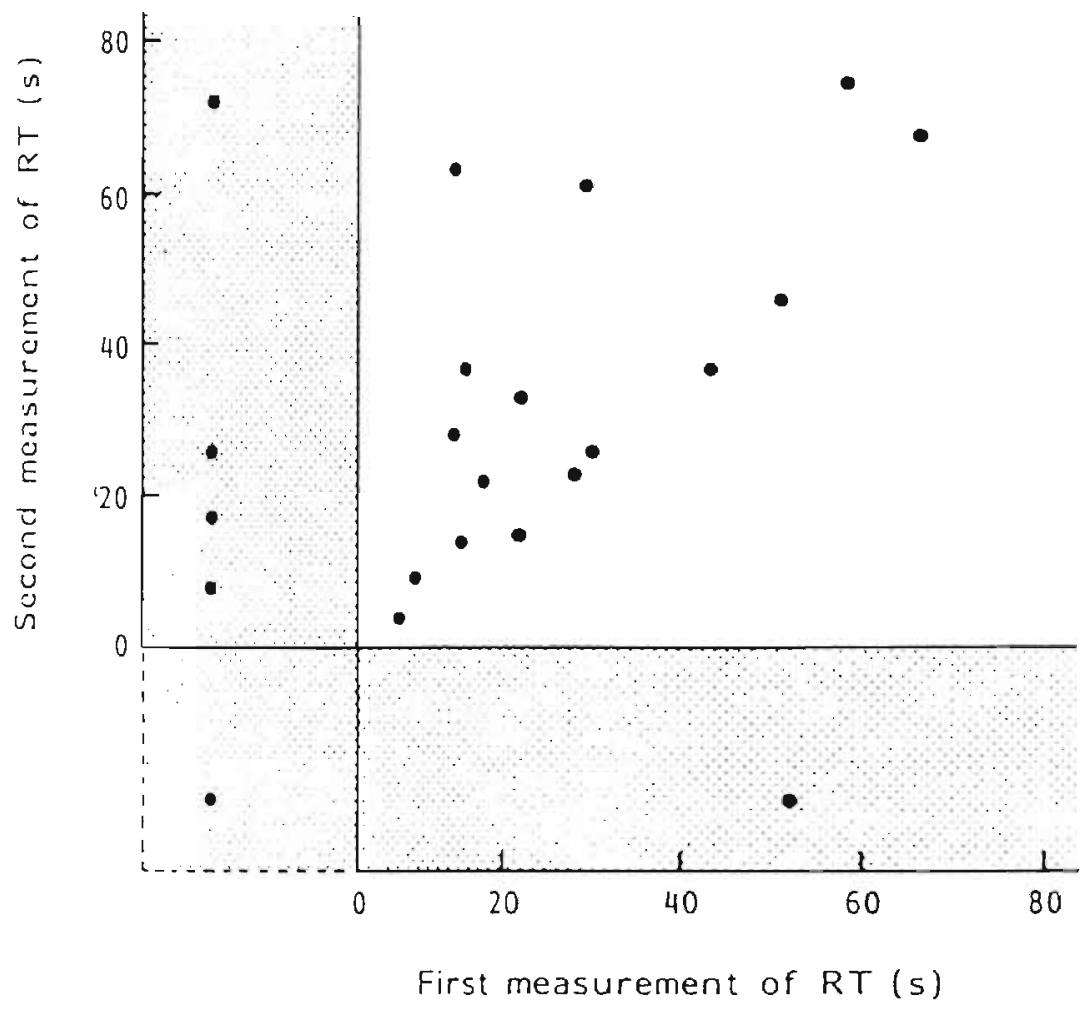

Figure 8-2: Comparison between two measurements of refill time (RT) in healthy control limbs. Measurements shown in the shaded area were non-interpretable.

\section{Discussion}

The introduction of the PPG by Barnes in $1973^{1}$ and the observations by Abramowitz in which it appeared that PPG provided information comparable to venous pressure studies in deep venous insufficiency ${ }^{2}$, gave great impulse to the use of this method. Although first described in the diagnosis of the post phlebitic syndrome, later on there was growing 
interest in its application for the detection of superficial venous valvular incompetence $e^{3.46,7}$. This technique provided the clinician with a simple, non-invasive method to study the venous hemodynamics and document the effect of therapy. Hence, invasive pressure measurements were replaced by non-invasive methods like photoplethysmography during the past ten years. Attempts to duplicate the favourable initial results proved disappointing. In healthy limbs refill times were found within the abnormal range. Minor exercise and clinical conditions associated with reactive hyperaemia resulted in shortening of the venous refill time below the criteria for normality ${ }^{3}$. Modifications such as the half venous refill time and the calculated venous refill time were introduced, to make the PPG more accurate. The reliability of these modifications vary with their authors ${ }^{2,3,4,6,8}$. Many explanations have been given for the variety in PPG results.

The PPG picks up a strong skin reflection which disturbs the recordings substantially ${ }^{10.14}$. All PPG devices are sensitive to the illumination of the surrounding; a lighted lamp within a distance of one meter from the transducer can give a change in signal with a magnitude of the signal itself $^{5}$. The pressure with which the transducer is fixed to the skin is of importance, since different pressures give substantially different registrations $^{14}$. PPG recordings are furthermore dependant on skin temperature, room temperature ${ }^{11}$, skin pigmentation and haematocrit ${ }^{311,19-21}$. Although the precise location of the sensor was not found to be critical, placement directly over the saphenous vein or over a varix is to be avoided $d^{6}$. Recently published work suggests that photoplethysmografic recovery times reflect regional haemodynamics rather than overall venous haemodynamics in the $\operatorname{limb}^{22}$. Review of the original articles reporting favourable results with PPG reveals that these were obtained by repeated studies on the same limb. Divergent values thus were readily identified; by leaving them out of the calculation or by averaging the recovery times for a given limb and thereby diminishing the effect of a single divergent value, the favourable results were obtained. The number of repeated measurements varied from three to five. Our study in 533 limbs 
comparing the PPG to clinical investigation combined with doppler ultrasound testing gave rather disappointing results. Using the venous refill time as criterium, we found it to have a poor correlation with clinical investigation and ultrasound testing. The number of non-interpretable PPG registrations was found to be unacceptably high. Noninterpretable PPG registrations had an equal distribution over the sub groups of venous valvular incompetence and do not in itself have a diagnostic meaning. Additional criteria such as the half venous refill time and the calculated venous refill time gave no better discrimination and have an even higher percentage of non-interpretable registrations.

\section{Conclusion}

The present study suggests that photoplethysmography is not the noninvasive method of choice in the routine evaluation of superficial venous valvular incompetence. 


\section{References}

1 Barnes RW, Yao JST, Photoplethysmography in chronic venous insufficiency. In: Bernstein EF ed. Non-invasive diagnostic techniques in vascular disease. St.Louis: Mosby Co. 1982: 514- 34

2 Abramowitz HB, Queral LA, Flinn RW, Nora PF, Peterson LK, Bergan JJ, Yao JST. The use of photoplethysmography in the assessment of venous insufficiency: A comparison to venous pressure measurements.

Surgery 1979; 86: 434-441

3 Norris CS, Beyrau A, Barnes RW. Quantitative photoplethysmography in chronic venous insufficiency: A new method of non-invasive estimation of ambulatory venous pressure.

Surgery 1983; 94: 759-763

4 Kempczinski RF, Berlatzky Y, Pearce WH. Semi-quantitative photoplethysmography in the diagnosis of lower extremity venous insufficiency.

J Cardiovasc Surg 1986; 27: 17-23

5 Fisher M, Wuppermans Th. Vergleich der Wertigkeit der Phlebodynamometrie mittels unblutiger Infrarot Photoplethysmographie und blutiger Drackmessung

Phlebologie und Proctologie 1982; 11: 259-263

6 Burnham SJ. Varicose veins: patient selection and treatment. In: Rutherford RB. ed. Vascular Surgery. Philadelphia: Saunders Co 1989: 15131517

7 Barnes RW, Ross EA, Strandness DE. Differentiation of primary from secondary varicose veins by doppler ultrasound and strain gauge plethysmography.

Surg Gynecol Obstet 1975; 141: 207-211

8 Barnes RW. Doppler techniques for evaluation of lower extremity venous disease. In: Bergan JJ, Yao JST, eds. Surgery of the Veins. Grune \& Stratton, Orlando, 1984: 99-109

9 Pearce WH, Rico JP, Queral LA, Flinn WR, Yao JST. Hemodynamic assessment of venous problems.

Surgery $1983 ; 93: 715$

10 Weindorf N, Schulz-Ehrenburg U. Der Wert der Photoplethysmographie in der Phlebologie. 
Vasa 1986; 15: 397

11 Eikirson E. Photoplethysmografic studies of venous disease of the legs. Acta Chir Scand 1986 (suppl): 398-401

12 Colgan MP, Sumner DS. How does a vascular laboratory influence the management of venous disease. In: Greenhalgh RM, Jamieson CW, Nicolaides AN, eds. Vascular Surgery. Issues in Current Practise. Grune \& Stratton, London,1986: 119-131

13 Schraibman IG. The Diagnosis of Saphenofemoral Incompetence. In: Negus D, Jantet G, eds. Phlebology 1985. J.Libbey and co, London-Paris, 1986: $92-93$

14 Wienert V. Funktionelle Phlebologische Diagnostik mit Hilfe der LichtReflexions-Rheographie,

Dtsch Med Wochenschr 1984; 25: 997-999

15 McIrvine AJ, Corbett CRR, Aston NO, Sherriff EA, Wiseman PA, Jamieson CW. The demonstration of Saphenofemoral incompetence; Doppler ultrasound compared with standard clinical tests.

Br J Surg 1984; 71: 509-510

16 Bemmelen PS, Bedford G, Beach K, Strandness DE. Quantitative segmental evaluation of venous valvular reflux with duplex ultrasound scanning.

J Vasc Surg 1989; 10: 425-431

17 Schouten HJA. Measuring pairwise agreement among many observers. Biom J 1980; 22: 497-504

18 Koran L.M. Reliability of clinical methods, data and judgments $(1,2)$.

N Engl J Med 1975; 642-646, 695-701

19 Ris HB, Gfeller Ch, Mahler F, Nachbur B. Comparative Evaluation of Three Ambulatory Plethysmographic Devices as regards Accuracy and Handling in Daily Practice.

Eur J Vasc Surg 1991; 5: 159-164

20 Raju S, Fredericks R. Evaluation of methods for detecting venous reflux. Perspectives in venous insufficiency.

Arch Surg 199; 125: 1463-1467

21 Van den Broek ThAA. Chronic venous insufficiency and venous reconstructive surgery. Thesis, Amsterdam, The Netherlands 1989; 23-24

22 Rosfors $S$. Venous plethysmography, relationship between transducer 
position and regional distibution of venous insufficiency.

J Vasc Surg 1990; 11: 436-440 


\section{Chapter 9: Stripping or high ligation combined with sclerotherapy in the treatment of the incompetent greater saphenous vein; a rando- mised trial.}

Summary

In a prospective randomised study the effect of treatment of insufficiency of the greater saphenous vein combined with local varicosities by means of stripping operation combined with local avulsion of varicose veins was compared to treatment by high ligation of the sapheno-femoral junction (crossectomy) combined with sclerocompression therapy. The diagnosis was based on clinical investigation including tourniquet tests combined with Doppler ultrasound findings. One hundred eighty one consecutive patient legs were included in the study, 89 were randomly allocated to stripping, 92 to high ligation combined with sclerotherapy. Both groups were comparable regarding clinical and denrographic characteristics. Follow up at three months, one, two and three years after treatment consisted of clinical investigation and Doppler ultrasound testing. Complaints as well as cosmetic results, judged by the patient subjectively and by the surgeon in an objective manner, were scored in a standard way. Clinical tests and Doppler ultrasound tests were used to demonstrate absence or presence of reverse flow at the sapheno-femoral junction or along the saphenous trunk. At three years 68 patient limbs in the stripping group (76\%) and 73 patient limbs in the high ligation-sclerotherapy group (79\%) were still available to follow up. Results at three years showed significant differences (Chi-square, $\mathrm{P}<0.05$ ) for cosmetic results as judged by patient as wel] as by the surgeon and for clinical and Doppler ultrasound evidence of reverse flow in the saphenous vein in favour of the standard stripping operation. Therefore the medium tern results of treatment of isolated saphenous vein insufficiency by stripping operation are considered superior to those obtained by high ligation combined with sclerotherapy.

This chapter has been submitted for publication 


\section{Introduction}

For many years both operative treatment and sclerotherapy have found use in the treatment of varicose veins, operative treatment being the oldest (Celsus 25 B.C.-50 A.D.), injection therapy having had its introduction in 1853 by Cassaignac. 'The popularity of each therapy varied throughout time and disagreement still persists concerning the indication for each form of treatment. The stripping operation became popular in the early 1950's. Before that time a high saphenous ligation with retrograde injection of sclerosant was commonly performed resulting in a high recurrence rate. The stripping operation was founded on the premise that insufficiency in a vein that has been removed cannot recur. ${ }^{2}$ Following the modification of sclerotherapy by Fegan ${ }^{3}$ this therapy found renewed widespread use. In several publications results of sclerotherapy comparable to those of operative treatment have been reported. ${ }^{4,5,6}$ In 1974 Hobbs demonstrated that the best primary treatment for dilated superficial veins and for incompetent perforating veins in the lower part of the legs was injection compression therapy. Surgery was more successful and longlasting when there was involvement of either of the saphenous systems with junctional incompetence. ${ }^{7}$ It was demonstrated that the period of observation after treatment was of importance; unsatisfactory results were a function of the period of observation. ${ }^{7.8}$ The long term results of Fegans method were uncertain but the cost saving was so great that it has been advised to use it always as first procedure. ${ }^{9}$ In judging the result of treatment there was only a $40 \%$ agreement between surgeon and patient as to what constituted a good result. ${ }^{10}$ Despite welldefined criteria, two or more investigators may evaluate a given result differently. " Jakobsen concluded that the primary treatment for incompetence of the saphenous vein should be a radical operation. ${ }^{12}$ Rivlin found stripping to the ankle unnecessary and advised a more selective operation of the proximal saphenous vein. ${ }^{13}$

Recently trials have been published in which selective stripping compared favourably to standard stripping. ${ }^{14.15}$ Long saphenous vein saving surgery for varicose veins has been advised based on the assumption that 
removal of the saphenous vein is unnecessary if insufficient perforating veins have been ligated. ${ }^{16}$ Recurrence rates as judged by repeated plethysmographic examinations have been reported of $12 \%$, five years after stripping operation and of $11 \%$ five years after high ligation. ${ }^{16}$ Also in both groups a significant improvement of plethysmographic venous refill time was found after treatment.

This prospective study was started to investigate whether treatment of incompetence of the greater saphenous vein combined with local varicosities by standard stripping and avulsion of varicosities gives medium term results comparable to results of high-ligation combined with sclerotherapy of tributaries. In order to study the effect of both treatments on local haemodynamics, standard non-invasive tests were used during follow-up.

\section{Material and methods}

Both limbs of 268 consecutive patients (533 limbs), presenting at our surgical out-patient department with varices were examined for this study. Complaints for each of the limbs were registered separately. Examination consisted of clinical and Doppler ultrasound testing. All clinical investigations were performed by two experienced vascular surgeons and consisted of inspection, palpation of varicosities and tourniquet tests. Tourniquet tests were aimed at finding retrograde filling of the greater saphenous vein on release of a high thigh tourniquet. The Doppler ultrasound investigations in this study were done with a bidirectional CW Doppler device (Vasculab Doppler Medasonics). The resulting signals were judged acoustically by two experienced vascular laboratory technicians. During examination the patient was in supine position for the examination of the femoral veins and the posterior tibial veins. The popliteal veins were tested in a prone position. The erect position was used for examination of the greater saphenous vein at the sapheno-femoral junction, and along it's course to the below knee level and for the lesser saphenous vein. During proximal muscle compression, 
reflux can be heard if there is valvular incompetence. Occasionally a short refluxing signal could be heard (less than 1 second) which was not considered as being pathological. Reflux at the sapheno-femoral junction was tested by the Valsalva manoeuvre.

Based on these tests 181 legs, belonging to 156 patients, were considered to have an isolated incompetence of the greater saphenous vein combined with local varicosities. 78 patients $(89$ legs) were randomised to the standard stripping operation combined with surgical avulsion of varicosities, 78 patients (92 legs) to high ligation of the sapheno-femoral junction (in Europe often termed crossectomy) combined with sclerocompression therapy of the varicosities.

For practical reasons both limbs of patients with bilateral greater saphenous vein incompetence were treated in a similar manner (11 patients in the stripping group and 14 patients in the high ligation sclerotherapy group).

The stripping operation was performed under general aesthesia. Through groin incisions the proximal tributaries of the long saphenous vein were ligated and divided. The saphenous vein was divided flush at the sapheno-femoral junction. Then an incision was made directly anterior to the medial malleolus at the ankle, exposing the saphenous vein. After distal introduction of the stripper the vein was ligated and divided. Care was taken to identify and isolate the saphenous nerve from the adventitia of the vein. Local varicosities were avulsed through multiple stab incisions and stripping was then performed from ankle to groin. After wound closure compressive bandages were applied. One day after operation these bandages were changed for compressive stockings. Stockings were maintained for 4 weeks. Hospital admission usually lasted 2 to 3 days.

The sapheno-femoral ligation in the high ligation-sclerotherapy group was performed as an outpatient procedure under local infiltration analgesia.

Preceding the ligation the injection sclerotherapy was performed as described by Fegan but slightly modified, using a 1\% solution of ethoxysclerol (Kreussler(B)). Injection sites were selected and marked at variable 
intervals depending on the size of the varices. With the patient standing the needle was inserted into the filled vein which was then emptied by digital pressure. Immediately after injection foam rubber pads were applied over the injection sites and adjacent veins and covered by a layer of compressive bandages. The maximum dose of ethoxysclerol used was $12 \mathrm{cc}$. per patient per session. Sapheno-femoral ligation was done in the same way as described in the stripping group.

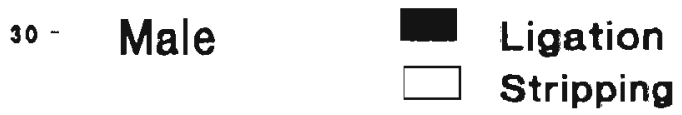

$20-$
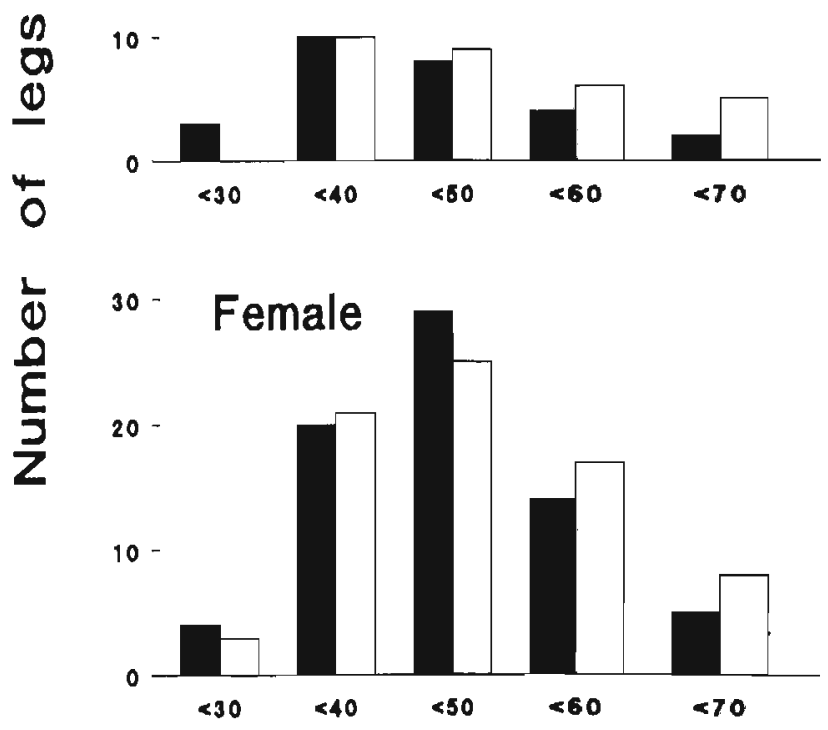

\section{Age in yrs}

Figure 9-1: Patients age and sex distribution of 181 randomised varicose legs. 
The stripping group consisted of 89 legs and the high ligation-sclerotherapy group of 92 legs. Both groups were comparable with regard to demographic characteristics. There were $75 \%$ female patients compared to $25 \%$ male patients in the whole group. The age distribution is given in Figure 9-1. Randomisation resulted in an even distribution over the two treatment modalities both for sex and age categories.

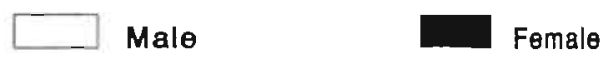

100

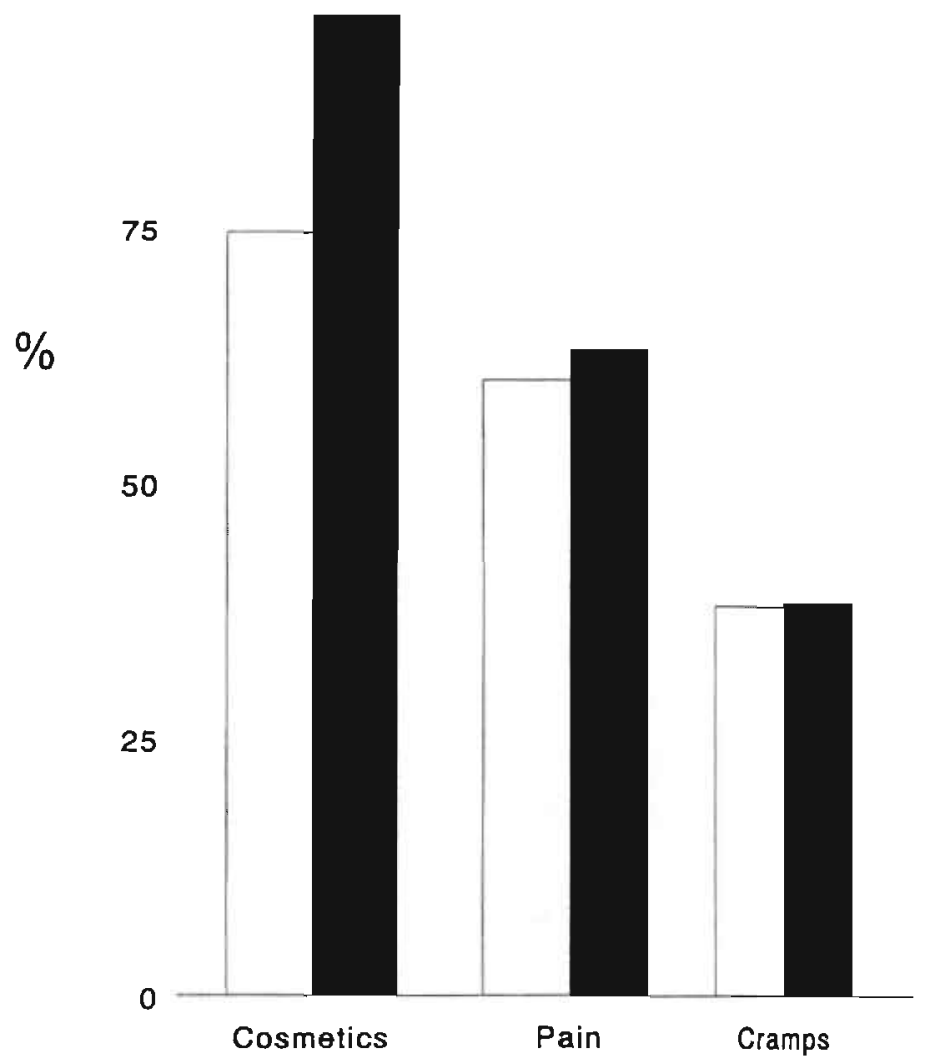

Figure 9-2: Proportional occurrence of main presenting complaints in 181 randomised patient legs. 
The number of left and right legs affected was equal. Twenty-five percent of the patients had a standing occupation, whereas $75 \%$ had sitting work. A family history of varicosis was present in $76 \%$ of the patients. The proportional occurrence of the main complaints is summarised in Figure 9-2.

Follow up at three months and one, two and three years after treatment consisted of a structured interview, clinical investigation and Doppler ultrasound testing. Patient's complaints were noted and compared to the complaints before treatment by asking the patients to classify them as absent, unchanged or worse

Cosmetic results were judged by the patients as excellent, moderate or poor. Cosmetic results were also judged by one surgeon not involved in the initial treatment according to the following criteria:

- excellent: no visible or palpable varicose veins

- fair: $\quad$ visible or palpable varicose veins less than $5 \mathrm{~mm}$. in diameter (fair).

- poor: varicose veins with a diameter of more than $5 \mathrm{~mm}$ or visible incompetent main trunks

Results according to complaints or cosmetic assessment were finally classified as "good" (excellent or fair cosmetics, or absence of complaints) or "bad" (cosmetic assessment poor, or complaints unchanged or worse).

Clinical and Doppler tests were done to demonstrate absence or presence of reverse flow at the sapheno-femoral junction or over the greater saphenous vein.

In the high ligation-sclerotherapy group the number of injection sessions and the total volume of sclerosing agent injected were registered. In both groups residual or recurrent varicosities during follow up were treated by sclerotherapy if requested by the patient. At three years 68 limbs in the stripping group (76\%) and 73 limbs in the high ligation-sclerotherapy group (79\%) were still available for evaluation.

In both groups one patient had died from non-related causes. 


\section{Statistical analysis}

The percentages of symptomatic and cosmetic failures and of clinical and haemodynamical recurrences of incompetence of the greater saphenous vein for both treatment modalities were compared by simple Chi-square tests. The relation between Doppler evidence of persisting reflux over the saphenofemoral junction and along the course of the saphenous vein for both treatment modalities and complaints, cosmetic assessment by the patients and cosmetic assessment by the surgeon on the other hand was analyzed by means of Fisher's exact test. The initial allocation of patients to one of the treatment groups was maintained throughout the study, according to the "intention to treat principle".

\section{Results}

In the high ligation-sclerotherapy group, the 92 legs were treated the first time with an average sclerodose of $8.1 \mathrm{ml} ., 20$ legs were treated a second time at an mean interval of 11 months using an average sclerodose of $6.7 \mathrm{ml}$.. In 3 legs it was necessary to repeat the sclerotherapy a third time, the average sclerodose for these legs was $3 \mathrm{ml}$.. Five of the total of 92 legs had to be treated surgically. Indication for reoperation was incompetence of the lesser saphenous vein once, a remaining greater saphenous vein insufficiency three times and once an exploration of the groin was performed for suspected sapheno-femoral reflux which proved negative.

In the stripping group of 89 legs, additional sclerotherapy was necessary in 12 limbs to achieve satisfactory results. This sclerotherapy was performed at an mean interval of 10 months following operation with an average dose of sclerosing agent of $5.5 \mathrm{ml}$. In two cases a reoperation was needed. Both times the indication for reoperation was incompetence of the lesser saphenous vein resulting in persisting complaints. Stripping resulted in damage to the saphenous nerve in 27 limbs (33\%) causing sensory loss or a distressing traumatic neuritis involving the medial aspect of the ankle. In the majority of the cases the neuralgia persisted for one year, in four cases however it persisted up to three years. 
In Figures 9-3 and 9-4 results of follow-up are given at three months and at one, two and three years after treatment. Chi-square testing showed significant $(\mathrm{P}<0.05)$ differences for cosmetic results as judged by the patients themselves as well as by the surgeon, and for clinical and Doppler ultrasound evidence of reverse flow in the saphenous vein at three years. In all cases the results were better for the stripped legs than for the legs treated by high ligation-sclerotherapy.

No statistical differences could be found between the two groups concerning persisting post-treatment complaints at any follow-up moment.

\section{HIGH LIGATION STRIPPING}

Freedom of

Complaints
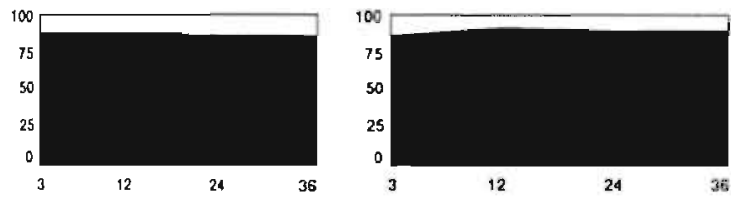

Good

Cosmetics

(subjective)
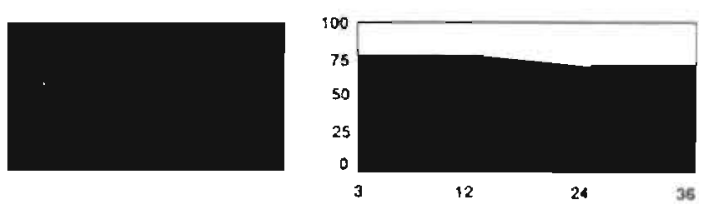

Good

Cosmetics

(objective)
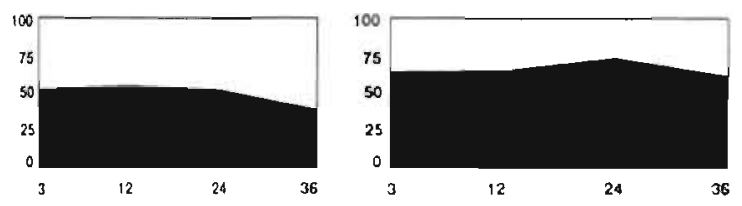

Figure 9-3: Proportion of patient's legs with freedom of complaints, and good cosmetic results as judged by the patients and by the surgeon at three months and one, two and three years after treatment for the stripping group and the high ligation sclerotherapy group. 
By means of Fisher's exact test a significant association $(\mathrm{P}<0.05)$ between the surgeon's assessment of the cosmetic results and Doppler evidence of saphenous reflux could be demonstrated at three years of follow-up in the high ligation-sclerotherapy group only. There appeared to be no association between saphenous reflux and complaints or patient's cosmetic evaluation in either of the two treatment groups at three years follow-up.

\section{HIGH LIGATION STRIPPING}

\section{Clinical}
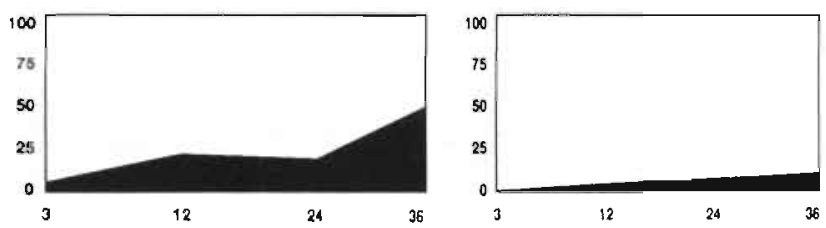

\section{Doppler}
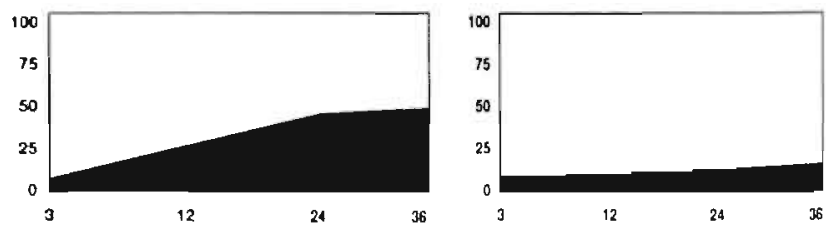

Figure 9-4: Clinical and Doppler ultrasound evidence of residual incompetence of the greater saphenous vein for both groups at three months, one, two and three years after treatment for the stripping group and the high ligation sclerotherapy group. 


\section{Discussion}

In 1968 Hobbs reported that at 2 years results of sclerotherapy for various forms of superficial venous valvular incompetence compared favourably to surgical treatment. ${ }^{19}$ In 1974 however he reported that the one year "cure" rate of $82 \%$ in the sclerotherapy group had fallen to a mere $7 \%$ at five years and only $30 \%$ still remained "improved". In contrast $20 \%$ of the surgical group remained "cured" and $80 \%$ were still "improved" at 5 years. ${ }^{7}$ In our study, combining sclerotherapy with high saphenous ligation resulted in patient's satisfaction in over 90\%. However, after three years the Doppler ultrasound examination shows that in almost $50 \%$ of these patients there is already or still evidence of saphenous reflux. So in this way the intention of the treatment, i.e. abolishing the reflux, can be considered a failure. Persisting reflux apparently does not influence the patient's appreciation of cosmetic results and plays no role in persisting complaints.

A possible explanation for the difference in results between the two forms of therapy is the fact that the high ligation in the stripping group was performed under general aesthesia perhaps allowing a better groin exposure and accordingly a more radical ligation of the saphenous vein and its tributaries. Most authors stress the importance of a radical elimination of all side branches.

The treatment of varicose veins should consist of eliminating escape points of reflux and abolishing the pathway of incompetence that feeds the existing varicosities. The traditional total stripping of the greater saphenous vein or ligation of the sapheno-femoral junction was based on the assumption that reflux invariably occurs at this junction. The assumption of the sapheno-femoral escape as the sole source of reflux into the saphenous system now seems incorrect. ${ }^{15}$

Recently in only $64 \%$ of truncal varicosities escape points were found to be localised at the sapheno-femoral junction; in the remainder proximal escape points were localised elsewhere and of non-junctional nature. ${ }^{15}$ These non-junctional escapes are missed by high ligation whereas they are in fact treated by radical as well as selective stripping. Stripping 
enables the incompetent thigh communicating veins to be removed together with the greater saphenous vein. ${ }^{13}$ The $33 \%$ damage to the saphenous nerve is alarming. When this trial was started it was practise that the vein should be stripped from ankle to groin. Now, in our clinic full length stripping has been abandoned in favour of knee to groin stripping.

The period of observation might be short in our series. Although in both groups the number of successful results declined during the three years of follow-up, the results remained significantly better for the stripping group compared to high ligation-sclerotherapy group. As Jacobsen notes there is no reason to assume that these relationships should change after a longer period of follow-up. ${ }^{12}$ The group of patients lost to follow-up in both treatment groups ( $24 \%$ vs. $21 \%$ ) might contain a disproportionably high number of dissatisfied persons who have sought treatment elsewhere. The real proportion of satisfactory results therefore is probably lower than reported here.

\section{Conclusion}

The medium term haemodynamic and cosmetic results of treatment of isolated insufficiency of the greater saphenous vein by the stripping operation are superior to those obtained by high ligation combined with sclerotherapy. 


\section{References}

1 Rowden Foote R. Varicose Veins 1952 Butterworth \& Co, London , 1-21

2 Lofgren ET. The treatment of Long Saphenous Varicosities and their recurrence: A long term follow-up. In Surgery of the Veins. Bergan JJ, Yao JST. eds. Grune \& Stratton, Orlando, 1985: 285-299

3 Fegan G. Varicose veins: Compression sclerotherapy. 1967 Heinemann Medical, London

4 Reid RG, Rothnie NG. Treatment of varicose veins by compression sclerotherapy.

Br J Surg $1968 ; 55: 889-895$

5 Stother IG, Bryson A, Alexander S. The treatment of varicose veins by compression sclerotherapy.

Br J Surg 1974; 61: 387-390

6 Sigg K. Treatment of varicose veins by injection sclerotherapy: a method practised in Switzerland. In: The treatment of venous disorders. Hobbs JT. Ed. MTP Press Limited, Lancaster , 1977: 113-138

7 Hobbs JT. Surgery and Sclerotherapy in the treatment of varicose veins. Arch Surg 1974; 109: 193-796

8 Van der Stricht J. Technik und Indikationen der Chirurgischen Behandlung von Varizen und ihrer Kombination mit Verödung. Zentralbl Phlebol 1966; 5: 39-45

9 Doran FSA, White M. A clinical trial designed to discover if primary treatment of varicose veins should be by Fegans method or by an operation.

Br J Surg 1975; 62: 72-77

10 Raj TB, Makin GS. A randomised controlled trial of two forms of compression bandaging in outpatient sclerotherapy of varicose veins.

J Surg Res 1981; 31: 440-444

11 McAdam WAF, Horrocks JC, DeDombal FT. Assessment of the results of surgery for varicose veins.

Br J Surg 1976; 63: 137-140

12 Jakobsen HJ. The value of different forms of treatment for varicose veins Br J Surg 1979; 66: 182-184 
13 Rivlin S. The surgical cure of primary varicose veins Br J Surg 1975; 62: 913-917

14 Koyano K, Sakaguchi S. Selective stripping operation based on Doppler ultrasonic findings for primary varicose veins of the lower extremities. Surgery 1988; 103: 615-619

15 Munn SR, Morton JB, Macbeth WAAG, McLeish AR. To strip or not to strip the long Saphenous vein? A varicose vein trial.

Br J Surg 1981; 68: 426-428

16 Hammarsten J, Pedersen P, Cederlund CG, Campanello M. Long Saphenous Vein Saving Surgery for Varicose veins. A Long Term Follow-up Eur J Vasc Surg 1990; 4: 361-364

17 Madar G, Widmer LK. Varicosis und Chronische Venöse Insuffizienz, Geringfügige Gesundheitsstörung oder Krankheit? Phlebol Proctol 1990; 19: 69-79

18 Goren G, Yellin AE. Primary Varicose Veins: Topographic and hemodynamic Correlations.

J Cardiovasc Surg 1990; 31: 672-677

19 Hobbs JT. Treatment of varicose veins. A random trial of injection compression therapy versus surgery.

Br J Surg 1968; 55: 777 


\section{Chapter 10: Surgical implications of the anatomy of the}

saphenous nerve.

\section{Summary}

The anatomical relationship between the saphenous nerve and the greater saphenous vein was investigated in seventy-five patient legs in which the saphenous vein was harvested for coronary artery bypass procedures. Aim of the study was to locate a point at which level damage to the saphenous nerve could be reduced to a minimum when stripping the saphenous vein for varicasities of the main trunk.

This point was found situated at $5 \mathrm{~cm}$. below knee level. Selective stripping with this point as distal boundary is advised.

This chapter has been submitted for publication 


\section{Introduction}

At the moment the most common operation in the treatment of isolated insufficiency of the greater saphenous vein is ligation of the saphenofemoral junction, ligation of the groin tributaries and stripping of the saphenous vein from ankle to groin to. This technique can result in a damage to the saphenous nerve causing distressing paraesthesia, numbness or pains in the distribution area of the nerve. The skin over the medial aspect of the ankle is mainly involved. Most of the losses of sensation are related to bruising of the nerve during dissection at the ankle, but many are probably due to stretching of the nerve during stripping or actual inclusion of the nerve within the ligature with consequent stripping of the nerve. Saphenous nerve neuralgia is underestimated. The incidence of the neuralgia varies from 28 to $58 \%$. In order to minimize the risk of injury to the nerve stripping from proximal to distal has been proposed ${ }^{2.16}$. In the majority of cases the neuralgia persists for one year ${ }^{6}$, in a few cases however it can persist up to three years and necessitate blocking the nerve. It is not a disabling injury, but it is certainly an undesirable complication.

It was demonstrated in a randomised trial that the results of treatment as judged by patients were biased against stripping, because of the increased incidence of paraesthesia in the stripped limbs, although results of treatment judged solely by the incidence of varicosities at follow up were significantly better in limbs from which the saphenous vein had been stripped compared to high ligation without stripping. Ligation of the sapheno-femoral junction without stripping, often called "crossectomy" avoids nerve damage but results in recurrence of varicose veins in $60 \%$ of the cases ${ }^{3}$. Crossectomy combined with sclerotherapy is an alternative for stripping but long term results are inferior for functional as well as cosmetic results ${ }^{7}$. Rivlin has recommended that the long saphenous vein should be stripped from $4 \mathrm{~cm}$. below the tibial tubercle to the groin. Stripping from this level at which the nerve is not in intimate relations- 
hip with the vein would achieve the benefits of stripping with a lower incidence of distressing side effects ${ }^{5,8}$. A few studies of the anatnmy of the saphenous nerve have been done, mostly post mortem ${ }^{9,10.16}$. The saphenous nerve is a purely sensory branch of the femoral nerve. It pierces the fascia between the tendons of the gracilis and sartorius muscles; further distally the nerve usually lies directly beneath the saphenous vein, separated by a layer of subcutaneous fat. In the distal third of the leg the nerve assumes an increasingly close position to the vein, often being adherent to the adventitional sheath. In order to obtain information about the anatomy of the saphenous nerve relevant to varicose vein surgery an in vivo study of this anatomy was performed in patients undergoing vein-harvesting for coronary bypass surgery.

\section{Material and Methods}

This study comprised 75 lower limbs, male/female distribution 3 to 1 , mean age 65 years (range 53-89 years), mean length $164 \mathrm{~cm}$. (range 148$187 \mathrm{~cm}$.). All patients were undergoing coronary artery bypass surgery for ischemic heart disease. No leg had been used for harvesting the greater saphenous vein previously.

Incisions were made from the medial ankle to above the knee. The length of the incision varied with the length of vein required. The total length of the vein was exposed as well as the main trunk of the saphenous nerve and its side branches. The anatomical relationship was registrated. The distance from the level of the knee joint to the point where the vein becomes adherent to the nerve was measured and the distance from the medial malleolus to this junction as well.

\section{Results}

Almost without exception the nerve was found to be completely adherent to the adventitia of the vein in the distal part of the leg. No connection at all between the nerve and the vein was only seen in two of the cases. In the majority of cases the nerve gave a side branch and in this way formed a bifurcation under which the saphenous vein passed. The 
bifurcation was usually situated in between halfway and the distal third of the lower leg (figure 10-1).

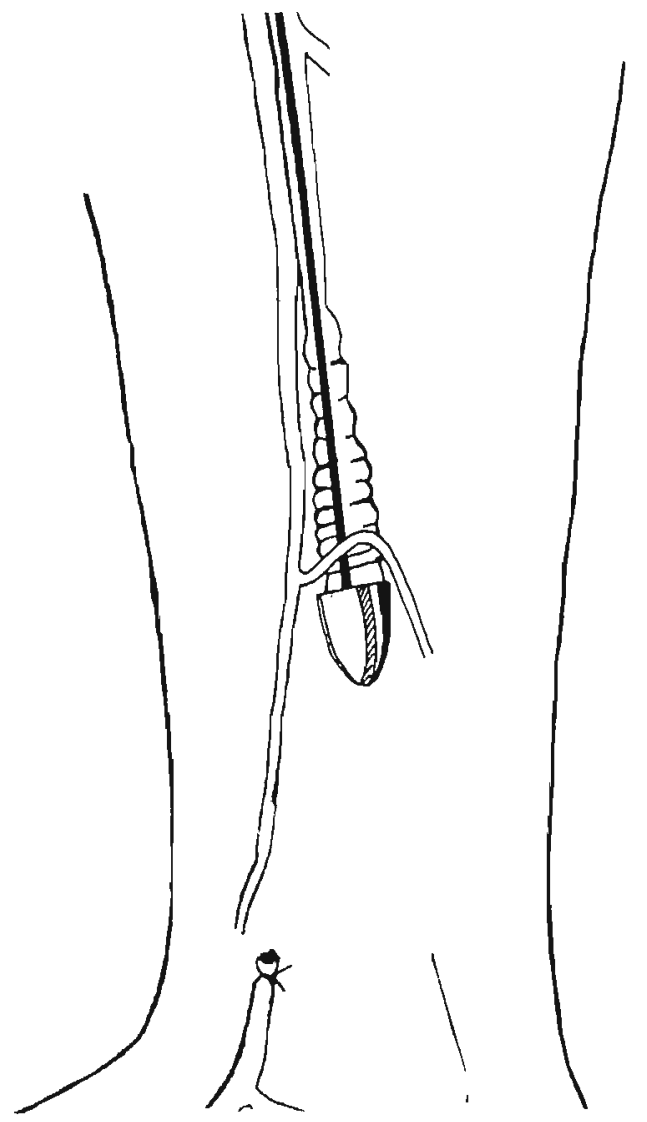

Figure 10-1: Stripper head passing under the bifurcation of the saphenous nerve and so damaging the nerve

The distance from knee level to the junction of the saphenous vein and nerve measured $17.6 \mathrm{~cm}$ (range $1-29 \mathrm{~cm}$ ). The distance from the medial malleolus to the junction of the saphenous vein and nerve measured 26.4 $\mathrm{cm}$ (range $1-32 \mathrm{~cm}$ ). At $10 \mathrm{~cm}$ distal to the knee joint the vein was still firmly connected to the nerve in $22 \%$ of the legs; at $5 \mathrm{~cm}$ distal to the knee joint $6 \%$ of the veins were found to be adherent to the nerve (figure 10-2). 


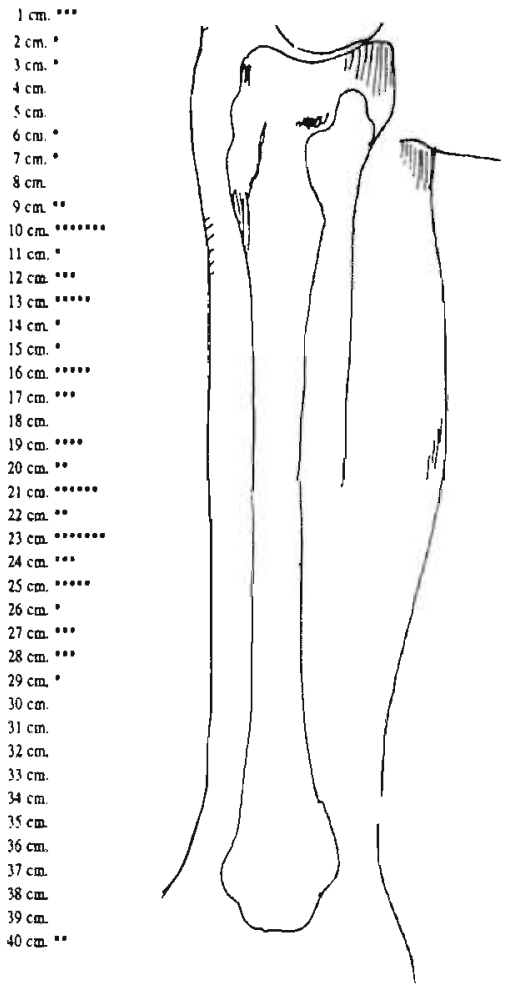

Figure 10-2: Distribution of distances from knee level to the junction of the saphenous nerve and vein in $\mathrm{cm}$

\section{Discussion}

A few papers dealing with the anatomical relation between the saphenous nerve and vein have been published, most of the information was gathered post mortem ${ }^{10,16}$. Our study is one of the first in vivo studies dealing with this matter. The results of this study confirm what was known about the incidence of damage to the saphenous nerve from clinical experience ${ }^{3 \cdot 12}$. In the original description by Babcock in 1907 the 
extraction of the incompetent vein was done in distal direction. Later on stripping in both directions became practise.

Randomised trials revealed a significantly greater incidence of sensory loss following upward extraction compared to downward extraction $\mathrm{n}^{45.16}$.

The introduction of the limited or selective stripping operation makes the direction of stripping irrelevant ${ }^{3}$. The greater saphenous vein is usually only dilated and incompetent to the upper third of the calf, at which point it is joined by the largest calf tributaries. Passing the stripper down from the groin demonstrates whether the saphenous vein is incompetent and to what extent. In most cases the stripper stops just below the knee ${ }^{3}$. It is unnecessary to strip any part of the vein that is not incompetent ${ }^{11}$.

Since the most distal incompetent perforating vein is always within a centimetre or two distal to the level of the tibial tubercle, there is no need for stripping to the ankle ${ }^{9}$. The below-knee portion of the greater saphenous vein is never involved in varicosity and should not be removed at operation ${ }^{15}$. A second trend is toward increased sophistication in the technology of investigation enabling identification of abnormalities to specific parts of the venous system only. This justifies more limited procedures which previously would have been labelled incomplete ${ }^{2}$. Clinical trials have shown comparable results of selective stripping to complete extraction with regard to residual varicosis ${ }^{36}$. In a randomised prospective study comparing total stripping and partial stripping, lesions of the saphenous nerve were found in $39 \%$ and $7 \%$ respectively ${ }^{12}$. Preservation of the distal saphenous vein for subsequent coronary artery bypass surgery seems an additional advantage of limited stripping ${ }^{10}$. A further reason for maintaining the distal part of the saphenous vein is the important role it plays in the accessory drainage of the foo $\mathrm{t}^{14}$.

\section{Conclusion}

Our in vivo anatomical study makes stripping with a point located at 5 $\mathrm{cm}$. below knee level as distal boundary advisable in order to reduce damage to the saphenous nerve without compromising the symptomatic and functional success of the operation. 


\section{References}

1 Dodd H, Cockett FB. The Pathology and Surgery of the Veins.

Churchill Livingstone, Edinburgh, 1976: 95-157.

2 Bumham SJ. Varicose Veins: Patient Selection and Treatment. In: Rutherford RB. ed.

Vascular Surgery. Philadelphia. Saunders 1989: 1512-1517.

3 Negus D. Should the incompetent Saphenous vein be stripped to the ankle? Phlebologie 1986; 1: 33-36

4 Cox SJ, Wellwood JM, Martin A. Saphenous nerve injury caused by stripping of the long saphenous vein.

Br Med J 1974; 1: 415-417

5 Jacobsen BH, Wallin L. Proximal or distal extraction of the internal saphenous vein? Vasa 1975; 4: 240-242

6 Koyano K, Sakaguchi S. Selective stripping operation based on Doppler ultrasonic findings for primary varicose veins of the lower extremities. Surgery 1988; 103: 615-619

7 Kith LM, Smead WL. Saphenous Vein Stripping and Its Complications. Surg Clin of North America 1983;63: 1303-1311

8 Munn SR, Morton JB, MacBeth WAAG, McLeish AR. To strip or not to strip the long Saphenous vein? A varicose veins trial.

Br J Surg 1981; 68: 426-428

9 Rivlin $S$. The surgical cure of primary varicose veins. Br J Surg 1975; 62: 913-917

10 Holme JB, Holme K, Sorensen LS. The anatomic relationship between the long saphenous vein and the saphenous nerve.

Acta Chir Scand 1988; 154: 631-633

11 Schultz-Ehrenburg. In Phlebology 85. Negus D, Jantet G, eds. $1986 \mathrm{~J}$. Libbey \& co London, 150

12 Garnjost W. Injury to the saphenous nerve following operation for varicose veins.

Surg Gynec Obstet 1964; 119: 359-61 
13 Holme JB, Skajaa K, Holme K. Incidence of lesions of the saphenous nerve after partial or complete stripping of the long saphenous vein. Acta Chir Scand 1990: 156: 145-148

14 Hamilton Jacobson B. The venous drainage of the foot. Surg Gynec Obstet 1970; 131: 22-24

15 Barabas AP. The long saphenous vein in primary varicose veins. Br J Surg 1986; 73: 320-324

16 Ramasastry SS, Dick GO, Futrell JW. Anatomy of the saphenous nerve; Relevance to saphenous vein stripping.

Am J Surg 1987; 53: 274-277 
Chapter 11 : Varicose veins and the vascular surgeon:

from nuisance to challenge.

Eur J Vasc Surg 1993 (in press) 


\section{Introduction.}

Treatment of varicose veins of the legs is one of the more common activities in general surgery. In addition, many vascular surgeons in continental Europe and Britain are dealing with them on a regular basis, even though not all of them consider varicose veins to fall within the specific domain of their specialty. Inspite of this much scientific interest in varicose veins has not yet been aroused among vascular surgeons, as evidenced by the small number of publications about varices in vascular surgical journals. For instance, only five out of a total of 485 publication (or $1 \%$ ) in the first five volumes of the new European Journal of Vascular Surgery dealt with this subject.

The causes for this relatively low priority of research in peripheral venous disease among vascular surgeons are probably the general and justified feeling that venous haemodynamics are more complex and less understandable than arterial haemodynamics and the negative attitude of many surgeons towards venous problems. Varicose veins are usually associated with unrealistic cosmetic aims or with tedious operations, well suited to junior trainees and resulting in annoyingly high recurrence rates. This negative attitude together with the understandably. high demands of leg and life-threatening arterial pathology in their clinics may encourage vascular surgeons to consider their dealing with varicose veins a necessary evil, if not a nuisance, rather than an activity with challenging aspects.

\section{Pathophysiological concepts}

There have been no changes in the concepts of the pathophysiology of varicose veins in the last three to four decades. However, recently introduced techniques which allow anatomical and functional examination of the venous system have allowed adjustments of these concepts.

Varicose veins are traditionally classified according to their aetiology (primary or secondary), morphological appearance (saphenous or reticular), clinical significance ('disorder' vs 'disease') or the anatomical sites of the underlying functional derangement. These different classi- 
fications are not only of academic interest, but have a direct bearing on the selection of the optimal therapy for a specific patient.

The aetiology of varicose veins, especially of primary varicosities, is still far from clear. Duplex ultrasound examination has the potential to increase knowledge of venous valve function and vessel wall compliance and might well be a way of gaining more insight in the causes of primary varicose veins.

Varicosities may be present in the absence of demonstrable haemodynamic disturbances. In the case of functional disturbances, their anatomical location is a defective muscle pump or in circumscribed 'escape points', where reflux occurs from the deep venous system into the subcutaneous superficial veins. Ultrasound examination in particular has increased our knowledge of the relative contribution of the various escape points to an extent unattainable with the use of the various traditional clinical or plethysmographic techniques.

Surgeons have always been aware of the prominent role of saphenous incompetence in primary varicose veins, especially at the sapheno-femoral junction. The role of incompetence at the sapheno-popliteall junction and via incompetent thigh or calf perforating veins in varicose disease is nowadays becoming better defined: ${ }^{1-6}$

The introduction of ultrasound testing of varicose veins, for instance, has led to the recognition that short saphenous vein insufficiency is present about twice as often in patients with primary varicose veins than suspected on clinical grounds. ${ }^{1}$

Awareness is also growing that incompetent thigh perforators, which may be found anywhere in the thigh from the knee to the groin, but mainly in its middle third, ${ }^{4}$ frequently contribute to insufficiency of the long saphenous vein and are a major cause of residual reflux in that vein after high ligation. ${ }^{6,7}$ 


\section{Diagnosis}

Clinical examination, including Trendelenburg's test, can only demonstrate simple, isolated, primary varicosities of the greater saphenous vein, provided the varicosities are of sufficient prominence to allow a clear distinction between collapse and distension to be made. In all other types of varicose veins the relevant pathophysiological disturbances cannot reliably be pinpointed or excluded through clinical testing alone. ${ }^{1,2}$ Therefore, even in apparently simple varicose veins, at least continuous wave Doppler ultrasound scanning of the major vein trunks with interrogation of the usual escape points has to be performed by the surgeon or by an experienced vascular laboratory technician, whenever interventional therapy is considered. ${ }^{1-3,69,10}$ Better diagnostic information is obtainable by ultrasonic Duplex scanning of the deep and superficial veins. ${ }^{2,11}$ For the time being, the limited availability of Duplex equipment and the expertise required in Duplex studies preclude its application in the diagnosis of common varicose veins outside specialized clinics. Phlebography or varicography will remain necessary from time to time as a final diagnostic procedure in complex varicose problems, but has no place in the routine examination of patients with varicose veins.

A variety of venous volume plethysmographic techniques are available for the study of the venous system.

These allow an overall assessment of calf muscle pump function and - in combination with tourniquet testing - to some extent a separate determination of the contribution of the deep and the superficial venous system to reflux. ${ }^{10,12,13}$

Venous plethysmographic examinations, which are important for the scientific study of deep venous haemodynamics, are less valuable for practical, daily decision making in varicose vein problems. They do not sufficiently differentiate between the components of superficial venous insufficiency and are cumbersome in their application. Photoplethysmography, which has gained some popularity among phlebologists because of its applicability in the consulting-room, has the same limitations as other plethysmographic modalities in the differentiation of 
superficial venous insufficiencies, and is also unreliable ${ }^{13,14}$

\section{Treatment}

The aims of radical treatment of varicose veins are the elimination of junctional and non-junctional points of incompetence of insufficient vein trunks and of dilated tributaries. There is ample evidence from literature, supported by clinical experience, that each of these goals can in principle be achieved through surgery as well as sclerotherapy. Opinions differ regarding the durability of these two principal treatment modalities for the various components of varicose disease.

Diversions in opinion seem to be based on the geographical or professional backgrounds of the discussants rather than on comparative clinical studies. Only two studies have been published in which treatment of varicose veins entirely by sclerotherapy was compared with an exclusively surgical treatment. ${ }^{15.16}$ Both studies were performed before the era of non-invasive functional venous testing. In these studies the classification of patients and the evaluation of treatment were based on clinical grounds only, which one would consider insufficient at the present time.

The classic study of Hobbs showed that incompetent lower leg perforators and dilated vein tributaries are better treated to the patient's and surgeon's satisfaction by sclerotherapy than by surgery. For the varicose saphenous systems, sclerotherapy performed better than radical surgery for the first 2-3 years after treatment, after which period the sclerosed patients did worse than the operated patients. ${ }^{15}$ In Hamilton Jakobsen's study, which included only saphenous varicose veins, the objective clinical success of "sclerotherapy was significantly less than the success of radical surgery ( 37 vs. $90 \%$ ) at the end of a 3 years follow-up period. The subjective appreciation of success by the patient was less divergent (70 vs. 93\%). ${ }^{16}$ The poor long term success of treatment of incompetent saphenous veins solely by injection-compression therapy does not warrant its application, a conclusion supported by data in a recent leading article on the treatment of varicose veins. ${ }^{9}$ 
The question as to which is the best treatment for long saphenous vein insufficiency has been addressed in three randomised studies, comparing stripping of the vein against high ligation. ${ }^{16.17,18}$ Both treatment modalities were combined with surgical ligation of perforators in all three studies and with either surgical avulsion ${ }^{17,18}$ or injection-sclerotherapy ${ }^{16}$ of local varicosities. The studies did not lead to uniform conclusions. The patient's appreciation of long-term successes were equal for both methods of treatment in all three studies, partly because of a bias against stripping due to a high incidence of paraesthesia in the limbs treated with long stripping from the ankle to the groin. The surgeon's assessment, based on the observed extent of persisting or recurrent varicosities, was in favour of stripping in two of the studies and equal for both methods in the other study, ${ }^{17}$ in which a similar, durable restoration of the plethysmographic venous return time was also found for the two methods.

The essential step in the treatment of long saphenous vein insufficiency is not the removal of the saphenous trunk as such, but the elimination of junctional incompetence (by high ligation) and of escape via thigh perforators (by local surgery or stripping of the saphenous vein). ${ }^{7,17,19}$ The choice between high ligation or stripping of the long saphenous vein can not yet be based on firm scientific data and hence patient's or surgeon's preference or socio-economic considerations are valid arguments to tip the balance in favour of either of the two in individual cases.

Stripping of the long saphenous vein should preferably be performed from just below the knee to the groin. This avoids the prohibitively high incidence of saphenous nerve damage by the long stripping procedure, occurring in around 30 percent of cases, without compromising the symptomatic and functional success of the operation. ${ }^{19,20-22}$

Comparative studies of the best treatment of incompetence of the short saphenous vein are not available. Analogous to the treatment for long saphenous stem vein incompetence it is worthwhile considering also selective treatment of points of incompetence in the drainage area of the short saphenous vein. ${ }^{5.19}$ 
For the local elimination of varicose tributaries compression-sclerotherapy works well. A good surgical alternative is the minimal invasive treatment by stab evulsion phlebectomies. ${ }^{23}$ Compression-sclerotherapy is a good treatment for incompetent lower leg perforator veins $9^{9,15}$ If surgical therapy for incompetent lower leg perforators is preferred, the traditional Dodd's and Linton's subfascial surgical eradication procedures are often too traumatic to the compromised skin to be considered a good solution. In line with the modern trend towards less traumatic and 'video' surgery, the endoscopic subfascial discission of perforating veins is gaining ground as a better surgical alternative. ${ }^{24}$

\section{Conclusion}

Until a few years ago, the surgical scene of varicose disease was stagnant: the indiscriminate use of standard stripping procedures after a brief clinical examination and acceptance of repeated operations and disappointing results was the rule rather than the exception. Improved patient assertiveness, growing awareness of the achievements of non-surgical phlebologists and the need to relieve the pressure on hospital resources, all brought the surgeons in Europe to look beyond established positions and to adopt a differentiated approach to treatment of varicose disease. ${ }^{9}$ Concurrent with these socio-economic developments was the introduction of diagnostic ultrasound Doppler and Duplex techniques which was the most important impetus to more insight and new interest in venous haemodynamics.

Since radical treatment of varicose veins is impossible without a considerable surgical contribution and surgeons actually are the only specialists who can single-handedly offer an integral treatment of varicose disease, surgeons are most suited to take a leading position in the study of venous disease and to give guidance on a differentiated, individualized treatment of varicose veins based on pathophysiological principles. Vascular surgeons are in a particularly good position as they are familiar with haemodynamics and have access to ultrasound technology, which is essential for the diagnosis of varicose disease. 


\section{References}

1 Mitchell DC, Darke SG. The Assessment of Primary Varicose Veins by Doppler Ultrasound - the Role of Sapheno-popliteall Incompetence and the Short Saphenous Systems in Calf Varicosities. Eur J Vasc Surg 1987; 1: 113-115

2 Vasdekis SN, Clarke GH, Hobbs JT, Nicolaides AN. Evaluation of noninvasive and invasive methods in the assessment of short saphenous vein termination. Br J Surg 1989; 76: 929-932

3 Goren G, Yellin A. Primary varicose veins: topographic and hemodynamic correlations. J Cardiovasc Surg 1990: 31: 672-677

4 Papadakis K, Christodoulou C, Christopoulos D, Hobbs JT, Malouf GM, Grigg M, Irvine A, Nicolaides AN. Number and anatomical distribution of incompetent thigh perforating veins. Br J Surg 1989; 76: 581-584

5 Zukowski AJ, Nicolaides AN, Szendro G, Irvine A, Lewis R, Malouf GM, Hobbs JT, Dudley HA. Haemodynamic significance of incompetent calf perforating veins. Br J Surg 1991; 78: 625-629

Almgren B, Eriksson I. Valvular incompetence in superficial, deep and perforator veins of limbs with varicose veins. Acta Chir Scand 1990; 156: $69-74$

7 Sutton R, Darke SG. Stripping the long saphenous vein: peroperative retrograde saphenography in patients with and without venous ulceration. Br J Surg 1986; 73: 305-307

8 McIrvine AJ, Corbett CRR, Aston NO, Sherrif EA, Wiseman PA, Jamieson $\mathrm{CW}$. The demonstration of saphenofemoral incompetence; Doppler ultrasound compared with standard clinical tests. $\mathrm{Br} \mathrm{J}$ Surg 1984; 71: 509-510

9 Eklof B. Modern treatment of varicose veins. Br J Surg 1988; 75: 297298

10 Colgan MP, Sumner DS. How Does a Vascular Laboratory Influence Management of Venous Disease? In: Greenhalgh RM, Jamieson CW, Nicolaides AN, eds. Vascular surgery: issues in current practice. Grune \& Stratton, London, 1986: 119-134

11 van Bemmelen PS, Bedford G, Beach K, Strandness DE. Status of the valves in the superficial and deep venous system in chronic venous 
disease. Surgery 1991; 109: 730-734

12 Christopoulos D, Nicolaides AN, Szendro G. Venous reflux: Quantification and correlation with the clinical severity of chronic venous disease. Br J Surg 1988; 75: 352-356

13 Nicolaides AN, Miles C. Photoplethysmography in the Assessment of Venous Insufficiency. J Vasc Surg 1987; 5: 405-412

14 Ris HB, Gfeller Ch, Mahler F, Nachbur B. Comparative Evaluation of Three Ambulatory Plethysmographic Devices as regards Accuracy and Handling in Daily Practice. Eur J Vasc Surg 1991; 5: 159-164

15 Hobbs JT. Surgery and Sclerotherapy in the Treatment of Varicose Veins. Arch Surg 1974; 109: 793-796

16 Hamilton Jakobsen B. The value of different forms of treatment for varicose veins. Br J Surg 1979; 66: 182-184

17 Hammersten J, Pedersen P, Cederlund CG, Campanello M. Long Saphenous Vein Saving Surgery for Varicose Veins. A Long-term Follow-up. Eur J Vasc Surg 1990; 4: 361-364

18 Munn SR, Morton JB, MacBeth WAAG, McLeish AR. To strip or not to strip the long varicose vein? A varicose veins trial. Br J Surg 1981; 68: $426-428$

19 Koyano K, Sakaguchi S. Selective stripping operation based on Doppler ultrasonic findings for primary varicose veins of the lower extremities. Surgery 1988; 103: 615-619

20 Holme JB, Skajaa K, Holme K. Incidence of lesions of the saphenous nerve after partial or complete stripping of the long saphenous vein. Acta Chir Scand 1990; 156: 145-148

21 Holme JB, Holme K, Sorensen LS. The anatomic relationship between the long saphenous vein and the saphenous nerve. Relevance for radical varicose vein surgery. Acta Chir Scand 1988; 154: 631-633

22 Ramasastry SS, Dick GO, Futrell JW. Anatomy of the saphenous nerve: relevance to saphenous vein stripping. Am Surg 1987; 53: 274-277

23 Goren $G$, Yellin AE. Ambulatory stab evulsion phlebectomy for truncal varicose veins. Am J Surg 1991; 162: 166-174

24 Hauer G, Barkun J, Wisser I, Deiler S. Endoscopic subfascial discission of perforating veins. Surg Endosc 1988; 2: 5-12 


\section{Chapter 12: General Discussion and summary}

For this thesis a group of 532 legs of consecutive patients presenting with varicose veins of the lower extremities at the Surgical outpatient department of the Maastricht University Hospital was investigated to assess the value of certain non-invasive tests in the diagnosis of superficial venous valvular incompetence. This same group of legs was used to study the symptoms and signs of varicose veins and their relation to haemodynamic findings. The subgroup of patient's legs diagnosed as having an isolated insufficiency of the greater saphenous vein was allocated to two different treatment forms. The treatment forms compared were stripping of the entire saphenous vein and high ligation of the sapheno-femoral junction combined with sclerotherapy. During a three year follow-up the effect of both treatment modalities on complaints, cosmetics and non-invasive hemodynamic parameters was followed.

Varicose veins were recognised by the ancient Egyptians. Treatment was primarily by the knife until the introduction of the hypodermic syringe in 1845. From then on there were two camps, in one varicosities were treated entirely by surgery, in the other entirely by sclerotherapy. The relations between the camps were difficult and rare ${ }^{1}$ (Chapter 1 ).

While the anatomy of the greater saphenous system is fairly constant and knows little variation, the location of the sapheno-popliteall junction definitely is not. The sapheno-popliteall junction is not always situated in the middle of the popliteal fossa, but can be located at any point proximal to the fossa, while sometimes there is a total absence of the junction. Because of this variation adequate surgery can only be carried out if the exact location of the junction has been determined pre-operatively (Chapter 2).

The calf muscle pump is sometimes termed "second heart" of the circula- 
tion. The function of this "heart" can be jeopardised by an ineffective circular motion of blood as in primary varicose veins. This can lead to functional decompensation of the venous system resulting in a chronic venous insufficiency. The pathway of circular motion can be junctional but also non-junctional through incompetent communicating veins located from mid-thigh to ankle.

The theory of descending venous valvular incompetence in the development of varicose veins has been replaced by the concept that vessel wall weakness, probably hereditary of origin, is the real cause of the development of varicose veins (Chapter 3)

In the Western population the prevalence figures for varicose veins are near to the prevalence figures for diabetes and stomach ulcers. Recent studies concerning the etiology of varicose veins have demonstrated that age is the only and single factor which correlates to the development of varicose veins. Factors such as childbirth, bodyweight, bowel habit and even the wearing of corsetry, seemed significant because of the higher age of the inspected population. After correction for age these factors appear to play no role in the development of varicose veins of the legs. Varicose veins of the lower extremities are a socio-economic problem of considerable magnitude as demonstrated by the Basle study ${ }^{2}$ which differentiates between venous "disorder" (superficial varicosis with no main stem insufficiency) and venous "disease" (reticular veins or hyphen webs combined with stem insufficiency). Ninety percent of the patients with venous "disease" seek medical care and 13\% undergo loss of work because of the disease, compared to $36 \%$ and $3.4 \%$ respectively in the venous "disorder" group (Chapter 4).

Many physicians still believe that the majority of patients with "straightforward" varicose veins require nothing more than a full history and a careful physical examination. However clinical criteria alone as rationale for operation are not sufficient ${ }^{3}$. A Doppler examination, or if available a duplex investigation, is necessary to determine whether varicose veins 
are primary or secondary and to judge the patency of the deep venous system. Exact investigation and localisation of escape points of venous reflux, whether junctional or non-junctional,will determine the mode of treatment and is only possible with ultrasound techniques (Chapter 5).

Varicose veins are probably the most common as well as the worst treated disorder presented to the general surgeons ${ }^{4}$ (Chapter 6). Dormandy described venous disease as the Cinderella among the circulatory disorders ${ }^{5}$. Despite the development of short stay or out-patient surgery, varicose patients constitute a considerable part of surgical waiting lists.

There could be a place for simpler and less expensive methods than surgery, provided these methods were as effective as surgery. The cost of compression-sclerotherapy (CST) is about $15 \%$ of the cost of surgical correction, but what are the costs of recurrence requiring later redo surgery? The reports by Hobbs ${ }^{6}$ and Jakobsen ${ }^{7}$ indicate that approximately $20 \%$ of patients who are eligible for surgery in an unselected population may be equally well treated by CST. Geographical differences seem to play an important role in treatment choice. In some countries such as France and Switzerland, sclerotherapy is still the preferred method of treatment. In the Scandinavian countries surgery is the method of first choice, whilst in America long and short saphenous veins are stripped indiscriminately and all varicose tributaries are treated by excision through multiple incisions; injection sclerotherapy is hardly accepted ${ }^{8}$. However various controlled trials establish a place for sclerotherapy. Chant (1972) in a randomised study found no significant differences three years after surgery compared to compression sclerotherapy, although re-treated patients were included in the results and various forms of varicosis were treated. Doran (1975) found one year results in favour of CST (24\% failures) over surgery ( $44 \%$ failures) but at two years the difference had disappeared ( $21 \%$ versus $16 \%)^{10}$.

Three prospective randomised trials with long term follow-up comparing 
surgery with compression sclerotherapy are available. Hobbs (1968) found two years results of sclerotherapy favourable compared to surgical results.

In 1974 however he reported that the one year cure rate of $82 \%$ in the CST group had fallen to a mere $7 \%$ at five years, and only $30 \%$ were still improved. In contrast $20 \%$ of the surgical group remained cured and $80 \%$ improved at five years ${ }^{6}$. He concluded that patients with saphenofemoral incompetence were best treated by surgery. Evaluation of treatment results was made both objectively and subjectively. Hamilton Jacobsen's study with a three year follow-up included only incompetent greater saphenous veins?. Three treatment modalities were applied: surgery, CST and a combination of CST with minor surgery. A somewhat better objective immediate result was found after surgery than after CST, but there was a fall in cure rate with both methods used. The failure rate after surgery however was very low and the cure rate in the long term was better than after CST. Combining CST with minor surgery (resection of incompetent communicating veins or ligation of the sapheno-femoral junction) gave results better than CST alone but not as good as surgery. Einarson performed foot volumetric measurements to support the clinical evaluation of results. He found that throughout the follow-up the patients operated upon had a better venous function than those treated by CST alone, and a group treated by CST combined with minor surgery revealed foot volumetric test results in between those of the CST group and the surgically treated group. This indicates that surgical interruption of at least the sapheno-femoral junction is important in the treatment of sapheno-femoral incompetence. Munn (1981) deinonstrated in a randomised trial that the results of treatment as judged by patients were biased against stripping because of the high incidence of paraesthesia in the stripped limbs, although results of treatment judged purely by the recurrence of varicosities at follow-up were significantly better in the limbs from which the saphenous vein had been stripped compared to the results after high ligation without stripping ${ }^{11}$. Clearly nerve damage is unacceptable to patients as part of an operation for 
purely cosmetic purposes. Hammarsten (1990) compared results of terminal branch ligation, perforating vein ligation and standard stripping of the greater saphenous vein to terminal saphenous branch ligation, ligation of perforating veins and ligation of the sapheno-femoral junction without stripping ${ }^{12}$. Treatment evaluation was by means of plethysmography. Excellent or good results were obtained in $88 \%$ of the stripped group compared to $89 \%$ of the ligated group. Recurrent varicosities were found in $12 \%$ versus $11 \%$ respectively. Removal of the saphenous vein is apparently of no therapeutic value if all perforating veins to the deep veins have been ligated. Selective stripping limited to segments with Doppler demonstration of reflux compared excellent to complete stripping in patients in whom reverse flow was demonstrated in the saphenous trunk ${ }^{13}$. When there is incompetence of proximal long or short saphenous vein (which is present in more than $6 \%$ of primary varicose veins) surgery is the method of choice because injection alone cannot produce long term success, since compression cannot be maintained at the upper thigh, groin or popliteal fossa. Sclerotherapy alone of the greater saphenous vein in the presence of sapheno-femoral junctional or greater saphenous vein stem reflux is unlikely to remain successful in the long term. These patients require control of the refluxing junction prior to sclerotherapy.

Obliteration of the greater saphenous vein after sclerotherapy was found by means of colour duplex scanning in only $6 \%$ below a refluxing junction and in $40 \%$ below a non refluxing junction ${ }^{14}$.

The new understanding of venous haemodynamics has led to altered concepts of treatment. With the use of duplex ultrasonography patterns of reflux can be exactly mapped ${ }^{15}$. In this way it was demonstrated that isolated main trunk insufficiency is far less frequent than branch insufficiency. Also the assumption of the sapheno-femoral escape as the sole source of reflux into the saphenous system now seems incorrect. Recently in only $64 \%$ of truncal varicosities escape points were found to be localised at the sapheno-femoral junction. In the remainder proximal 
escapes were localised elsewhere and non-junctional ${ }^{15}$. Twenty percent of the legs have a combined deep, communicating and superficial vein incompetence. In the absence of a specific incompetent communicating vein, feeding a superficial varicosity, routine perforator ligation without regard to it's incompetence seems unwarranted. A surprising amount of deep reflux was found in legs with no prior evidence of thrombotic disease. This might be an extra support to the theory of venous recirculation which determines the surgical management of truncal varicosis. Venous recirculation causes secondary popliteal or femoral vein insufficiency because the increase in dynamic vein pressure leads to functional decompensation of the deep venous system ${ }^{16}$. These data support the heterogenicity of venous disease in patients with varicose veins and suggest that surgical therapy be directed to the patients specific pattern of incompetence rather than routine sapheno-femoral junction ligation or stripping of the greater saphenous trunk.

The relation between symptoms and signs at clinical investigation and the various forms of superficial venous valvular incompetence was investigated (Chapter 7). Using a complaint severity score constituted from the three most common symptoms pain, cramps and swelling it is possible to differentiate between superficial varicosis with and without main branch involvement. But the standard deviation is so large that this finding has no clinical relevance. When there is main branch involvement a further differentiation into the nature of the insufficient branch is not possible by means of symptoms and signs.

In chapter 8 the value of photoplethysmography in the diagnosis of superficial venous valvular incompetence of the lower limbs was compared to clinical investigation combined with Doppler ultrasound testing in 533 limbs of a consecutive group of 268 patients. The main problem encountered was the unacceptably high number of uninterpretable PPG registrations which makes it's use in the routine evaluation of superficial venous valvular incompetence problematic. Attempts to diminish the 
uninterpretable results proved fruitless. Comparison with literature reveals that this problem has been encountered by other authors.

Favourable results with PPG by others were only obtained after averaging the outcome of repeated investigations on one limb and leaving out divergent values. Introduction of additional criteria in our study such as the half venous refill time and the calculated venous refill time gave an even higher percentage of non-interpretable PPG registrations. Excluding the non-interpretable PPG results, the Kappa value as measure of agreement between PPG and clinical investigation combined with Doppler was as low as 0.30 . Explanations for the poor PPG results are the sensitivity of the device for surrounding illumination, skin reflection, skin and room temperature, skin pigmentation, haematocrit and pressure with which the transducer is fixed to the skin. Furthermore PPG recovery times probably reflect regional haemodynamics rather than overall venous hemodynamics in the limb. Our results are confirmed by recent investigations in which it was found that photoplethysmography has the same value to predict the presence of multilevel reflux as inspection of the skin in the gaiter area ${ }^{17}$. From our results we conclude that PPG is not the method of choice in the routine evaluation of superficial venous valvular incompetence. It's continued use is not warranted, although it is still used for this purpose in many vascular laboratories.

The treatment of varicose veins has an enormous impact on the costs of public health. This results in a tendency to turn to high saphenous ligation and sclerotherapy as an attractive out-patient alternative to hospital admission for operative treatment. In order to compare the symptomatic, cosmetic and haemodynamic results of treatment of isolated valvular incompetence of the greater saphenous vein by classical stripping from ankle to groin to high ligation combined with sclerotherapy this study was undertaken (Chapter 9).

In order to objectively study the effect of both treatments on local haemodynamics standard, non-invasive tests were used during the 
follow-up. A total of 181 patient legs were randomised to either of both treatment modalities. After three years of follow-up, significant differences were found in favour of classical stripping both with regard to patient's and surgeon's evaluation of cosmetic results and with regard to clinical and Doppler ultrasonic evidence of reflux in the greater saphenous vein. No statistically significant differences could be found between the two groups regarding residual or persisting complaints at any follow-up moment. The reasons for the differences found between the two groups are explained in two ways. First general anaesthesia, as used in the stripping group, permits a more radical ligation of the sapheno-femoral junction and the groin tributaries. Secondly, stripping eliminates the thigh communicating veins, which are an important source of non-junctional reflux. High ligation eliminates only the saphenofemoral junction as source of reflux. At the time this study was started, stripping from ankle to groin was the standard surgical treatment option in our clinic. If a study like this would now be initiated, classical stripping would surelely be replaced by "selective stripping" from just below the knee to the groin. The three year results of both treatment modalities can be considered disappointing when looking at the percentages of good results. This is not confirmed by the patient's appraisal of therapy, which as a whole is quite satisfactory. This underlines that evaluation of therapy by subjective judgement by patients alone is insufficient to determine the value of different treatment modalities for varicose veins.

Confronted with an unacceptable high incidence of damage to the saphenous nerve after stripping from ankle to groin, an in vivo anatomic study was undertaken (Chapter 10). Aim of the study was to locate a level at which damage to the saphenous nerve could be kept to a minimum while stripping the main trunk of the saphenous vein. Seventy-five patient legs in which the saphenous vein was harvested for coronary artery bypass procedures were investigated. In almost al cases the nerve was completely adherent to the saphenous vein in the lower part of the leg. In the majority of cases a bifurcation of the nerve was found in 
between the distal third and halfway the tibia. During the stripping procedure the stripper head has to pass under this bifurcation, usually causing avulsion of the side branch. Five $\mathrm{cm}$. distal to the knee joint the saphenous nerve was adherent to the vein in only $6 \%$ of the cases. We believe selective stripping down to this point will reduce damage to the saphenous nerve without compromising the symptomatic and functional success of the operation. 


\section{References}

1 Ouvry PA, Davy A. Sclerotherapy after stripping. In: Phlebology 85, Negus D, Jantet G. Eds. John Libbey, London, 1986: 125-128

2 Widmer L, Zemp E, Delley A, Biland L. Medical and socioeconomic aspects of varicose veins and chronic venous insufficiency. Basle vein follow-up. In: Phlebology 85, Negus D, Jantet G. Eds. John Libbey, London, 1986: 82-84

3 Haeger K. Venous incompetence and concomitant disease of the leg. J Cardiovasc Surg 1965; 6: 482-488

4 Editorial Treatment of varicose veins. Lancet 1975: 1: 311-312.

5 Hume M. Presidential adress: A venous renaissance? J Vasc Surg 1992; 6: 947-951

6 Hobbs JT. A randomised trial of treatment of varicose veins by surgery and sclerotherapy. In: Treatment of venous disorders. Hobbs JT. Ed. MTP Press, Lancaster, 1977: 195-207.

7 Hamilton Jakobsen B. The value of different forms of treatment for varicose veins.

Br J Surg 1979; 66: 182-184

8 Einarson E. Compression sclerotherapy of varicose veins. In: Controversies in the management of venous disorders. Eklof B, Gjores JE, Thulesius O, Bergqvist D. Eds. Butterworths, London, 1989: 203-210

9 Chant ADB, Jones HO, Weddell JM. Varicose veins: a comparison of surgery and injection sclerotherapy.

Lancet 1972; Dec: 1188-1191

10 Doran FSA, White H. A clinical trial designed to discover if the primary treatment of varicose veins should be by Fegans method or by operation. Br J Surg 1975; 62: 72-76

11 Munn SR, Morton JB, Macbeth WAAG. To strip or not to strip the long saphenouv vein? A varicose vein trial.

Br J Surg 1981; 68: 426-428

12 Hammarsten J, Pedersten P, Cederlund C, Campello M. Long saphenous vein saving surgery for varicose veins. A long term follow-up.

Eur J Vasc Surg 1990; 4: 361-364 
13 Koyano K, Sakaguchi S. Selective stripping operation based on Doppler ultrasonic findings for primary varicose veins of the lower extremities. Surg 1988; 103: 615-619

14 Bishop CCR, Fronek HS, Fronek A. Real-time colour Duplex scanning following sclerotherapy of the greater saphenous vein J Vasc Surg 1991; 13: 16-28

15 Goren G, Yellin AE. Primary varicose veins: Topographic and hemodynamic correlations

J Cardiovasc Surg 1990; 31: 672-677

16 Hach $\mathrm{W}$. The role of venous recirculation in primary truncular varicosis in explaining recurring varicosis after operation.

13th International Vascular Workshop Sulden Italy 1992

17 S Van Bemmelen P, Van Ramshorst B, Eikelboom BC. Photoplethysmography reexamined: lack of correlation with Duplex scanning. Surgery 1992 in press. 


\section{Summary}

In this thesis aspects of diagnosing and treating varicose veins are studied. The approach to the diagnosis of varicose veins varies from clinical investigation alone to an array of non-invasive tests to define the extent of valvular incompetence. Trealment modalities for varicose veins consist of classical stripping of the greater and lesser saphenous veins, ligation of the sapheno-femoral or sapheno-popliteal junction combined with sclerocompression therapy or sclerocompression therapy alone. Also multiple phlebectomies can be performed. Only a few trials have compared these forms of treatment, most of which were not prospective. In most of them treatment evaluation was based on clinical examination alone.

The present study was started with the following objectives:

-To evaluate some frequently used non-invasive tests for superficial venous valvular incompetence.

-To compare the symptomatic, clinical and haemodynamic results of treatment of isolated valvular incompetence of the greater saphenous vein by classical stripping operation to treatment by high ligation combined with sclerotherapy.

-Because of the high rate of damage to the saphenous nerve found after stripping, in an in vivo study the anatomic relationship between the saphenous vein and the saphenous nerve was investigated in an attempt to help minimising the risk of damage to the nerve during stripping.

-To investigate the relationship between symptoms, signs and hemodynamic findings in patients with varicose veins.

Chapter 1 contains an overview of the development and history of the surgical and the non-surgical treatment of varicose veins.

In chapter 2 the anatomy of the venous system of the lower extremity 
and the differences between the anatomy of the greater and lesser saphenous systems are discussed in relation to the treatment of varicose veins. Emphasis is placed on the need of pre-operative localisation of the sapheno-popliteal junction.

Chapter 3 deals with the physiology and the pathophysiology of varicosis of the lower extremities. The role of the calf muscle pump is discussed. Interruption of the circular ineffective motion of blood, caused by varicose veins, should be the aim of treatment. Vessel wall weakness is seen as the main cause of the development of varicose veins.

In chapter 4 the incidence and etiology of varicose veins are discussed. Age is the only and single factor which correlates with the development of varicose veins. The socio-economic significance of this form of venous disease is demonstrated.

In chapter 5 the diagnostic methods of superficial venous incompetence are outlined. Opposite to the widely held opinion that full history laking and physical examination are sufficient for the diagnosis of varicosis, Doppler examination of escape points of reflux is advocated.

Chapter 6 gives a description of the treatment modalities of varicose veins. There is a place for surgery as well as sclerotherapy. The choice of treatment is historically and geographically influenced. If there is main branch involvement in the incompetence, surgery is the therapy of choice. Incompetent communicating veins and reticular varicosis is best treated by sclerotherapy. The complications of the various treatment modalities are discussed.

In chapter 7 own work is described as to the relation between clinical symptoms and signs at investigation in the various forms of superficial venous valvular incompetence. Reticular varicosis without main branch involvement can be differentiated from other forms of superficial incom- 
petence by introduction of a "complaint severity score". However because of the large standard deviation this has no clinical relevance. Based on symptoms and signs no differentiation can be made with regard to the various forms of varicosis with main brach involvement.

In chapter 8 the results of a study comparing the value of photoplethysmography (PPG) to clinical investigation combined with Doppler ultrasound in the routine evaluation of superficial venous valvular incompetence are presented. The Kappa value as measure of agreement between the two forms of investigation was as low as 0.30 . Therefore PPG lests are considered useless for routine evaluation of varicose veins. The various reasons for the poor PPG results are discussed.

Chapter 9 gives the results of a prospective randomised trial comparing treatment of isolated incompetence of the greater saphenous vein by classical stripping to treatment by high ligation combined with sclerocompression therapy. The diagnosis was based on clinical investigation combined with Doppler ultrasound investigation. A total of 181 patient's legs were entered into the study, 89 legs were treated by stripping, 92 legs by high ligation combined with sclerotherapy. Follow-up up at three months, one, two and three years after treatment was done by means of clinical combined with Doppler ultrasound investigation. After three years significant differences were found in favour of stripping with regard to cosmetic evaluation of results both by patients and surgeons and with regard to clinical and Doppler ultrasonic evidence of reflux in the treated legs. Therefore the stripping operation is considered superior to high ligation combined with sclerotherapy.

In chapter 10 the results are given of an in vivo anatomical study of the relation between the saphenous nerve and the saphenous vein. At $5 \mathrm{~cm}$. distal to the knee joint a level was found at which the saphenous nerve was adherent to the vein in only $6 \%$ of the cases. Stripping down to this level will minimise the risk of damage to the nerve. 
In chapter 11 a surgical point of view is given concerning present day treatment of varicose veins and the role the surgeon plays in this treatment.

Chapter 12 contains a general discussion of the results of the studies 


\section{Samenvatting}

In dit proefschrift worden een aantal aspecten van de diagnostiek en van de behandeling van varicosis belicht. De benadering van de diagnostiek van varices varieert van klinisch onderzoek alleen, tot een spectrum van non-invasieve onderzoeksmethoden. Behandelings methodes voor varices omvatten exerese ("strippen") van de stamvenen (vena saphena magna en vena saphena parva), ligatie van de sapheno-femorale confluens ("crossectomie"), al dan niet gecombineerd met sclerocompressietherapie, het verrichten van locale flebectomieen en sclerocompressie therapie alleen. In slechts enkele klinische onderzoeken zijn deze behandelingsvormen tegen elkaar uitgezet, echter veelal niet prospectief of gerandomiseerd. De evaluatie van het resultaat van de verschillende behandelingen was veelal zuiver subjectief.

Opzet van dit proefschrift was het volgende:

- De evaluatie van enkele frequent gebruikte non-invasieve testen in de diagnostiek van oppervlakkige veneuze insufficientie.

- Het vergelijken van de symptomatische, de klinische en de haemodynamische resultaten van de behandeling van geisoleerde insufficientie van de vena saphena magna middels strippen enerzijds, crossectomie gecombineerd met sclerocompressie therapie anderzijds.

- Vanwege de hoge incidentie van de, als zeer hinderlijk ervaren, neuralgie van de nervus saphenus na strippen, werd in een in vivo onderzoek de anatomische relatie tussen deze zenuw en de vena saphena magna bepaald. Opzet hierbij was, dat toepassen van kennis hiervan schade aan de nervus mogelijk zou kunnen beperken.

- Onderzoek bij patienten met varicosis van de relatie tussen klachten enerzijds en bevindingen bij lichamelijk onderzoek en hemodynamische testen anderzijds.

Hoofdstuk 1 bevat een historisch overzicht van de ontwikkeling van de 
chirurgische en niet-chirurgische behandeling van spataderen.

In hoofdstuk 2 wordt de anatomie van het veneuze systeem van de onderste extremiteiten uiteengezet. Terwijl de vena saphena magna een vrijwel constante localisatie kent, is dit bij de vena saphena parva zeker niet zo. Vanwege deze variatie is pre-operatieve localisatie van de overgang noodzakelijk.

Hoofdstuk 3 behandelt de fysiologie en pathofysiologie van varicosis. De kuitspierpomp wordt well tweede hart van de circulatie genoemd. De functie van dit tweede hart kan in het gedrang komen door de ineffectieve circulaire beweging van bloed zoals bij primaire varicosis. Dit kan leiden tot decompensatie van het veneuze systeem. De circulaire beweging van bloed kan plaatsvinden via de sapheno-femorale overgang, maar ook via insufficiënte perforantes. De theorie van descenderende klepinsufficiëntie in het onstaan van varices is minder waarschijnlijk dan een wandzwakte, waarschijnlijk erfelijk overgedragen, als de werkelijke oorzaak van varicosis.

In hoofdstuk 4 worden epidemiologische en etiologische aspecten van varicosis besproken. Leeftijd is de enige etiologische faktor die correleert met het ontstaan van varices. Faktoren zoals doorgemaakte zwangerschappen, lichaamsgewicht en toiletgewoonten, spelen geen rol na correctie voor leeflijd. Uit resultaten van de Basel studie blijkt dat ten gevolge van varicosis waarbij de hoofdstam van de vena saphena magna betrokken is, $13 \%$ van de patienten arbeid verzuimt en dat $90 \%$ van de patienten behandeling zoekt.

In hoofdstuk 5 worden de verschillende onderzoeksmethodes in de diagnostiek van varicosis behandeld. Vele clinici geloven dat anamnese en lichamelijk onderzoek voldoende zijn voor de behandeling van spataderen. Doppler onderzoek of indien aanwezig een duplex onderzoek 
is echter noodzakelijk om de aard van de varices en de functie van het diepe systeem vast te leggen. Tevens kunnen hiermee de ontsnappingspunten van oppervlakkige reflux ("escape points") bepaald worden.

In hoofdstuk 6 wordt een overzicht gegeven van de verschillende behandelings mogelijkheden voor varices. Hieruit blijkt dat er een plaats is voor zowel chirurgie als voor sclerocompressie therapie. De keuze voor een van beiden wordt deels historisch, deels geografisch bepaald. De kosten van ambulante sclerocompressietherapie zijn maar een fractie van operatieve behandeling.

Echter uit literatuur onderzoek blijkt dat, wanneer er sprake is van betrokkenheid van de stam van de vena saphena magna bij de varicosis, de beste behandeling bestaat uit eliminatie van deze stam. Behandeling van insufficiente venae perforantes en convoluten kan zeer goed met behulp van sclerotherapie. Daarnaast worden de complicaties ten gevolge van de diverse behandelingsvormen besproken.

Aan de hand van een eigen studie wordt in hoofdstuk 7 bekeken of er een verband bestaat tussen de diverse vomen van varicosis (oppervlakkige varices zonder betrokkenheid van een stam, geisoleerde insufficiëntie van de vena saphena magna, geisoleerde vena saphena parva insufficiëntie, vena perforans insufficiëntie, diepe veneuze insufficiëntie of combinaties hiervan) en klachten en symptomen. De oppervlakkige varicosis blijkt zich te onderscheiden van de vormen waarbij de stam betrokken is door een lagere klachten score. Echter de standaarddeviatie is zo groot dat het geen klinische relevantie heeft. Op grond van klachten en symptomen is geen onderscheid te maken tussen de verschillende vormen van staminsufficiënties.

Hoofdstuk 8: In dit hoofdstuk worden de resultaten gepresenteerd van een onderzoek dat photoplethysmografie (PPG) in de diagnostiek van oppervlakkige veneuze insufficiëntie vergelijkt met klinisch onderzoek 
gecombineerd met Doppler ultrageluid. De Kappa coefficiënt als mate van overeenkomst tussen beide onderzoeksmethoden was slechts 0.30 . Het hoofdprobleem bij dit onderzoek bestond uit het hoge aantal niet interpreteerbare PPG resultaten, waardoor deze test feitelijk waardeloos wordt in de routine evaluatie van oppervlakkige varicosis. Redenen voor het niet interpreteerbaar zijn van de PPG uitslagen worden besproken.

In hoofdstuk 9 worden de resultaten beschreven van een prospektief gerandomiseerd onderzoek waarin de behandeling van geïsoleerde insufficiëntie van de saphena saphena magna middels exerese werd vergeleken met behandeling middels crossectomie gecombineerd met sclerocompressie therapie. De diagnose werd gebaseerd op klinisch onderzoek inclusief tourniquet tests, gecombineerd met Doppler ultrageluid. In totaal werden 181 aangedane benen van een reeks van opeenvolgende patiënten in de studie opgenomen. Uiteindelijk kwamen 89 benen in de exerese groep terecht, terwijl 92 benen werden behandeld middels crossectomie gecombineerd met sclerotherapie.

Beide patiëntgroepen waren vergelijkbaar qua klinische en demografische karakteristieken. Follow-up geschiedde na een interval van 3 maanden, 1 jaar, twee en drie jaar na behandeling en bestond uit klinisch onderzoek en Doppler ultrageluid. Klachten, zowel als cosmetisch resultaat, beoordeeld door zowel patiënt als chirurg werden op standaard wijze genoteerd en konden goed of slecht zijn. Klinisch en Doppler onderzoek werden gebruikt om aan- of afwezigheid van reflux over de vena saphena magna of over de sapheno-femorale overgang te demonsireren. Na drie jaar waren 68 patiënten $(76 \%)$ in de exerese groep en 73 patiënten (79\%) in de crossectomie-sclerotherapie groep beschikbaar voor follow-up. Statistisch significante verschillen in het voordeel van strippen werden gevonden na drie jaar voor het cosmetisch resultaat, zoals beoordeeld door patient en chirurg, als ook voor de objectieve aantoonbaarheid (Doppler) van veneuze insufficiëntie. De middellange termijn resultaten van de behandeling middels strippen worden daarom als superieur aan die van crossectomie gecombineerd met sclerotherapie 
beschouwd.

In hoofdstuk 10 wordt een in vivo onderzoek beschreven naar de anatomie van de nervus saphenus en de relatie tot de vena saphena magna. De exerese van de vena saphena magna kent een hoog percentage beschadiging van de nervus saphenus, leidend tot paresthesie of sensibiliteitsverlies in zijn distributiegebied. In onze kliniek werd deze complicatie bij strippen van enkel tot de lies in $33 \%$ van de gevallen waargenomen. Om te bepalen vanaf welk distaal niveau zonder veel kans op deze complicatie de vene gestript zou kunnen worden, werd de anatomische relatie tussen de vena saphena magna en de nervus saphenus bekeken bij 75 patiënten waarbij de vene len behoeve van een kransslagaderoverbruggingsoperatie werd geoogst. In het distale deel van het onderbeen was de zenuw zonder uitzondering adherent aan de adventitia van de vene. Vanaf $10 \mathrm{~cm}$ onder de knie is de vene in $22 \%$ van de gevallen adhaerent, vanaf $5 \mathrm{~cm}$ is dit nog maar in $6 \%$ van de gevallen. Bij strippen tot $5 \mathrm{~cm}$ onder de knie is het daarom te verwachten dat de beschadiging van de nervus tot een minimum beperkt zal blijven zonder het cosmetisch of functionele resultaat nadelig te beinvloeden.

In hoofdstuk 11 wordt een chirurgische visie gegeven op onderzoek en behandeling van varices zoals die heden ten dage zou moeten zijn. De rol van de chirurg in dit proces wordt benadrukt.

Hoofdstuk 12 bevat een algemene beschouwing van de resultaten van de onderzoeken. 


\section{Dankwoord}

Het is onmogelijk de bijdrage van Prof. Dr. P.J.E.H.M. Kitslaar bij de totstandkoming van dit proefschrift naar waarde te schatten. Als kritisch "leermeester" enerzijds, zijn afschuwelijke rode pen door zoveelste versies van maniuscripten hanterend, als vaderlijk figuur anderzijds mij wakker schuddend, achter zijn computer met de woorden "ben je er nog" terwijl ik al elders verkeerde in een wereld waar spataderen niet voorkomen of blijkbaar geen probleem vormen. Bedankt, Peter voor je geduld en je pogingen mij de werking van een computer bij te brengen. Van mijn kant heb ik je, naar ik mag hopen op onomstotelijke wijze kunnen aantonen dat een computer in staat is om hele hoofdstukken van de aardbodem te laten verdwijnen.

In een fase van dit proefschrift, waarin mijn typesnelheid was opgevoerd tot een halve bladzijde per avond en dit een afronding in het jaar 2000 in het vooruitzicht stelde, zond de Heer Yvonne Daemen. Haar inzet vanaf het eerste moment, optimisme over de goede afloop en gevoel voor humor toen ik besloot dat we samen de lay-out ook nog wel konden doen zullen mij altijd bijblijven en met dankbaarheid vervullen.

Het vaatlab van het A.Z.M. heeft een zeer grote rol gespeeld bij de PPG onderzoeken en de gerandomiseerde trial. Mijn dank aan de vaatlaborantes Edith Ermers en Rene Penders voor dit onderdeel, en aan de secretaresse Yvonne Reinders voor haar logistieke ondersteuning.

Prof. Dr. Gauke Kootstra dank voor de mij geboden gelegenheid dit onderzoek op jouw afdeling te verrichten. De vanzelfsprekendheid waarmee je aanneemt dat iedereen behoort te promoveren werkte via de weg van irritatie op mij aanstekelijk. Prof. Dr. Dirk Gouma, bedankt dat je speciaal een nieuwe computer aanschafte, zodat ik je oude voor een prikkie kon overnemen. Ik stel de door je getoonde vriendschap en de belangstelling in mijn vorderingen bijzonder op prijs.

Dr. Jan Tordoir, mijn beste kameraad uit de Maastrichtse periode, als dank voor jouw grote aandeel in mijn opleiding tot vaatchirurg komen al 
mijn varices patiënten voortaan op jouw poli.

Dank aan alle Limburgers die mij hun spataders ter beschikking stelden gedurende drie jaar.

Gewoonlijk wordt tot slot de familie bedankt. Aangezien ik van mening ben dat de dank voor de steun in de afgelopen tijd niet in woorden valt uit te drukken, en zelfs indien dit mogelijk zou zijn het in privé kring dient te geschieden zal ik dit hier ook niet proberen. Een uitzondering wil ik maken voor mijn vader Hans Rutgers die na de voltooing van dit proefschrift onmiddellijk aan het corrigeren is geslagen en bij het naar de drukker gaan van het manuscript reeds tot het derde hoofdstuk was gevorderd. 


\section{Curriculum Vitae}

Peter Hans Rutgers werd op 21 september 1952 geboren als zwaarste baby van Den Helder. Na doorlopen van de HBS-B opleiding aan het Dalton Lyceum te Voorburg, verdedigde hij de landsgrenzen tot 1974. Hij studeerde geneeskunde aan de Rijksuniversiteit te Leiden waar in 1982 het artsdiploma werd behaald. Tijdens de studie ontmoette hij Anneke de Waard, waarmee hij later trouwde. Daarna volgde de opleiding tot algemeen chirurg in het Westeinde Ziekenhuis te 's-Gravenhage (opleiders Dr. J.R. Leo en Dr. R.K.J. Koumans). In 1988 werd Bob geboren. Inschrijving in het Specialisten Register vond plaats in 1989. Daarna deed hij de vervolgopleiding Vaatchirurgie in het Academisch Ziekenhuis te Maastricht (Hoofd Prof. Dr. G. Kootstra, opleider vaatchirurgie Prof. Dr. P.J.E.H.M. Kitslaar). In 1990 werd Claire geboren. Sinds 1 januari 1993 is hij als vaatchirurg werkzaam in het Ziekenhuiscentrum Apeldoorn in maatschapsverband met de chirurgen H.W. Bolhuis, Dr. W.H. Bouma, Dr. G.H. Hage, Dr. E.J. Hesselink, H.L. Molier, J.G.J. Roussel en de orthopedisch chirurgen Th. Burbach, E. Breemans, L. Daniëlisz en K. Schäffer. 
